\title{
Design and Manufacturing of Loop Heat Pipes for Electronics Cooling
}

\author{
by \\ Shane Storring \\ A thesis submitted to the Faculty of Graduate Studies and Research \\ in partial fulfilment of the degree requirements of \\ Master's of Applied Science \\ In Aerospace Engineering \\ Ottawa-Carleton Institute for \\ Mechanical and Aerospace Engineering \\ Department of Mechanical and Aerospace Engineering \\ Carleton University \\ Ottawa, Ontario, Canada \\ February, 2006 \\ Copyright $(\mathcal{C}$ \\ 2006 - Shane Storring
}




$\begin{array}{ll}\begin{array}{l}\text { Library and } \\ \text { Archives Canada }\end{array} & \begin{array}{l}\text { Bibliothèque et } \\ \text { Archives Canada }\end{array} \\ \begin{array}{l}\text { Published Heritage } \\ \text { Branch }\end{array} & \begin{array}{l}\text { Direction du } \\ \text { Patrimoine de l'édition }\end{array} \\ \begin{array}{l}\text { 395 Wellington Street } \\ \text { Ottawa ON K1A ON4 }\end{array} & \begin{array}{l}\text { 395, rue Wellington } \\ \text { Ottawa ON K1A ON4 } \\ \text { Canada }\end{array}\end{array}$

Your file Votre référence ISBN: 978-0-494-16469-3 Our file Notre référence ISBN: 978-0-494-16469-3

NOTICE:

The author has granted a nonexclusive license allowing Library and Archives Canada to reproduce, publish, archive, preserve, conserve, communicate to the public by telecommunication or on the Internet, loan, distribute and sell theses worldwide, for commercial or noncommercial purposes, in microform, paper, electronic and/or any other formats.

The author retains copyright ownership and moral rights in this thesis. Neither the thesis nor substantial extracts from it may be printed or otherwise reproduced without the author's permission.
AVIS:

L'auteur a accordé une licence non exclusive permettant à la Bibliothèque et Archives Canada de reproduire, publier, archiver, sauvegarder, conserver, transmettre au public par télécommunication ou par l'Internet, prêter, distribuer et vendre des thèses partout dans le monde, à des fins commerciales ou autres, sur support microforme, papier, électronique et/ou autres formats.

L'auteur conserve la propriété du droit d'auteur et des droits moraux qui protège cette thèse. $\mathrm{Ni}$ la thèse ni des extraits substantiels de celle-ci ne doivent être imprimés ou autrement reproduits sans son autorisation.
In compliance with the Canadian

Privacy Act some supporting forms may have been removed from this thesis.

While these forms may be included in the document page count, their removal does not represent any loss of content from the thesis.
Conformément à la loi canadienne sur la protection de la vie privée, quelques formulaires secondaires ont été enlevés de cette thèse.

Bien que ces formulaires aient inclus dans la pagination, il n'y aura aucun contenu manquant.

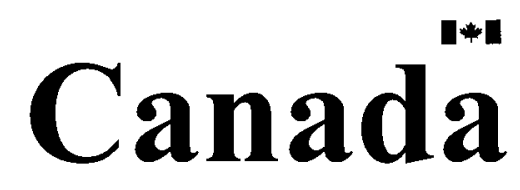




\begin{abstract}
A loop heat pipe (LHP) is a two-phase heat transfer device that uses the latent heat of vaporization of a working fluid for heat transfer. Due to their inherent robustness, LHPs are ideal candidates to meet the ever increasing thermal challenges facing the electronics and spacecraft industries. Through miniaturization, LHPs have the potential to efficiently transport, spread, and dissipate heat in advanced electronics packages where the heat dissipation is rapidly increasing with decreasing volume.

In this study, three LHPs were designed, manufactured, and tested to help gain the knowledge necessary for developing smaller and more efficient designs for use in future Canadian space missions. A detailed development process was discussed and included initial design criteria and selection, material preparation and treatment, assembly, evacuation, charging, and sealing. A series of tests were conducted to investigate the thermal performance characteristics of each unit. Tests were performed under ambient conditions to study the effect of fluid inventory on LHP start-up, steady-state operating temperature, effective thermal resistance, and overall heat transfer coefficient. Alternate configurations were investigated to measure the effect of orientation and periodic heating on thermal performance. LHP operation was also examined for temperature hysteresis during rapid power variations.
\end{abstract}

iii 
Numerical models were developed to aid in the design phase of the study by estimating the properties of various working fluids, calculating fluid inventory, and sizing the compensation chamber. The models also provide the foundation for future work on a 1-D steady state solver to predict operational characteristics such as steady-state temperatures, system pressure drop and mass flow rate for any given design. 


\section{Acknowledgements}

First of all, I would like to express my sincere gratitude and appreciation to my thesis supervisor, Dr. Tarik Kaya, for giving me this opportunity and for his help and guidance throughout the project. I would also like to acknowledge his flexibility in allowing me to pursue my goals and career outside of the University. I would like to acknowledge Feng Cai and Michel Garcia for their many hours of help in the lab as well as the complete staff in the machine shop for their many lessons on how not to injure myself. I would like to give credit to everyone who helped review my thesis, their time is very much appreciated. Also, I would like to recognize the staff at Bristol Aerospace their flexibility and support during the final phase of my thesis. Finally, I would like to thank my family and friends for their love and support during the most difficult times. They are always there for me when I need it the most and give me the confidence I need as I embark on a new journey in life. 


\section{Table of Contents}

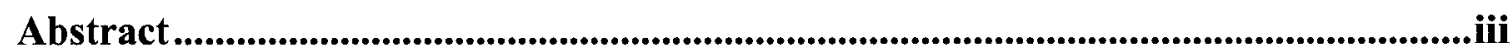

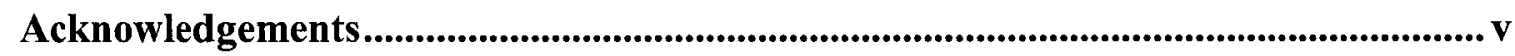

Table of Contents ............................................................................................................................ vi

List of Tables.........................................................................................................................................

List of Figures ............................................................................................................................ xi

Nomenclature $\quad$....................................................................................................................... xiv

Chapter 1: Introduction ................................................................................................................. 1

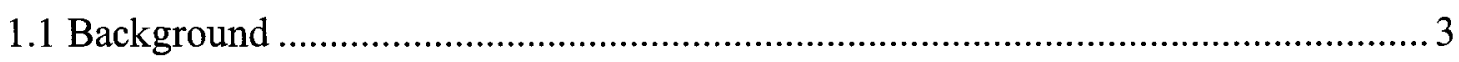

1.1.1 Conventional Heat Pipes ............................................................................ 3

1.1.2 Capillary Pumped Loops (CPL) …………………….................................. 5

1.1.3 Loop Heat Pipes (LHP) …………………………................................ 6

1.1.4 Miniature Loop Heat Pipe (MLHP) ……………………………………...

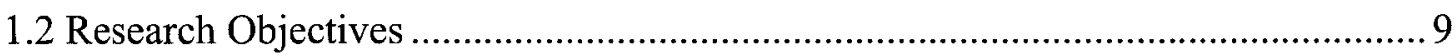

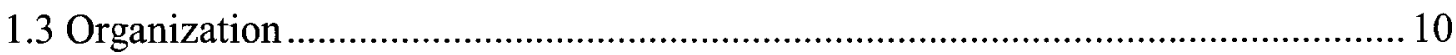

Chapter 2: Literature Review .............................................................................................................. 12

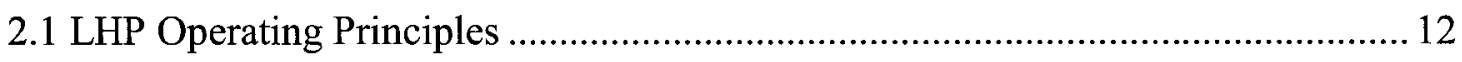

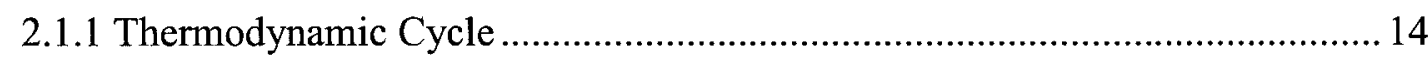

2.2 LHP Operating Characteristics.............................................................................. 18

2.2.1 Loop Operating Temperature .................................................................... 18

vi 


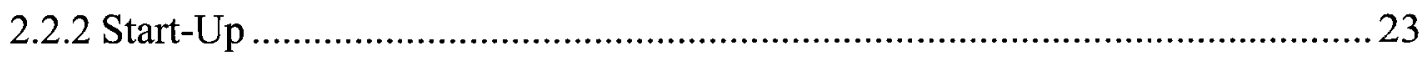

2.2.3 Temperature Hysteresis ................................................................................26

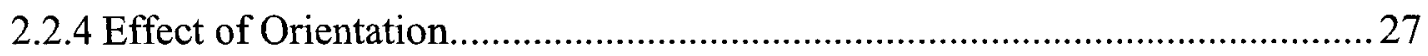

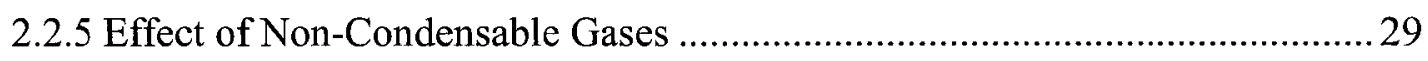

2.3 Design of Loop Heat Pipes ..................................................................................2 29

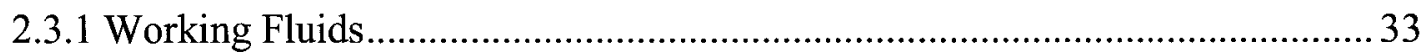

2.3.2 Primary and Secondary Wicks ...................................................................... 36

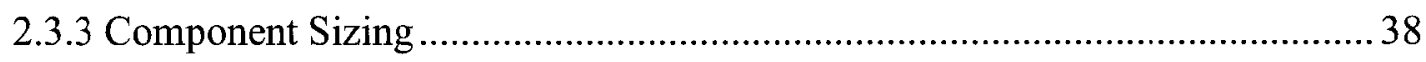

2.3.4 Fluid Inventory and Compensation Chamber ................................................... 38

Chapter 3: LHP Design.....................................................................................................................44

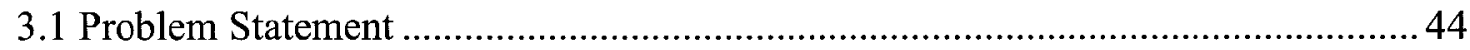

3.2 Design Approach .......................................................................................... 45

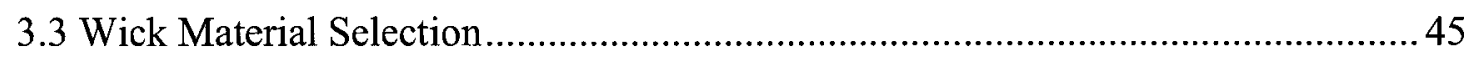

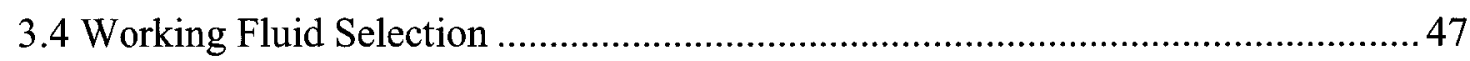

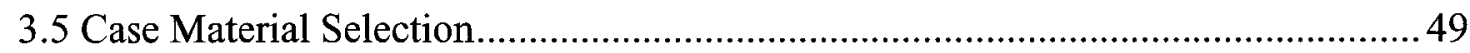

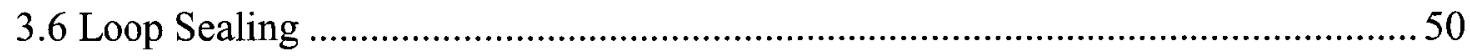

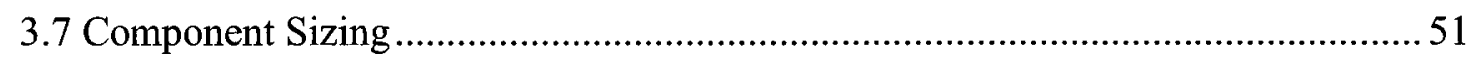

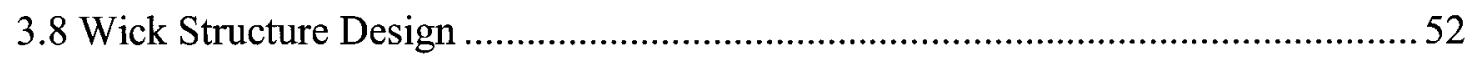

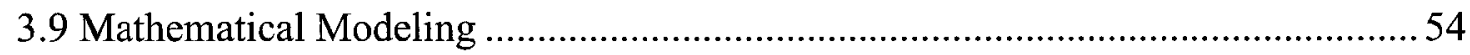

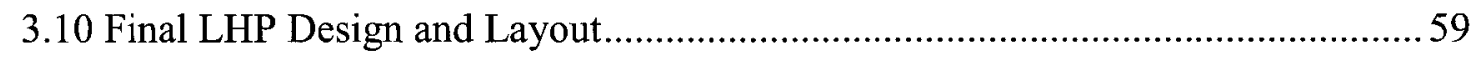

Chapter 4: LHP Manufacturing ..........................................................................................61

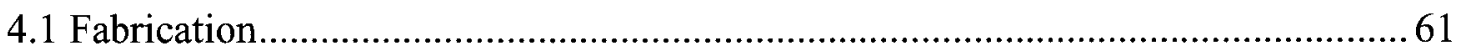

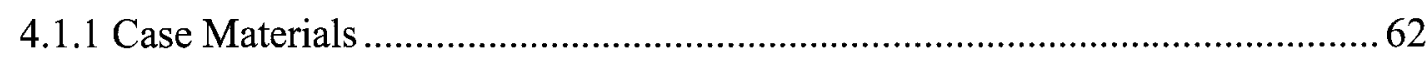

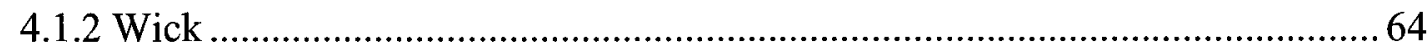

4.1.3 Heat Source and Heat Sink Saddles ................................................................6 66

4.2 Component Cleaning......................................................................................... 69

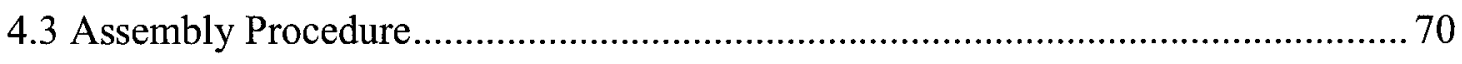

4.3.1 Swagelok Fittings ................................................................................... 72

vii 


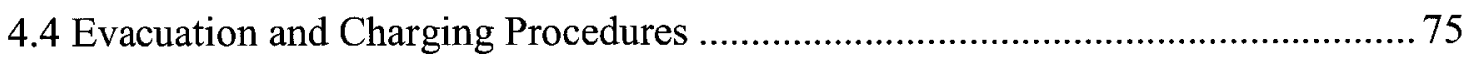

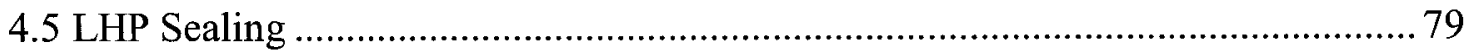

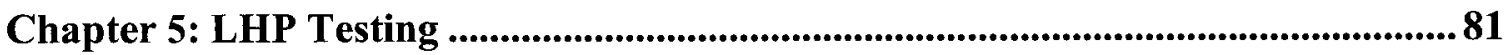

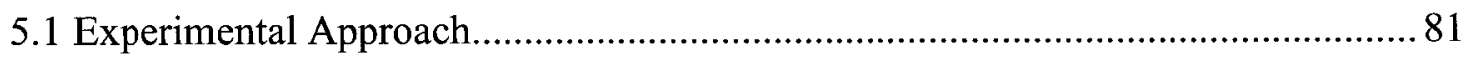

5.2 Test Specimen and Experimental Setup........................................................... 81

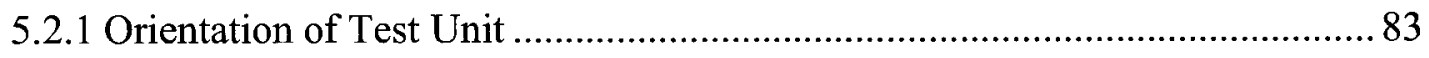

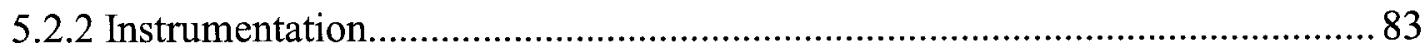

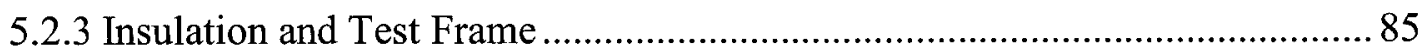

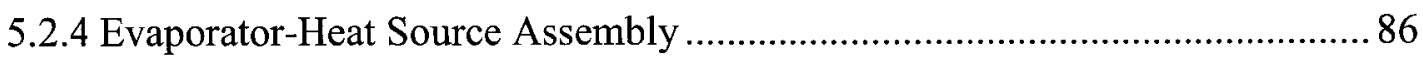

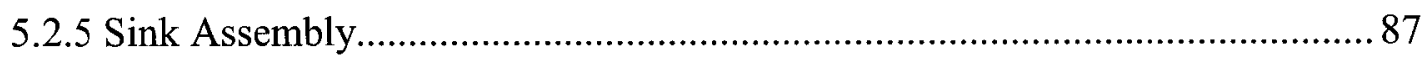

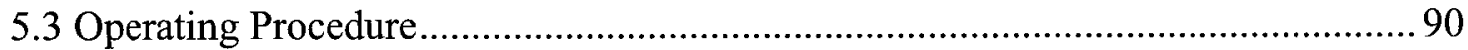

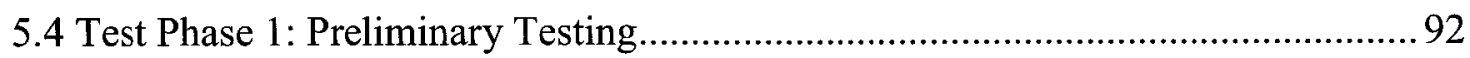

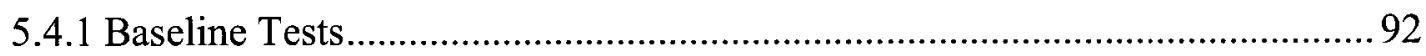

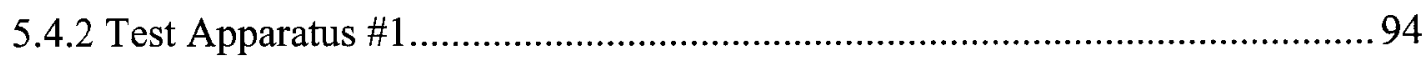

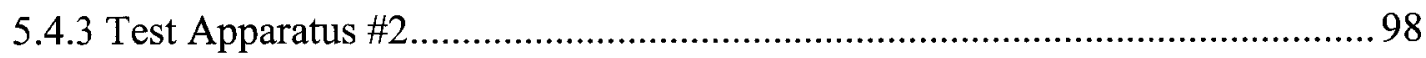

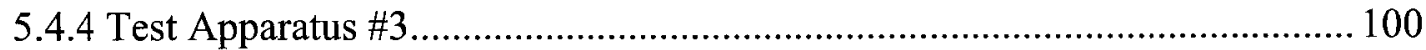

5.5 Test Phase 2: Experimental Study of the Effect of Fluid Inventory on LHP

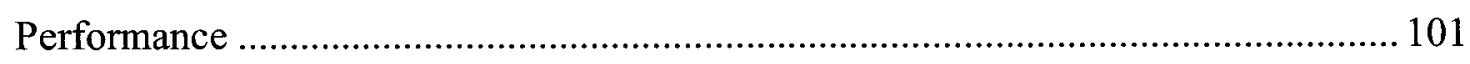

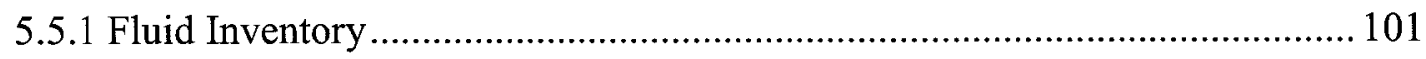

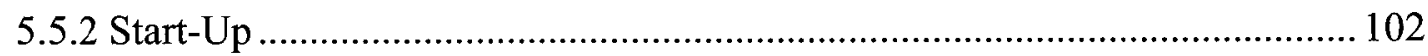

5.5.3 Steady-State Operating Temperatures.................................................... 111

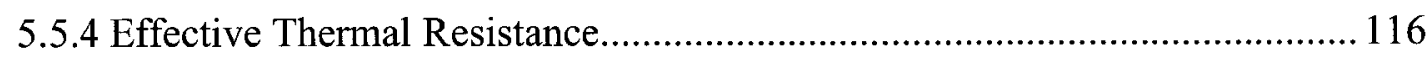

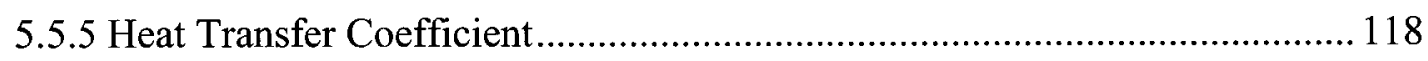

5.6 Test Phase 3: Experimental Study of LHP Operating Characteristics ................. 120

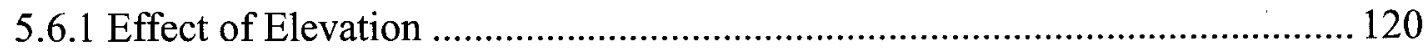

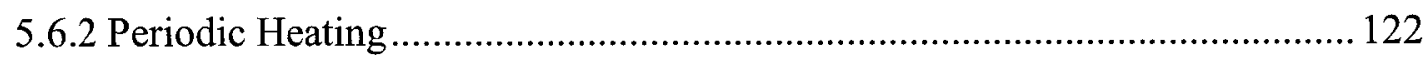

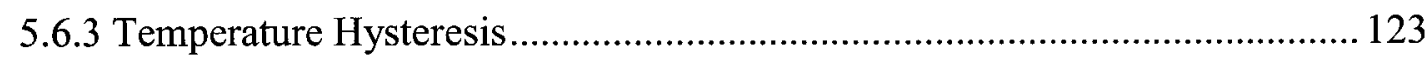

Chapter 6: Mathematical Modeling ......................................................................... 126

viii 


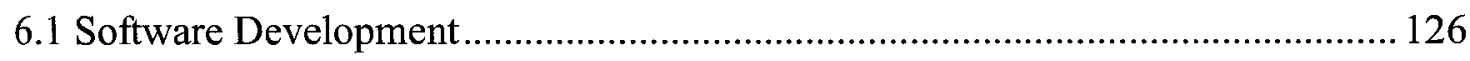

6.1.1 Graphical User Interface (GUI) \& Input/Output Parameters ......................... 126

6.1.2 Fluid Properties ........................................................................................ 129

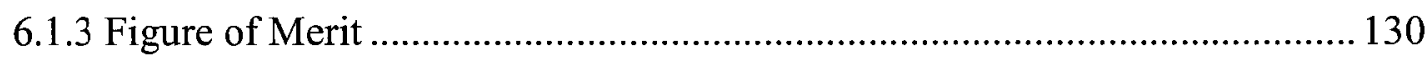

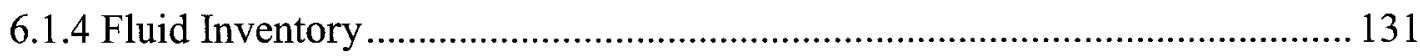

Chapter 7: Conclusions and Recommendations............................................................... 133

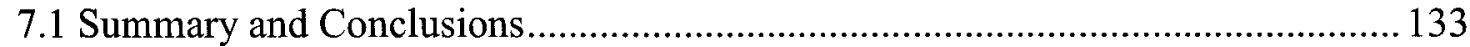

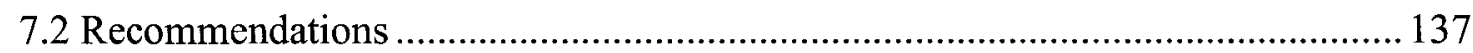

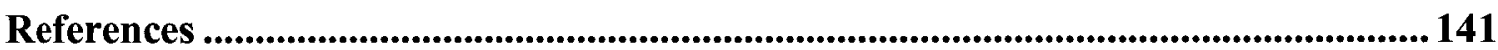

Appendix A ............................................................................................................. 143 


\section{List of Tables}

Table 2-1: Tested LHP Material-Working Fluid Combinations .................................... 31

Table 2-2: Components and their Influence on Design Requirements ........................... 32

Table 2-3: Operating Temperature Range of Various Fluids........................................ 34

Table 3-1: Potential Working Fluids and their Properties ......................................... 48

Table 3-2: Detailed Properties of each Test Unit.......................................................59

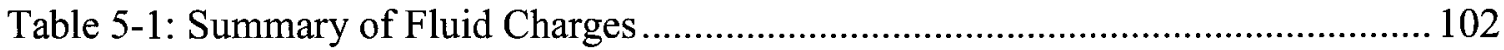

Table 5-2: Summary of Start-up Results for a Fluid Charge of $20 \mathrm{~g}$........................... 108

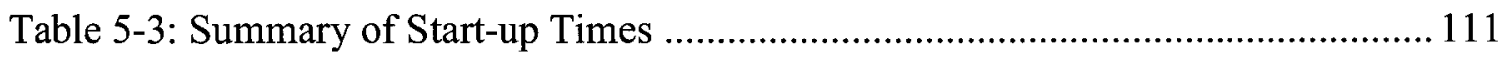




\section{List of Figures}

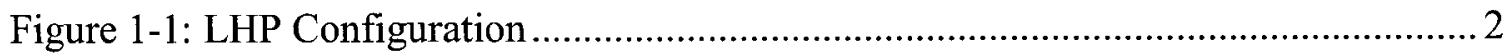

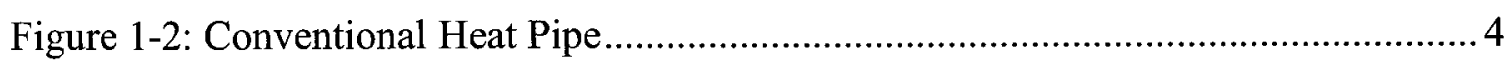

Figure 2-1: Pressure-Temperature Curve of Steady-State LHP Operation...................... 15

Figure 2-2: Simplified Thermal Network of the LHP Model ...................................... 19

Figure 2-3: Variable and Fixed Conductance Modes................................................. 23

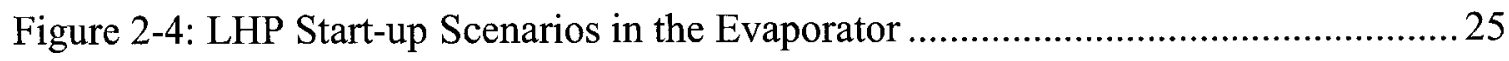

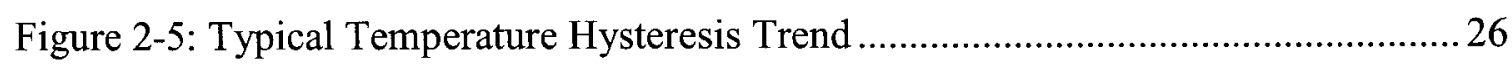

Figure 2-6: Loop Heat Pipe Design Procedure .......................................................... 30

Figure 2-7: Figure of Merit for Various Working Fluids............................................... 36

Figure 2-8: Fluid Distribution Scheme 1 ............................................................. 41

Figure 3-1: Design of Evaporator and Primary Wick Interface .................................... 54

Figure 3-2: Solid Model of Wick Structure with Vapour Grooves.................................. 54

Figure 3-3: EASY 2000 User Interface and Input Parameters .....................................56

Figure 3-4: Calculation of Fluid Inventory, Reservoir Volume, and LHP Mass ............. 57

Figure 3-5: Pressure Balance and Maximum Heat Flux Estimate for Given Design ....... 58

Figure 4-1: Loop Heat Pipe Manufacturing Process ................................................... 62

Figure 4-2: Band Saw used to Cut Stainless Steel Tubing........................................... 63

Figure 4-3: Lathe used to Round-Off Edges of Tubing ..............................................6 63

Figure 4-4: Lathe used for Diameter and Four Circumferential Grooves....................... 65

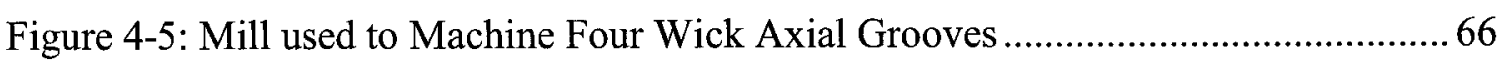

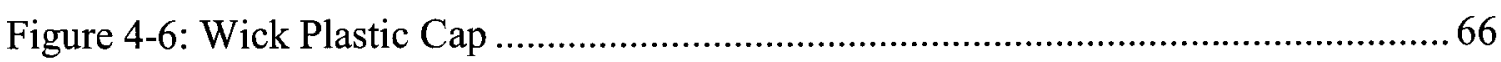

Figure 4-7: Milling Machine and Drill Press used for Manufacturing Saddles ...............67

Figure 4-8: Threads Machined using a 10-32 Hole Tap ........................................... 67

Figure 4-9: Final Evaporator Saddle Assembly .................................................... 68

$\mathrm{xi}$ 
Figure 4-10: Final Condenser and Subcooler Saddle Assembly ...................................6 68

Figure 4-11: Tube-in-Tube Parallel Flow Heat Exchanger........................................ 69

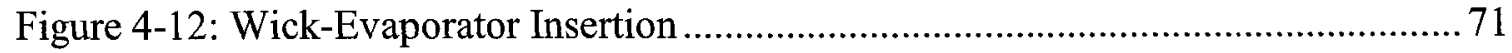

Figure 4-13: Evaporator Wall-Wick Contact after Insertion ....................................... 71

Figure 4-14: Swagelok Two-Ferrule Design......................................................... 72

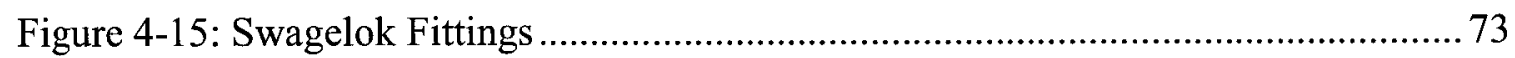

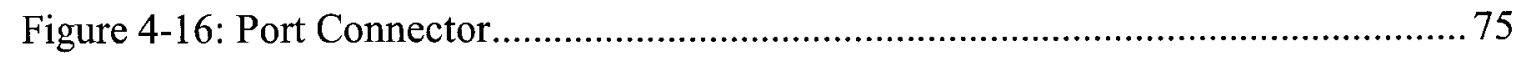

Figure 4-17: Evacuation and Charging System Assembly......................................... 76

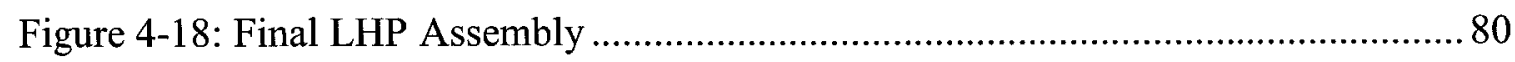

Figure 5-1: Schematic of Test Platform in Heat Pipe Laboratory................................ 82

Figure 5-2: Thermocouple Placement for both Configurations ..................................... 84

Figure 5-3: Evaporator-Heat Source Assembly ......................................................... 86

Figure 5-4: Condenser-Heat Exchanger Assembly 1 ................................................. 88

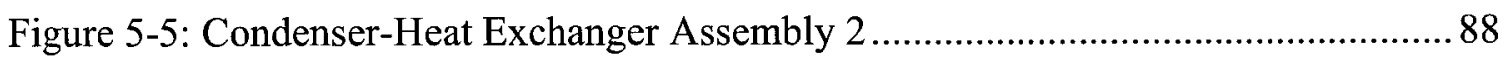

Figure 5-6: Addition of Subcooler to Liquid Line ...................................................... 90

Figure 5-7: Baseline Results for 5 and 10W Power Inputs .........................................93

Figure 5-8: Steady-State Evaporator Temperatures for a Given Power Input ................. 94

Figure 5-9: Temperature Profile for a $5 \mathrm{~W}$ Start-Up......................................................95

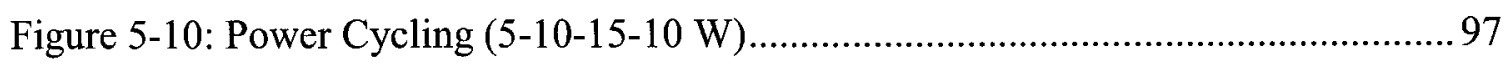

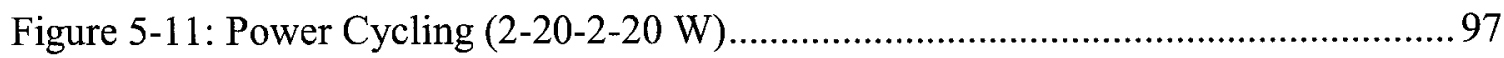

Figure 5-12: LHP Failure, 20 W Initial Input Power ...................................................98

Figure 5-13: LHP Failure, 10 W Initial Input Power ................................................ 100

Figure 5-14: 20 W Start-Up, 24 g Fluid Inventory .................................................. 103

Figure 5-15: Temperature Profile for $20 \mathrm{~W}$ Start-Up, $24 \mathrm{~g}$ Fluid Inventory .................. 104

Figure 5-16: Temperature Profile for $20 \mathrm{~W}$ Start-Up, $15 \mathrm{~g}$ Fluid Inventory ................. 105

Figure 5-17: 5 W Start-Up, 15 g Fluid Inventory ................................................... 106

Figure 5-18: 15 W Start-Up, 28 g Fluid Inventory ..................................................... 107

Figure 5-19: 15 W Start-Up, 20 g Fluid Inventory ................................................... 108

Figure 5-20: Temperature Profile for $20 \mathrm{~g}$ Fluid Inventory ......................................... 112 
Figure 5-21: Temperature Profile for 23 g Fluid Inventory ............................................. 113

Figure 5-22: Performance Curve for each Fluid Inventory........................................... 114

Figure 5-23: Effective Thermal Resistance for each Fluid Inventory............................ 117

Figure 5-24: Heat Transfer Coefficient for each Fluid Inventory .................................... 119

Figure 5-25: Effect of Elevation on Steady-State Operating Temperatures .................... 121

Figure 5-26: LHP Operation During Periodic Heating. 15 W, 10 min cycle................. 123

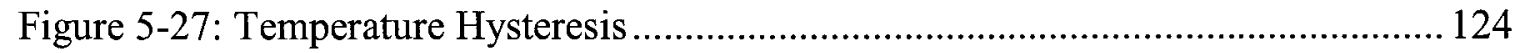

Figure 6-1: LHP Design Software Toolbar ................................................................ 127

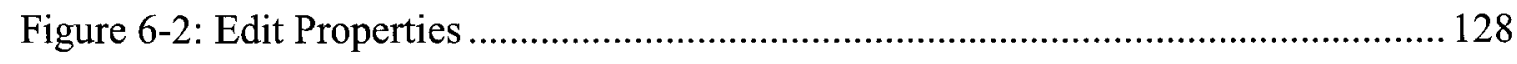

Figure 6-3: Working Fluid Properties Calculator ........................................................ 129

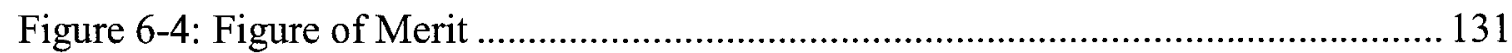

Figure 6-5: Fluid Inventory and Compensation Chamber Sizing ................................. 132

xiii 


\section{Nomenclature}

\begin{tabular}{ll}
$C_{p}$ & Specific heat, $\mathrm{J} / \mathrm{Kg}-\mathrm{K}$ \\
$D$ & Diameter, $\mathrm{m}$ \\
$f$ & Darcy friction factor \\
$g$ & Gravity, $9.81 \mathrm{~m} / \mathrm{s}^{2}$ \\
$h$ & Height between the evaporator and condenser, $\mathrm{m}$ \\
$k$ & Thermal conductivity, W/m-K \\
$k_{\text {eff }}$ & Effective thermal conductivity of the wick, $\mathrm{W} / \mathrm{m}-\mathrm{K}$ \\
$K_{\text {void }}$ & Coefficient of free volume in the reservoir \\
$L$ & Length, $\mathrm{m}$ \\
$\dot{m}$ & Mass flow rate, $\mathrm{kg} / \mathrm{s}$ \\
$M$ & Mass of fluid to be charged, $\mathrm{kg}$ \\
$\Delta P_{\text {cap }}$ & Capillary pressure developed in the wick, $\mathrm{N} / \mathrm{m}^{2}$ \\
$\Delta P_{\text {cond }}$ & Pressure drop across the condenser, $\mathrm{N} / \mathrm{m}^{2}$ \\
$\Delta P_{f}$ & Frictional pressure drop, $\mathrm{N} / \mathrm{m}^{2}$ \\
$\Delta P_{g}$ & Pressure drop/gain due to gravitational forces, $\mathrm{N} / \mathrm{m}^{2}$ \\
$\Delta P_{\text {grooves }}$ & Pressure drop in the grooves, $\mathrm{N} / \mathrm{m}^{2}$ \\
& \\
\hline &
\end{tabular}


$\Delta P_{l l} \quad$ Pressure drop across the liquid line, $\mathrm{N} / \mathrm{m}^{2}$

$\Delta P_{s c} \quad$ Pressure drop across the sub-cooler, $\mathrm{N} / \mathrm{m}^{2}$

$\Delta P_{t o t} \quad$ Total pressure drop in the system, $\mathrm{N} / \mathrm{m}^{2}$

$\Delta P_{v l} \quad$ Pressure drop across the vapour line, $\mathrm{N} / \mathrm{m}^{2}$

$\Delta P_{\text {wick }} \quad$ Pressure drop in the wick, $\mathrm{N} / \mathrm{m}^{2}$

$Q_{a p p} \quad$ Total heat load applied to the evaporator, W

$Q_{c c-a} \quad$ Heat exchange between compensation chamber and ambient, W

$Q_{e} \quad$ Net heat load applied to the evaporator, W

$Q_{e, c c} \quad$ Heat leak from the evaporator to the compensation chamber, W

$Q_{e, v a p} \quad$ Heat used during the vaporization process, $\mathrm{W}$

$Q_{l l, a} \quad$ Parasitic heating of the liquid line from the surroundings, W

$Q_{s c} \quad$ Amount of subcooling brought back by the liquid in liquid line, $\mathrm{W}$

$Q_{\text {wick }} \quad$ Heat flux through a porous wick, W

$r_{\text {eff }} \quad$ Effective radius of the meniscus in the wick, $m$

$R \quad$ Local radius of the meniscus in the wick, $\mathrm{m}$

$R_{e f f} \quad$ Effective thermal resistance of the LHP, ${ }^{\circ} \mathrm{C} / \mathrm{W}$

$S \quad$ Surface area, $\mathrm{m}^{2}$

$T_{a} \quad$ Ambient temperature, ${ }^{\circ} \mathrm{C}$

$T_{e} \quad$ Evaporator temperature, ${ }^{\circ} \mathrm{C}$ 
Fluid temperature, ${ }^{\circ} \mathrm{C}$

$T_{c c}$

Compensation chamber temperature, ${ }^{\circ} \mathrm{C}$

$T_{\text {sat }}$

Saturation temperature, ${ }^{\circ} \mathrm{C}$

$T_{s c}$

Temperature of the liquid leaving the sub-cooler, ${ }^{\circ} \mathrm{C}$

$T_{\text {sink }}$

Sink temperature, ${ }^{\circ} \mathrm{C}$

$T_{\text {wall }}$

Wall temperature, ${ }^{\circ} \mathrm{C}$

$\Delta T_{\text {wick }}$

Temperature difference across the wick, ${ }^{\circ} \mathrm{C}$

$\left(\frac{d T}{d P}\right)_{s a t}$

Saturation temperature-pressure slope, ${ }^{\circ} \mathrm{C} / \mathrm{Pa}$

$(U A)_{e, c c}$

Thermal conductance between the evaporator and compensation chamber,

$\mathrm{W} / \mathrm{K}$

$\left(\frac{U A}{L}\right)_{c c-a} \quad$ Compensation chamber to ambient conductance, $\mathrm{W} / \mathrm{m}-\mathrm{K}$

$\left(\frac{U A}{L}\right)_{\mathrm{f}-\mathrm{a}} \quad$ Fluid to ambient conductance, $\mathrm{W} / \mathrm{m}-\mathrm{K}$

$\left(\frac{U A}{L}\right)_{\text {f-sink }} \quad$ Fluid to the sink conductance, $\mathrm{W} / \mathrm{m}-\mathrm{K}$

$V \quad$ Velocity, $\mathrm{m} / \mathrm{s}$

$V_{c c} \quad$ Volume of the compensation chamber, $\mathrm{m}^{3}$

$V_{\text {cond }} \quad$ Volume of the condenser, $\mathrm{m}^{3}$

$V_{\text {grooves }} \quad$ Volume of the grooves, $\mathrm{m}^{3}$

$\mathrm{xvi}$ 


\begin{tabular}{|c|c|}
\hline$V_{l}$ & Liquid volume, $\mathrm{m}^{3}$ \\
\hline$V_{l h p}$ & Total volume of the system, $\mathrm{m}^{3}$ \\
\hline$V_{l l}$ & Volume of the liquid line, $\mathrm{m}^{3}$ \\
\hline$V_{\text {loop }}$ & Total volume of the loop (excluding the compensation chamber), $\mathrm{m}^{3}$ \\
\hline$V_{p w}$ & Volume of the primary wick, $\mathrm{m}^{3}$ \\
\hline$V_{s w}$ & Volume of the secondary wick, $\mathrm{m}^{3}$ \\
\hline$V_{v l}$ & Volume of the vapour line, $\mathrm{m}^{3}$ \\
\hline$\alpha$ & Void fraction of the compensation chamber \\
\hline$\alpha_{\text {cond }}$ & Heat transfer coefficient of the condenser, $\mathrm{W} / \mathrm{m}^{2}-\mathrm{K}$ \\
\hline$\alpha_{e}$ & Heat transfer coefficient of the evaporator, $\mathrm{W} / \mathrm{m}^{2}-\mathrm{K}$ \\
\hline$\beta$ & Fraction of compensation chamber volume occupied by the liquid \\
\hline$\varepsilon$ & Wick porosity \\
\hline$\kappa_{\text {wick }}$ & Wick permeability, $\mathrm{m}^{2}$ \\
\hline$\lambda$ & Latent heat of vaporization, $\mathrm{J} / \mathrm{kg}$ \\
\hline$\mu$ & Fluid viscosity, $\mathrm{m}^{2} / \mathrm{s}^{2}$ \\
\hline$\Delta v$ & Difference in the vapour and liquid specific volumes, $\mathrm{m}^{3} / \mathrm{kg}$ \\
\hline$\theta$ & Contact angle, rad \\
\hline$\rho$ & Density, $\mathrm{kg} / \mathrm{m}^{3}$ \\
\hline$\sigma$ & Surface tension, $\mathrm{kg} / \mathrm{s}^{2}$ \\
\hline$N u$ & Nusselt number \\
\hline
\end{tabular}

xvii 


$\begin{array}{ll}\text { Pr } & \text { Prandtl number } \\ \text { Re } & \text { Reynolds Number }\end{array}$

Subscripts

\begin{tabular}{ll} 
a & Ambient \\
e, evap & Condenser \\
eff & Evaporator \\
f & Effective \\
i & Fluid \\
l & Internal \\
ll & Liquid \\
o & Liquid line \\
sc & External \\
v & Sub-cooler \\
vl & Vapour \\
\hline
\end{tabular}

xviii 


\section{Chapter 1: Introduction}

A loop heat pipe (LHP) is a robust two-phase heat transfer device that uses the latent heat of vaporization of a working fluid to transport waste heat between a source and a sink. Similar to conventional heat pipes, LHPs are highly efficient devices that use the surface tension developed in a porous wick structure to create the forces necessary for circulation of the working fluid. LHPs also overcome some of the limitations imposed by conventional heat pipes such as operability against gravity, use of smooth-wall flexible transport lines, and fast diode action. Furthermore, LHPs are passive devices that require no external power or moving parts for operation and are therefore highly reliable and stable with a long operational life span. The presence of a secondary wick also provides turnkey start-up and resistance to deprime.

Traditional LHPs consist of five main components: an evaporator, a compensation chamber (or reservoir), a condenser, a vapour line, and a liquid line. Typically, only the evaporator and compensation chamber contain porous wick structures while the rest of the loop is made of smooth wall transport lines. A schematic diagram of a traditional LHP is shown in Figure 1-1. 


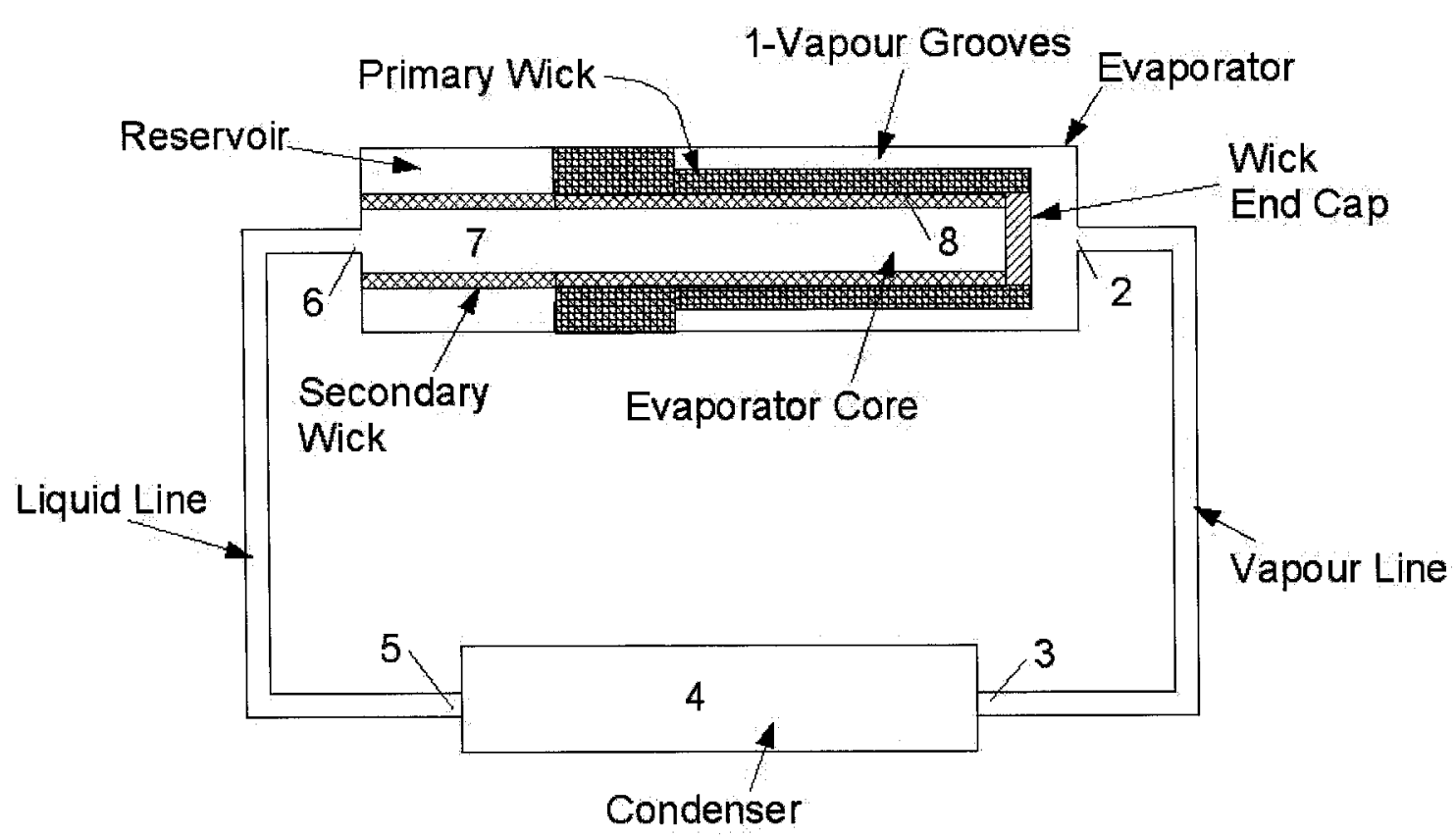

Figure 1-1: LHP Configuration

The primary wick, located in the evaporator, is made of small pores for the purpose of developing the necessary capillary pressure for circulating the fluid. In many LHPs a secondary wick is employed between the evaporator and compensation chamber, thermally and hydrodynamically connecting the two. The secondary wick is typically made of larger pores to reduce the pressure drop of liquid flow and ensure liquid is available to the primary wick at all times. The secondary wick also increases the tolerance to bubble formation in the evaporator core, thus ensuring efficient loop operation.

LHP operation is based on the same physical principles as those used in conventional heat pipes, however, they are organized more efficiently (Maidanik, 2005). The 
operation of a typical LHP begins with the application of heat to the evaporation zone. Initially, the temperature of the evaporator and compensation chamber rise together. Then, due to the thermal resistance of the wick, the temperature and pressure of the evaporator begins to rise above that of the compensation chamber. LHP start-up occurs once the temperature difference between the evaporator and compensation chamber is high enough to initiate circulation of the working fluid. Start-up is easily identified by a sudden increase in the temperature of the vapour line as superheated fluid flows through the vapour line from the evaporator outlet to the condenser inlet. Once in the condenser, heat is rejected and the vapour begins to condense into liquid phase. The condensed liquid is then subcooled in the liquid line and returns to the evaporator through the compensation chamber. The two-phase compensation chamber stores any excess fluid and is responsible for establishing the loop operation pressure and temperature. No external pumping power or moving parts are required for operation. Also, due to their inherent flexibility, LHPs have the ability to be controllable, reversible, ramified, flexible, and miniature, for a wide range of space and terrestrial applications.

\subsection{Background}

\subsubsection{Conventional Heat Pipes}

In 1944, Gaugler was the first to introduce the concept of a passive two-phase heat transfer device with a wicking material. The idea re-surfaced in 1962 in connection with the space program (Trefethen, 1962) and again in 1963 through a patent filed by Wyatt. 
In 1964, the concept became more widely accepted as a means for thermal control after Grover published results from an independent study. The publication by Grover was the first to apply the term 'heat pipe' and described the apparatus as a 'synergistic engineering structure which is equivalent to a material having a thermal conductivity greatly exceeding that of any known metal' (Peterson, 1994). Since that time, heat pipes have been employed in numerous applications ranging from temperature control of the permafrost layer under the Alaskan pipeline to the thermal control of optical surfaces in spacecraft (Peterson, 1994).

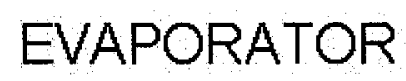

CONDENSER

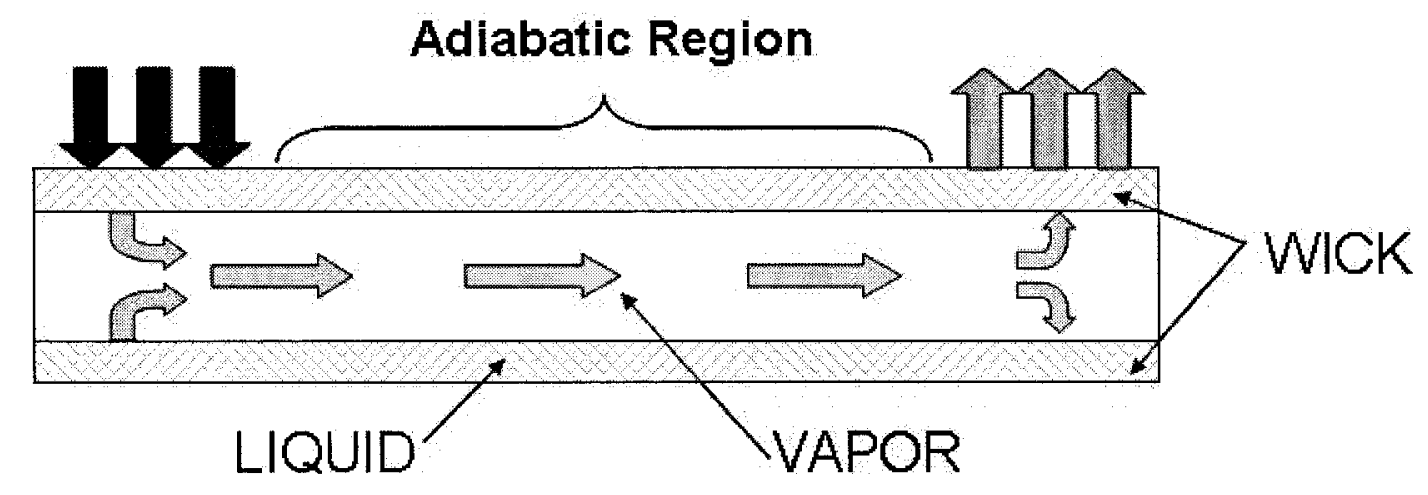

Figure 1-2: Conventional Heat Pipe

A heat pipe consists of a sealed container lined with a wicking structure. The wick is saturated with the liquid phase of a working fluid while the remaining volume (inner core) contains the vapour phase. As illustrated in Figure 1-2, a heat pipe consists of three distinct regions: an evaporator, a condenser, and an adiabatic region. Heat applied to the evaporator by an external source vaporizes the working fluid in this section. The 
resulting high pressure in the region drives the vapour from the evaporator to the condenser where the vapour condenses and gives up its latent heat of vaporization to a heat sink in this section. Capillary pressure, developed in the wick, then pumps the condensed liquid back to the evaporator for the cycle to continue. This process continues for as long as the flow of working fluid is not blocked and a sufficient capillary pressure is consistently maintained (Chi, 1976).

\subsubsection{Capillary Pumped Loops (CPL)}

The capillary pumped loop (CPL) is very closely related to the LHP. The CPL was invented in the United States in the 1960's, but active development did not begin until the early 1980's when the National Aeronautics and Space Administration (NASA) Goddard Space Flight Center sponsored Swales Thermal Systems and Dynatherm for a large portion of the development and test effort (Nikitkin and Cullimore, 1998). The main difference between a CPL and LHP is the location of the reservoir. In a traditional CPL, the reservoir is usually connected to the liquid line by a reservoir line to store excess liquid in the system and is sometimes thermally connected for temperature control purposes. As a result, the fluid returning to the evaporator from the condenser does not pass directly through the reservoir. In addition, the primary wick in a CPL is typically made of polyethylene, with a low thermal conductivity and relatively large pore size. These differences result in some operational differences between CPLs and LHPs. One disadvantage of a CPL is that it requires preconditioning, where the reservoir is heated to a temperature higher than the evaporator prior to start-up. In comparison, a LHP starts up 
as soon as the temperature gradient between the evaporator and compensation chamber is large enough to initiate fluid circulation. Another disadvantage of the CPL is its tendency to deprime without sufficient subcooling. Without sufficient subcooling, the evaporator core becomes blocked with vapour causing the wick to dry-out and the loop to deprime. In the case of a LHP, a decrease in liquid subcooling is balanced by an increase in loop operation temperature. Thus, LHP is 'autoregulating', ensuring stable and continuous operation (Nikitkin and Cullimore, 1998). One major advantage of the CPL in comparison to LHPs is its reservoir is relatively small and is separate from the evaporator. This characteristic makes the unit much less sensitive to heat leak and much more flexible for integration purposes. A detailed comparison between CPL and LHP technologies is available in (Nikitkin and Cullimore, 1998) and (Ku, 1993).

\subsubsection{Loop Heat Pipes (LHP)}

The development LHPs originated from a pair of scientists from the former Soviet Union. In 1972, at the Ural Polytechnical Institue of Thermal Physics, Gerasimov and Maidanik successfully constructed and tested a device with a length of $1.2 \mathrm{~m}$ and capacity of approximately $1 \mathrm{~kW}$ (Maidanik, 2005). In 1985, LHP design features and operation principles were disclosed through patents filed by Maidanik under the name 'Heat Transfer Apparatus' (Maidanik et al., 1985). It was in 1989 when the term 'loop heat pipe' was first used, the year in which the first LHP flight test was conducted aboard the Russian spacecraft Granat. During this flight test, long-term and reliable flight operation in microgravity was successfully demonstrated (Kaya and Hoang, 1999). Further flight 
testing experiments were conducted during the 1990's including the flight test of an American LHP on the STS-83 and STS-94 missions in 1997 (Lashley et al., 1998). During these flights, the LHP demonstrated perfect on-orbit operation. The LHP has since been widely accepted as a baseline technology for spacecraft thermal control including that of the Boeing-702 bus used for Telesat's ANIK F1 and ANIK F2 satellites as well as used for missions including NASA's GLAS, EOS-Chemistry and GOES spacecraft, ESA's ATLID, CNES's STENTOR, and RKA's OBZOR (Ku, 1999).

LHP technology may enable further innovation in spacecraft thermal control such as the use of deployable radiators or thermal control for human missions to Mars (Kaya and $\mathrm{Ku}$, 2003). LHPs may also offer excellent thermal control solutions for multiple payloads onboard small satellites. Introduction of LHPs into other industries has been slow because of their high fabrication costs. However, due to the recent research into low cost wicks and manufacturing techniques, it is becoming more feasible to implement LHPs into many advanced products for terrestrial application. LHPs have great potential for use in a wide range of areas such as high power density chips, laptop computers, avionics cooling, airplane anti-icing systems, nuclear power plants, road and bridge deicing, roof top solar installations, and remote communication sheds.

\subsubsection{Miniature Loop Heat Pipe (MLHP)}

Increased demand for components capable of handling higher heat load densities while decreasing component mass and size has made it necessary to look for new approaches to expand the potential application of LHPs. Therefore, more efficient designs with even 
smaller dimensions are required. Recent efforts directed towards miniature loop heat pipes (MLHPs) have yielded promising results. For example, Maidanik (2005) investigated several MLHPs with masses ranging from 10-20 $\mathrm{g}$ and evaporator diameters of 5-6 mm. Each MLHP was constructed with either stainless steel or aluminum and used ammonia as the working fluid. In almost all cases, the units were capable of transferring heat loads of up to $95 \mathrm{~W}$ over distances of up to $300 \mathrm{~mm}$ with a thermal resistance ranging from 0.1 to $0.2 \mathrm{~K} / \mathrm{W}$. Of importance was that each unit possessed sufficient mechanical flexibility, allowing for easy integration using a simple finned sink and fan at the condenser. Khrustalev et al. (2001) investigated an ammonia/stainless steel MLHP with a $5.6 \mathrm{~mm}$ outer diameter evaporator. The MLHP demonstrated successful operation between a heat load range of 1 to $100 \mathrm{~W}$ with an overall thermal conductance of about $5 \mathrm{~W} / \mathrm{K}$. An advanced feature in the design was that the temperature of the loop was controlled using a thermal electric cooler (TEC) attached to the compensation chamber. The temperature of the evaporator was maintained by either cooling or heating the compensation chamber as necessary. Pastukhov et al. (1999) investigated two ammonia/stainless steel MLHPs, both with a $6 \mathrm{~mm}$ outer diameter evaporator. Tests were performed under atmospheric conditions with heat removal at the sink using both free convection and forced convection. The first specimen possessed a heat transport capacity of $50 \mathrm{~W}$, but demonstrated unreliable start-up and operation capacity in unfavourable orientations. The second MLHP tested showed capacity to provide reliable start-up and stable operation with a heat transport capacity of up to $20 \mathrm{~W}$ in all 
orientations. Khrustalev (2001) investigated the use of low cost MLHPs for use in transporting, spreading, and dissipating heat in electronics. In particular, Khrustalev looked at the use of a single copper wick sintered directly in the evaporator envelope. The 'hybrid' wick structure was configured such that the liquid evaporates from the capillary structure similar to that in a conventional heat pipe with a non-inverted meniscus. The water/copper MLHP had an evaporator diameter of $9 \mathrm{~mm}$ and condenser length of $100 \mathrm{~mm}$. The MLHP transported more than $150 \mathrm{~W}$ at a steady-state temperature of $75^{\circ} \mathrm{C}$, approximately one order of magnitude better than water/copper conventional heat pipes.

\subsection{Research Objectives}

The main objective of this study was to gain an overall understanding of LHP technology and to design and develop several functional units for testing. The purpose of manufacturing an LHP was to demonstrate the technology's reliability and flexibility for use in many thermal control applications, and in particular, electronics cooling. Results from testing each unit were used as a stepping stone for the development of much smaller and more efficient designs. The following activities were considered to achieve the above mentioned objectives:

- Establish a set of design requirements

- Develop procedures for component selection, manufacturing, cleaning, assembly, evacuation and charging

- Equip the LHP laboratory with capabilities for LHP fabrication and testing 
- Establish an experimental approach and testing procedures

- Identify key areas of concerns to be addressed through performance testing

- Develop mathematical models to estimate working fluid properties, and calculate fluid inventory and compensation chamber sizing

Tests were performed on each LHP to experimentally study critical performance characteristics. The tests were carried out in three phases as follows:

1. Investigate LHP functionality

2. Investigate sensitivity of LHP performance with respect to fluid charge; measure steady-state operating temperature, maximum transport capacity, and effective thermal resistance.

3. Study the effect of elevation and periodic heating on the maximum transport capacity and stability of the LHP. Investigate temperature hysteresis characteristics.

\subsection{Organization}

This thesis presents a detailed discussion and analysis of the design and development of loop heat pipes and is organized as follows:

Chapter 1 Introduction: Introduces the concept of LHPs and provides a brief history of the technology and an overview of the main research objectives and organization of the thesis.

Chapter 2 Literature Review: Presents LHP operation principles and characteristics and discusses traditional design processes. 
Chapter 3 LHP Design: Introduces the problem statement and design approach. Also presents a detailed discussion of component sizing and selection.

Chapter 4 LHP Fabrication: Provides a detailed overview of the manufacturing process including cleaning, assembly, evacuation, and charging procedures.

Chapter 5 LHP Testing: Presents the experimental approach, setup, and procedure. Test results of each unit are also presented and examined.

Chapter 6 Mathematical Modeling: Discusses the development of mathematical models used to estimate working fluid properties, fluid inventory, and compensation chamber volume.

Chapter 7 Conclusions and Recommendations: Summarizes the work completed, provides conclusions, and discusses future work and recommendations. 


\section{Chapter 2: Literature Review}

\subsection{LHP Operating Principles}

The primary wick in the evaporator must develop a capillary pressure sufficient to overcome the total pressure drop in the loop to ensure continuous LHP operation. The total pressure drop in the system is the sum of the frictional pressure drops in the vapour grooves, vapour line, condenser, liquid line and evaporator wick plus any static pressure drop due to gravity $(\mathrm{Ku}, 1999)$ :

$$
\Delta P_{\text {tot }}=\Delta P_{\text {grooves }}+\Delta P_{v l}+\Delta P_{\text {cond }}+\Delta P_{l l}+\Delta P_{\text {wick }}+\Delta P_{s c}+\Delta P_{g}
$$

For fully developed single-phase flow, the frictional pressure drop can be calculated with the following equation:

$$
\Delta P_{f}=f\left(\frac{L}{D}\right)\left(\frac{\rho V^{2}}{2}\right)
$$

where $f$ is a dimensionless parameter called the Darcy friction factor and is a function of the Reynolds number and tube roughness. The pressure drop across the wick structure is characterized by the liquid viscosity and wick permeability and may be approximated as: 


$$
\Delta P_{\text {wick }}=\left(\frac{\mu_{l} \dot{m}}{2 \pi \kappa_{\text {wick }} \rho_{l}}\right) \ln \left(\frac{D_{o}}{D_{i}}\right)
$$

where $\kappa_{\text {wick }}$ is the permeability of the wick, $\mu_{l}$ is the liquid viscosity, and $\dot{m}$ is the mass flow rate of the working fluid. The gravity pressure losses are the result of hydrostatic pressure and are not temperature dependent. These losses are defined as:

$$
\Delta P_{g}=\rho g h
$$

One of the main advantages of any capillary loop is that the meniscus inside the wick automatically adjusts itself by reducing the radius of curvature, thus establishing a capillary pressure equal to that of the total system pressure drop. The capillary pressure developed by the wick is expressed by the Young-Laplace equation:

$$
\Delta P_{\text {cap }}=\frac{2 \sigma \cos \theta}{R}
$$

where $\mathrm{R}$ is the radius of curvature of the meniscus in the wick, $\sigma$ is the surface tension of the working fluid, and $\theta$ is the contact angle between the liquid and solid. As the heat load is increased, the radius of curvature will continue to decrease until it is equal to the effective pore radius of the wick, $r_{\text {eff }}$. At this point, the wick has reached its maximum capillary pressure. The maximum pressure that a wick structure can develop depends on design and size and is defined as:

$$
\Delta P_{c a p, \max }=\frac{2 \sigma \cos \theta}{r_{e f f}}
$$


If the total system pressure drop exceeds the capillary limit that the wick can provide, then the wick will experience 'dry-out'. In this situation vapour penetrates the evaporator core through the wick, and a sudden and sharp increase in operating temperature is observed. Fortunately, as evident in many designs, LHPs have the ability to recover from dry-out simply by lowering the heat load $(\mathrm{Ku}, 1999)$.

\subsubsection{Thermodynamic Cycle}

The steady-state operation of LHPs may be better understood through a simple thermodynamic analysis of a pressure-temperature diagram. Figure 2-1 illustrates the thermodynamic cycle upon which a typical LHP operates. The thermodynamic states indicated by the numbers in Figure 2-1 also correspond to the physical LHP locations shown in Figure 1-1. In the analysis to follow, it is assumed that the liquid and vapour lines are perfectly insulated. In reality however, there is usually some heat exchange with ambient through either convection or radiation. Correspondingly, the temperature in each line may increase, decrease, or stay the same depending on the heat exchange and temperature of ambient. 


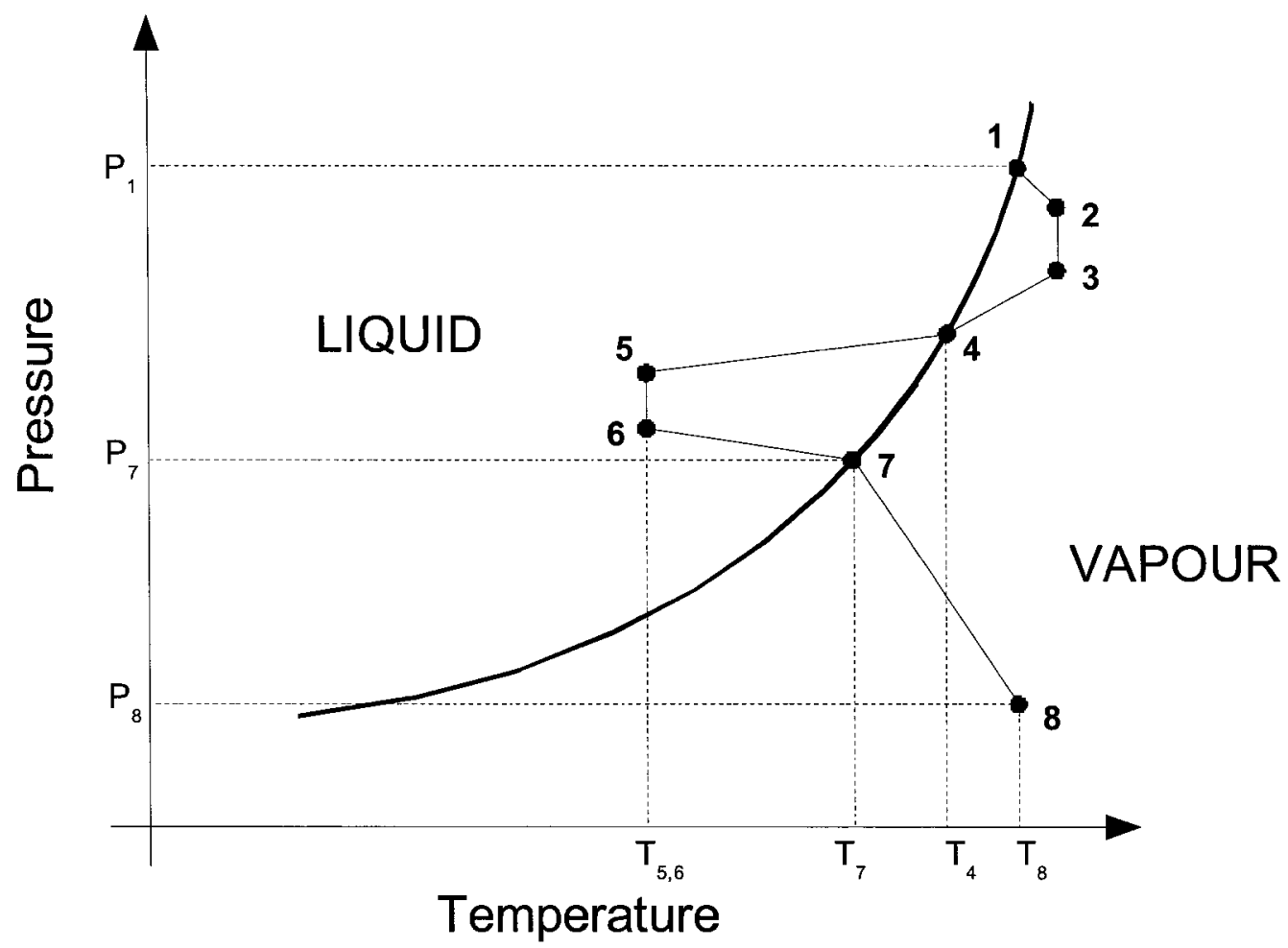

Figure 2-1: Pressure-Temperature Curve of Steady-State LHP Operation

As illustrated in Figure 2-1, point 1 represents the conditions at the evaporator surface (on the vapour side of the meniscus). As thermal energy is added to the working fluid, vapour is generated at the outer diameter of the evaporator wick and is at saturation temperature corresponding to the highest pressure in the system. As the vapour flows along the vapour grooves to the evaporator exit (point 2) it becomes slightly superheated due to a small decrease in absolute pressure and an increase in temperature caused by contact with the evaporator wall. As the vapour flows along the vapour line, between points 2 and 3, temperature remains constant while the pressure continually decreases due to frictional losses. At the end of the vapour line (point 3) the vapour becomes more 
superheated relative to the local saturation pressure. While in the condenser, heat from the vapour is rejected to the sink and the vapour begins to condense. Condensation of the vapour continues, with both pressure and temperature decreasing, until condensation is complete and the fluid reaches a saturated liquid state on the saturation line (point 4) which is often referred to as the liquid-vapour interface in the condenser. Assuming the condenser is not fully utilized, the liquid begins subcooling inside the condenser until it reaches the liquid line inlet at point 5 . In the liquid line, the temperature remains constant while the pressure gradually decreases along the line (points 5 to 6 ). Points 6 to 7 represents the liquid motion in the compensation chamber and evaporator core. Since the evaporator core is considered an extension of the compensation chamber, both have the same absolute pressure. Also, since the evaporator core is thermally and hydraulically connected to the compensation chamber, the temperature and pressure at the inner surface of the wick should be at saturation (point 7). Points 7 to 8 correspond to the liquid motion through the wick structure and back to the evaporation zone. Capillary action draws the liquid at the inner surface of the wick to the outer surface of the wick. As the fluid travels through the porous wicking material, it gains in temperature while also decreasing in pressure. Point 8 determines the state of the working fluid in the vicinity of the evaporating menisci and has the lowest pressure in the system (Chuang, 2003).

The difference in pressure between the evaporator and compensation chamber provides the driving force for the circulation of the fluid. Since the two saturation states 
are thermodynamically related, the following condition must be satisfied for steady-state LHP operation:

$$
P_{t o t}-P_{w i c k}=\left(\frac{d P}{d T}\right)\left(T_{e}-T_{c c}\right)
$$

More specifically, Eq. (2.7) can be written as:

$$
P_{1}-P_{7}=\left(\frac{d P}{d T}\right)\left(T_{1}-T_{7}\right)
$$

where:

$P_{1}, T_{1} \quad$ is the saturation pressure and temperature in the vapour grooves

$P_{7}, T_{7} \quad$ is the saturation pressure and temperature in the compensation chamber

$\frac{d P}{d T} \quad$ is the slope of the saturation line at the corresponding pressure and temperature of the compensation chamber

Furthermore, the derivative of $d P / d T$ is related to the physical properties of the working fluid by using the Clausius-Clapeyron equation:

$$
\frac{d P}{d T}=\frac{\lambda}{T_{7} \Delta v}
$$

where:

$\lambda \quad$ is the latent heat of vaporization of the working fluid

$T_{7} \quad$ is the saturation temperature of the fluid in the compensation chamber

$\Delta v \quad$ is the difference in the vapour and liquid specific volumes 
Eq. (2.8) illustrates that for a given pressure gradient between the evaporator and compensation chamber, there must be a corresponding difference in saturation temperatures. Furthermore, if external conditions change, the loop operating temperature will move along the saturation line until a new equilibrium is reached. $\mathrm{Ku}$ (1999) suggested that the demonstrated coupling between the pressure and temperature across the wick has implications on loop operating temperature at low heat loads and at adverse orientations.

\subsection{LHP Operating Characteristics}

\subsubsection{Loop Operating Temperature}

As previously discussed, the compensation chamber is located adjacent to the evaporator and is thermally and hydraulically connected by the primary and secondary wick. Also, the working fluid must pass through the compensation chamber from the condenser to the evaporator. For this reason, the temperature of the compensation chamber is a function of evaporator heat load and enthalpy of the subcooled fluid returning from the condenser. The condenser is a function of the condenser sink temperature and ambient temperature. As will be shown, the compensation chamber is the primary driver for the loop operating temperature. A simplified thermal network of the LHP model is shown in Figure 2-2 (a complete thermal network can be found in (TAIS, 2000)). The model is used to better understand the complex process. 


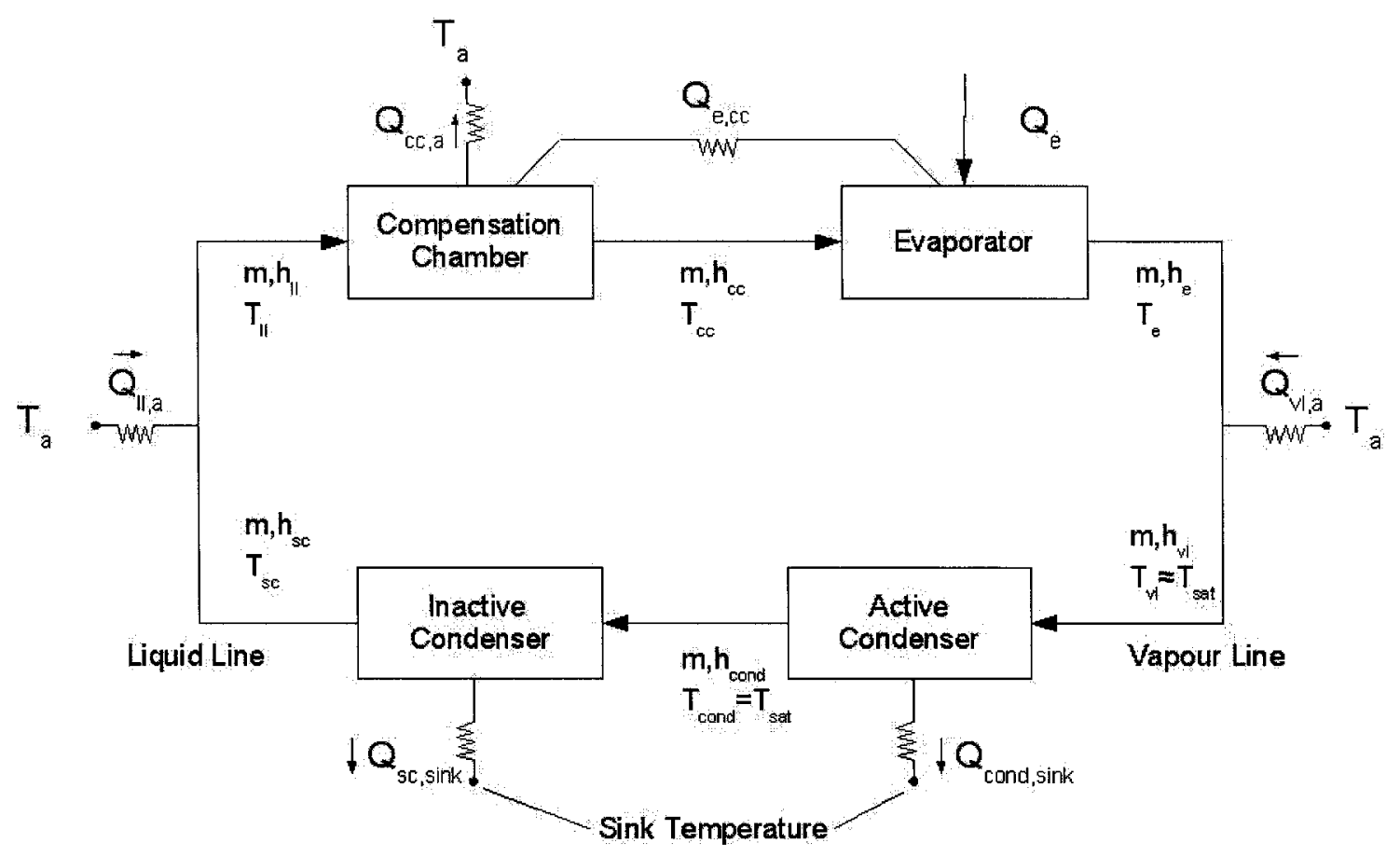

Figure 2-2: Simplified Thermal Network of the LHP Model

As shown in Figure 2-2, the compensation chamber exchanges energy with the evaporator, ambient, and subcooled liquid returning from the condenser. As heat is applied to the evaporator, part of it goes directly towards vaporization of the working fluid while the other part 'leaks' to the compensation chamber and is expressed as follows:

$$
Q_{e}=Q_{e, c c}+Q_{e, v a p}
$$

where $Q_{e}$ is the net heat load applied to the evaporator. The term, $Q_{e, v a p}$, is the heat used during the vaporization process of the working fluid and can be expressed as:

$$
Q_{e, v a p}=\dot{m} \lambda
$$


Any heat transfer from the evaporator to the compensation chamber is referred to as heat leak and is expressed as:

$$
Q_{e, c c}=(U A)_{e, c c}\left(T_{e}-T_{c c}\right)
$$

where $(U A)_{e, c c}$ is the thermal conductance between the evaporator and the compensation chamber. The amount of heat leak is proportional to the heat load and depends strongly on the flow conditions inside the evaporator (Chuang, 2003). More specifically, when the evaporator core is completely filled with liquid, heat transfer between the compensation chamber and evaporator is primarily through axial conduction of the evaporator body. However, if vapour is generated at the inner surface of the primary wick, it may be transported back to the compensation chamber thus increasing the heat leak through a process similar to a conventional heat pipe (ie. evaporation and condensation of the bubbles between the evaporator core and compensation chamber).

At steady-state, the heat leak from the evaporator must be balanced with the heat loss to ambient and the amount of subcooling that is brought back by the liquid from the condenser. Since the heat exchange between the compensation chamber and ambient is by natural convection, it is relatively small compared to the amount of subcooling brought back from the liquid line. Therefore, by assuming the heat exchange between the compensation chamber and ambient is negligible, the following must apply:

$$
Q_{e, c c}=\dot{m} C_{p} \Delta T=\dot{m} C_{p}\left(T_{c c}-T_{i n}\right)
$$


where $T_{\text {in }}$ is the liquid temperature at the entrance to the compensation chamber and $\Delta T$ is the amount of liquid subcooling. As the liquid exits the condenser and flows through the liquid line, it will exchange heat with its surroundings. The temperature difference caused by the heat exchange with ambient is expressed as:

$$
T_{i n}-T_{s c}=\frac{Q_{l l, a}}{\dot{m} C_{p}}
$$

where $T_{s c}$ is the temperature of the liquid leaving the subcooler and $Q_{l l, a}$ is the parasitic heating of the liquid line from the surroundings. At relatively low heat loads, a very small mass flow rate is produced and only part of the condenser is utilized for condensation. Consequently, as the liquid flows along the liquid line, its temperature is raised close to that of ambient due to parasitic heating. Decreased subcooling in the liquid line must be compensated for by an increase in the compensation chamber temperature in order to balance the heat leak from the evaporator. Demonstrated through Eq.(2.14), it is observed that a very large temperature increase may be required due to a very low mass flow rate. As the heat load is increased, the mass flow rate also increases and the liquid spends less time in the liquid line thus minimizing parasitic heating. By increasing both the mass flow rate and the liquid subcooling, the temperature of the compensation chamber decreases. This process continues until the condenser is fully utilized and only vapour exists. At this point, the compensation chamber temperature is at a minimum. 
This process is demonstrated using the performance curve of a classical LHP, as shown in Figure 2-3 for a sink temperature below ambient temperature. The figure is separated into two parts: variable conductance mode and constant conductance mode. In variable conductance mode, at very low powers, only a small section of the condenser is active while the rest is used to cool the liquid phase of the working fluid. As the power is increased, more condenser area becomes active thus increasing the conductance of the condenser and the overall conductance of the LHP. At a certain power, $\mathrm{Q}_{\mathrm{t}}$, the condenser is completely active and further increases in the overall conductance are no longer possible. Therefore, when the heat load is greater than or equal to $Q_{t}$, the LHP operates in fixed conductance mode. At this point, the vapour-liquid interface fluctuates near the end of the condenser line. Under this condition, since the condenser conductance and sink temperature are constant, the steady-state operating temperature increases linearly with increasing heat load (Nikitkin and Cullimore, 1998). The transition from variable to fixed conductance modes is dependent on sink temperature and the thermal coupling between the LHP and the environment (MacDonald, 2004). 


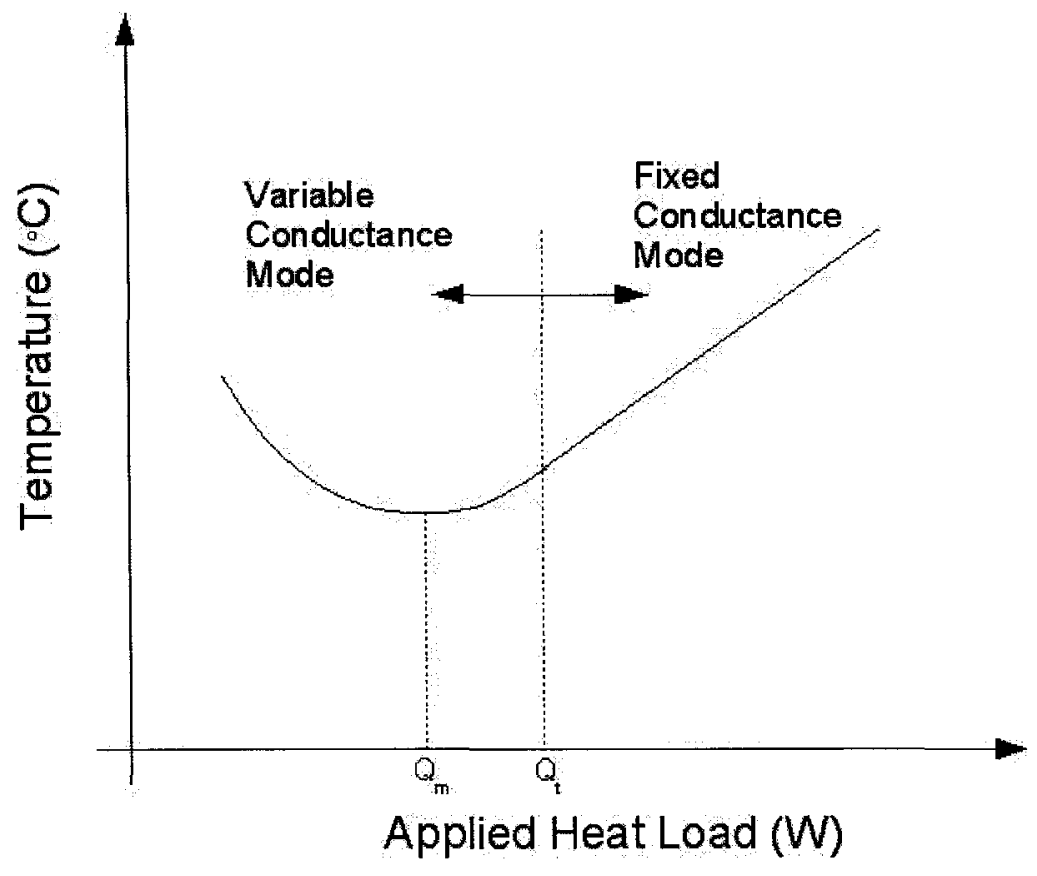

Figure 2-3: Variable and Fixed Conductance Modes

\subsubsection{Start-Up}

One of the primary advantages of an LHP is its reliable turnkey start-up. Unlike CPLs, LHPs do not require preconditioning. As heat is applied to the evaporator of an LHP, the working fluid circulates within the loop thus removing heat from the evaporator to the condenser. However, there exists a minimum power load in which an LHP will 'startup'. The heat load must be sufficient to produce the required pressure difference (due to a temperature gradient between the compensation chamber and evaporator) to initiate circulation of the fluid. It has been found that many LHP devices experience start-up problems at very low heat loads (usually $10 \mathrm{~W}$ or less) or in the presence of heavy masses attached to the evaporator. Nikitkin et al. (1998) suggested that under these conditions, a 
Peltier element might be needed to slightly and temporarily chill the compensation chamber to produce the required temperature gradient to start circulation. Similarly, an LHP can be stopped by heating the compensation chamber above the temperature of the evaporator. The minimum heat load for start-up is dependent on a number of factors which include the evaporator and compensation chamber design, initial conditions in the evaporator, and operating conditions prior to start-up. Most importantly, the initial state of the working fluid in the evaporator and across the wick greatly impacts LHP start-up characteristics including temperature overshoot and minimum power requirements.

$\mathrm{Ku}$ (1999) demonstrated four typical configurations of the liquid and vapour states inside the evaporator and compensation chamber prior to start-up (see Figure 2-4). He proposed that there are three major factors affecting start-up. First, if liquid completely fills the vapour grooves, a liquid superheat will be required to initiate boiling. However, if the vapour grooves already contain vapour, then boiling will be initiated as soon as power is applied and without any liquid superheat. Second, if the evaporator is completely liquid-filled, heat exchange between the evaporator and compensation chamber due to heat leak is minimized since heat is transferred primarily through conduction. However, if there is vapour present in the evaporator core, heat leak is significantly increased as the evaporator core becomes a vapour extension of the compensation chamber. Finally, the applied power affects start-up through interactions with the other two factors. 


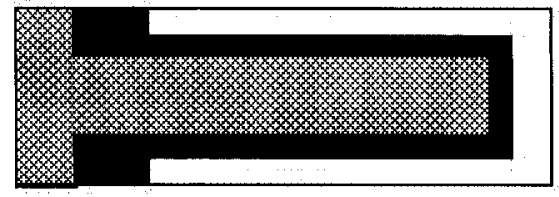

(a) Vapour channel two-phase Evaporator core: liquid-filled

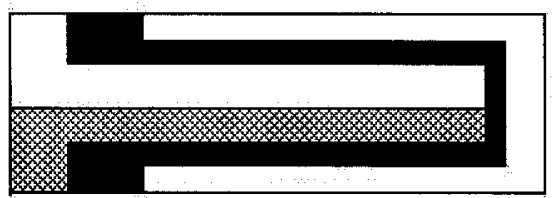

(c) Vapour channel: two-phase Evaporator core: two phase

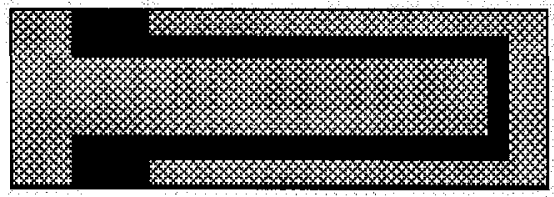

(b) Vapour channel: liquid-filled Evaporator core: liquid-filled

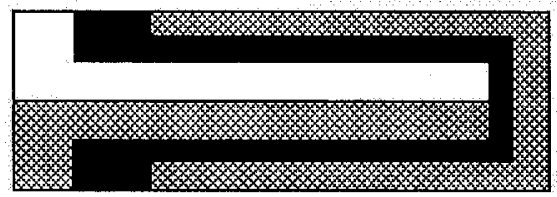

(d) Vapour channel liquid-filled Evaporator core two-phase

Figure 2-4: LHP Start-up Scenarios in the Evaporator

Experimental analysis of LHP start-up under varying conditions can be found in literature. For example, Cheung et al. (1998) presented experimental data suggesting that superheat of the liquid is significantly reduced when two-phase fluid exists in the vapour channels. Similarly, Kaya et al. (1999) demonstrated start-up characteristics at different orientations. They showed that the required superheat, maximum temperature at start-up, and time required for start-up strongly depend on loop orientation and therefore the overall pressure drop. They also proposed that the presence of vapour bubbles in the vapour grooves at high elevations promote nucleate boiling and as a result reduce the required superheat and time for start-up. 


\subsubsection{Temperature Hysteresis}

Temperature hysteresis is a phenomenon that occurs when the steady state operating temperature of an LHP depends not only on the applied heat load but also on the recent history of the heat load sequence for the same operating conditions such as sink temperature, ambient temperature and orientation. The typical trend of temperature hysteresis is shown in Figure 2-5 (Chuang, 2003) below.

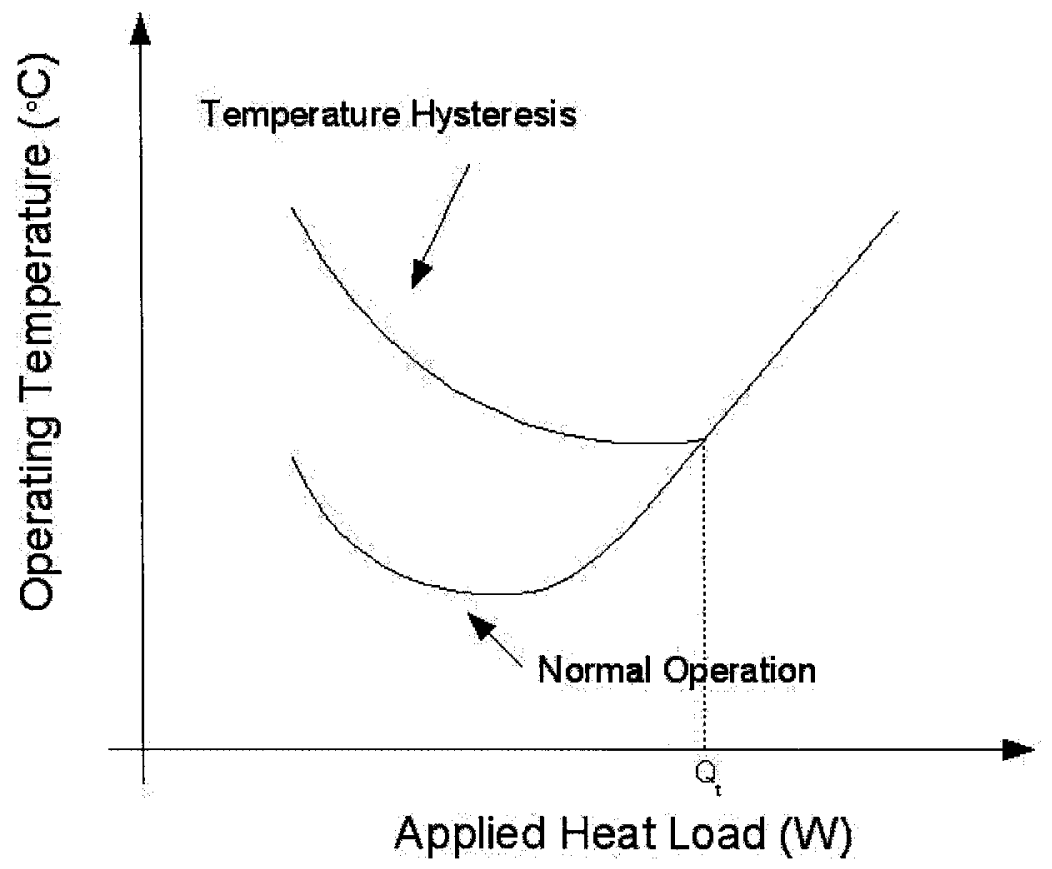

Figure 2-5: Typical Temperature Hysteresis Trend

As indicated in Figure 2-5, temperature hysteresis is dominant in the low power range and is associated with large decreases in applied power. This phenomenom may be explained as follows. As the heat load to the evaporator decreases, liquid from the compensation chamber is injected in the condenser. This process shifts the vapour-liquid interface towards the condenser entrance, reducing the area of condensation. For a 
moderate power decrease, the secondary wick ensures only liquid is supplied. However, with a large power decrease the pressure required to transfer liquid may exceed the capillary limit of the secondary wick. In this case, vapour bubbles may accumulate in the evaporator, changing the void fraction of the evaporator core. As the void fraction in the core increases, so to does the heat leak to the compensation chamber. Therefore, as more and more vapour is introduced into the evaporator core, the operating temperature of the loop increases since the subcooling term $\left(\dot{m} C_{p} \Delta T\right)$ can only compensate for the increased heat leak by increasing $\Delta T$. In the high power range, above $\mathrm{Q}_{\mathrm{t}}$, a higher mass flow rate increases liquid subcooling thus collapsing excess vapour bubbles inside the evaporator core and eliminating temperature hysteresis $(\mathrm{Ku}, 1999)$.

According to Kaya and $\mathrm{Ku}(1999)$, the temperature difference between the higher and lower trend strongly depends on the individual LHP design and in some cases may not even be present. Since the true mechanism of temperature hysteresis is not well understood, LHPs should be thoroughly tested for temperature hysteresis before implementation.

\subsubsection{Effect of Orientation}

As mentioned in section 2.2.1, heat leak from the evaporator to the compensation chamber greatly affects the operating temperature of a LHP. Therefore, LHP orientation in 1 -g environments can significantly influence loop temperature by promoting heat leak due to vapour bubble accumulation in the evaporator due to buoyancy forces. 
Using mathematical models, Chuang (2003) established that orientation has little effect on loop temperature at high heat loads because frictional pressure drops, which are the result of a high mass flow rate, dominate hydrostatic losses. In contrast, low heat loads produce lower mass flow rates, thus, gravitational head becomes a more dominant factor. These results were experimentally demonstrated by Wolf et al. (1994) using an ammonia LHP at two adverse elevations of $0.91 \mathrm{~m}$ and $2.74 \mathrm{~m}$. In their experiment, they found that LHP operating temperature increases with increasing adverse elevations for low to moderate power inputs. Similarly, Ku (1999) explains that the increase in LHP operating temperature due to an increase in adverse elevation is the result of an increase in pressure difference across the wick. An increase in pressure difference across the wick must result in an increase in saturation temperature difference across the wick (as required by Eq.(2.7)). Since the enthalpy of the liquid entering the compensation chamber does not change, the evaporator vapour temperature must increase to satisfy the increasing pressure drop. This is turn leads to an increase in heat leak between the evaporator and compensation chamber. The compensation chamber temperature must then increase in order to provide enough liquid subcooling which in turn results in an even higher evaporator vapour temperature. As a result, a dramatic increase in operating temperature may accumulate rapidly. However, since hydrostatic pressure losses are independent of flow rate, the effect of an increased adverse elevation may be suppressed by increasing the evaporator heat load. Increasing the evaporator heat load increases the mass flow rate in the loop which increases the liquid subcooling, sufficient to balance 
heat leak. Therefore, at high heat loads, any increase in operating temperature due to adverse orientation becomes unnoticeable.

\subsubsection{Effect of Non-Condensable Gases}

Significant non-condensable gases (NCGs) can sometimes be generated by improper cleaning procedures before assembly, impurity of the working fluid, and chemical reactions between the working fluid and case materials. The amount of NCGs generated is a function of the amount of working fluid, surface area of the materials in contact, operating conditions, and period of exposure $(\mathrm{Ku}, 1999)$.

The effect of NCGs on performance depends on the location of accumulation of the gases. The NCG typically collects in the compensation chamber or condenser. It may also circulate with the working fluid or be absorbed in the wick. In large quantities NCGs can sometimes increase the start-up time and operating temperature of the loop. This is accomplished if the NCG blocks part of the condenser thus reducing the overall thermal conductance. Presence of the gases in the evaporator core may also increase heat leak. However, Nikitkin and Bienert (1998) concluded that LHPs are relatively insensitive to the presence of NCGs after test results indicated that the effect on LHP performance is usually minimal.

\subsection{Design of Loop Heat Pipes}

Loop heat pipe design is an extremely complicated process involving a wide range of variables such as size, mass, shape, volume, working fluid, wick material, and case 
material. LHP design also involves such aspects as thermal load, transport length, evaporator/condenser length, operating temperature range, source-sink interfaces, fluid inventory, and life/reliability (Peterson, 1994). The design process can be streamlined by formulating an iterative procedure as outlined in Figure 2-6.

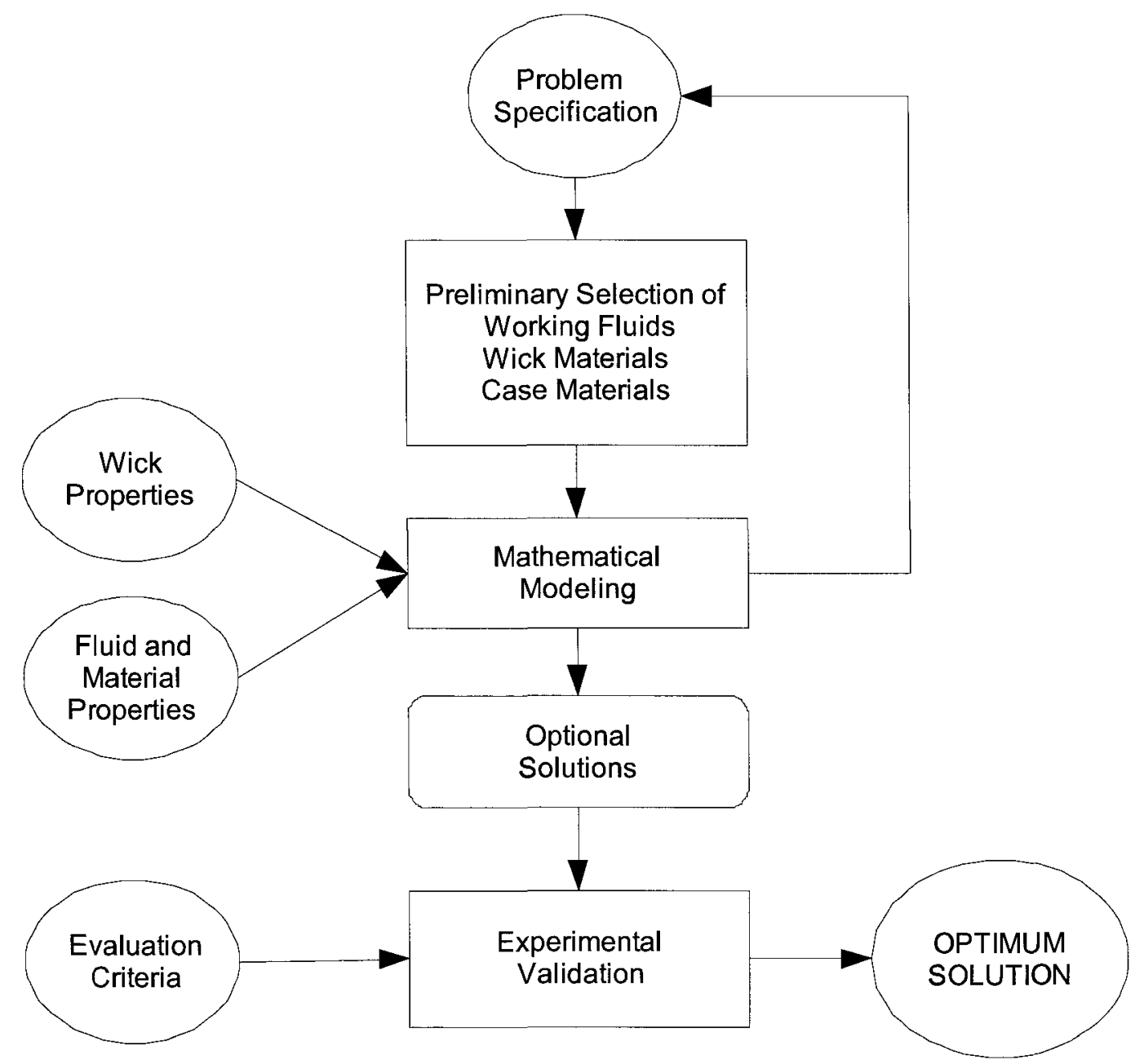

Figure 2-6: Loop Heat Pipe Design Procedure Adapted from (Chi, 1976)

The first step is to clearly identify the problem statement and requirements. This may include defining constraints for physical properties such as mass and external volume. It 
may also include specifying thermal performance requirements such as maximum transport capacity or operating temperature range. For example, it may be necessary to design a LHP for a limited volume application such as laptop cooling where operational temperatures are limited to -20 to $60^{\circ} \mathrm{C}$. Other requirements may include maximum heat load and heat flux, mode of heat rejection, and start-up at low power inputs. The second step involves preliminary selection of a working fluid, wick material, and case material. In this step, it is necessary to select components which are compatible with each other. Several combinations may exist that satisfy the requirements specified in the problem statement. Some combinations of case materials, wick materials, and working fluids have already been successfully applied in loop heat pipes. Examples of these combinations are listed in Table 2-1.

Table 2-1: Tested LHP Material-Working Fluid Combinations (Maidanik, 2003)

\begin{tabular}{ccc}
\hline Case Material & Wick & Working Fluid \\
\hline \hline Stainless Steel & Nickel & Water, Ammonia, \\
& & Acetone, Pentane, \\
& & Freon-152 A, Freon \\
& & 11, Propylene \\
& Water, Ammonia, \\
Stainless Steel & Titanium & Acetone, Pentane, \\
& & Freon-152 A, Toluene \\
Stainless Steel & Stainless Steel & Ammonia \\
Nickel & Titanium & Ammonia \\
Nickel & Nickel & Ammonia \\
Copper & Copper & Water \\
\hline
\end{tabular}

It is suggested to use similar combinations as a starting point. The effect of each component on operational characteristics must be determined before final selection. 
Table 2-2 provides some indication of how each of the three primary components affects various design requirements (Peterson, 1994).

Table 2-2: Components and their Influence on Design Requirements (Peterson, 1994)

\begin{tabular}{|c|c|c|c|}
\hline Design Requirements & $\begin{array}{l}\text { Working } \\
\text { Fluid }\end{array}$ & $\begin{array}{c}\text { Wick } \\
\text { Material }\end{array}$ & $\begin{array}{c}\text { Case } \\
\text { Material }\end{array}$ \\
\hline \multicolumn{4}{|l|}{ Thermal Performance } \\
\hline Transport Capacity & $S$ & $S$ & W \\
\hline Operating Temperature Range & $S$ & W & W \\
\hline Temperature Drop & M & $w$ & W \\
\hline \multicolumn{4}{|l|}{ Mechanical } \\
\hline $\begin{array}{l}\text { Physical Requirements (size, } \\
\text { weight, etc.) }\end{array}$ & W & W & M \\
\hline Wall Thickness - internal pressure & W & $N$ & $S$ \\
\hline Sink - source interface & $\mathrm{N}$ & $\mathrm{N}$ & $S$ \\
\hline Dynamic / static loads & W & $S$ & $M$ \\
\hline \multicolumn{4}{|l|}{ Reliability and Safety } \\
\hline Material Compatibility & $S$ & $S$ & $S$ \\
\hline External Corrosion & $\mathrm{N}$ & $\mathrm{N}$ & $S$ \\
\hline Fabrication & M & M & M \\
\hline Pressure containment/leakage & W & M & $S$ \\
\hline Toxicity & $S$ & W & W \\
\hline \multicolumn{4}{|l|}{ Gravitational Environment } \\
\hline$>1 \mathrm{~g}$ & $S$ & $S$ & $S$ \\
\hline $1 \mathrm{~g}$ & M & M & W \\
\hline$<1 \mathrm{~g}$ & W & $M$ & W \\
\hline
\end{tabular}

The third step involves the use of mathematical models, such as the one proposed by Kaya and Hoang (1999), to predict primary heat transfer characteristics. More specifically, steady-state energy balance and pressure-drop equations are modeled along the flow path of the LHP and used to estimate maximum heat load, system pressure losses, and operational temperatures for the selected components and properties in step 
two. The results are then verified against the requirements specified in the problem statement. Steps one through three are repeated several times to yield optional solutions for the specified design requirements (ie. varying combinations of each LHP component are evaluated). Finally, evaluation criteria such as cost and manufacturing techniques are input into an evaluation procedure to determine the optimum solution. The evaluation procedure includes experimental testing for performance verification of initial designs.

It should be noted that some mathematical models have been validated with a good degree of correlation to experimental values. However, some uncertainties related to their design still remain (Riehl and Dutra, 2005). For example, phenomena such as temperature hysteresis are not yet completely understood. Also, several simplifying assumption are typically required in the development of these models. Therefore, it may be necessary to manufacture and test several prototypes before an optimum design is obtained, provided all necessary requirements are met.

\subsubsection{Working Fluids}

Many factors affect the selection of an appropriate working fluid, including operational temperature range, vapour pressure, thermal conductivity, stability, toxicity, and compatibility with wick and case materials. Different types of working fluids have been studied and are well documented in literature for their use in conventional heat pipes. Traditionally, working fluids have been categorized as either: cryogenic fluids such as helium, neon, oxygen, and nitrogen; moderate-temperature fluids such as methanol, ammonia, acetone, and water; or high temperature-liquid metal fluids such as potassium, 
lithium, or sodium (Chi, 1976). Table 2-3 illustrates the typical operating temperature ranges for various working fluids.

Table 2-3: Operating Temperature Range of Various Fluids Adapted from (Faghri, 1995)

\begin{tabular}{ccccc}
\hline Working Fluid & $\begin{array}{c}\text { Melting } \\
\text { point, K } \\
\text { at 1 atm }\end{array}$ & $\begin{array}{c}\text { Boiling } \\
\text { point, K } \\
\text { at 1 atm }\end{array}$ & $\begin{array}{c}\text { Operating } \\
\text { Temperature } \\
\text { Range, K }\end{array}$ & $\begin{array}{c}\text { Classified } \\
\text { temperature } \\
\text { application }\end{array}$ \\
\hline Helium & 1 & 4.2 & $2-4$ & \\
Hydrogen & 13.8 & 20.4 & $14-31$ & \\
Neon & 24.4 & 27.1 & $27-37$ & Cryogenic \\
Nitrogen & 63.1 & 77.4 & $70-103$ & \\
Argon & 83.9 & 87.3 & $84-116$ & \\
Oxygen & 54.7 & 90.2 & $73-119$ & \\
Krypton & 115.8 & 119.7 & $116-160$ & Moderate \\
\hline Ammonia & 195.5 & 239.9 & $213-373$ & \\
Pentane & 143.1 & 309.2 & $253-393$ & \\
Freon 113 & 236.5 & 320.8 & $263-373$ & \\
Acetone & 180 & 329.4 & $273-393$ & \\
Water & 273.1 & 373.1 & $303-473$ & \\
Methanol & 175.5 & 338.2 & $273-513$ & \\
Ethanol & 158.8 & 351.4 & $273-513$ & \\
\hline \hline Sodium & 371 & 1151 & $873-1473$ & \\
Lithium & 453.7 & 1615 & $1273-2073$ & Hemperature \\
Silver & 1234 & 2385 & $2073-2573$ & \\
\hline
\end{tabular}

LHPs have been designed primarily for use in space and electronic applications. LHP applications in these areas require the selection of a working fluid with boiling temperatures between 250 and $375 \mathrm{~K}$. This typically limits the selection to fluids such as ammonia, acetone, methanol, water, and Freon-11 or 113.

For efficient loop operation, working fluids should possess the following characteristics: high latent heat of vaporization for more efficient heat transport, high 
thermal conductivity to minimize temperature drops across the wick, high surface tension to maximize capillary pumping capabilities, and low viscosity to minimize pressure losses along the fluid flow line. Chi (1976) combined these properties into what is known as the merit number or liquid transport factor to evaluate the effectiveness of various working fluids at specific operating temperatures. The merit number is calculated as follows:

$$
N_{l}=\frac{\rho_{l} \sigma k_{l}}{\mu_{l}}
$$

where:

$\begin{array}{ll}\rho_{l} & \text { is the liquid density } \\ \sigma & \text { is the surface tension } \\ k_{l} & \text { is the liquid thermal conductivity } \\ \mu_{l} & \text { is the liquid viscosity }\end{array}$

As an example, a figure of merit for some moderate to high-temperature working fluids is provided Figure 2-7. 


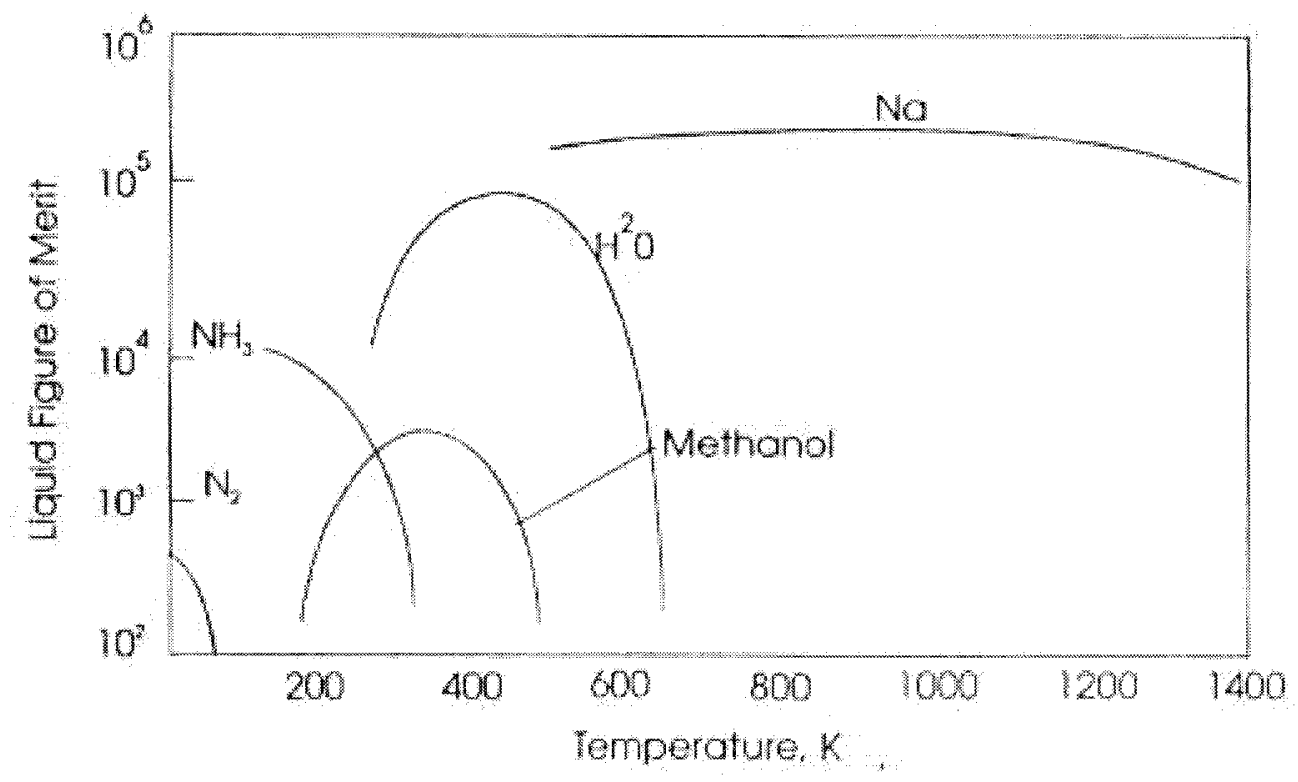

Figure 2-7: Figure of Merit for Various Working Fluids (Dunn and Reay, 1982)

Another concern regarding the selection of a working fluid is the compatibility between the fluid and case material. Any chemical reaction between the working fluid and case material creates non-condensible gases in the loop. The existence of NCGs may degrade LHP performance. Compatibility of various metals with working fluids can be found in literature (Faghri, 1995).

\subsubsection{Primary and Secondary Wicks}

The selection of the primary wick structure is an important step in the design process of LHPs. The primary wick is located in the evaporator section of a LHP and provides the required pressure that circulates the fluid in the system. The most critical properties to consider when selecting the wick structure are: effective pore radius, porosity, 
permeability, and effective thermal conductivity. Effective pore radius affects the capillary limit of the wick while porosity and permeability affects pressure drop due to fluid flow across the wick. Ideally, wick structures are manufactured to have an effective pore radius of $1 \sim 10 \mu m$, a porosity of $50 \sim 75 \%$, and a permeability of greater than $1 \times 10^{-13} \mathrm{~m}^{2}$. Effective thermal conductivity affects heat leak from the evaporator to the reservoir and should be minimized. Unfortunately, obtaining all of these properties simultaneously in one sample can be quite difficult since they are often contradictory. Therefore, some compromise is required when designing the wick structure. Another important aspect to consider is the overall cost. Traditionally, metal wicks such as sintered nickel, titanium, or copper powders are used in LHPs and are often the most expensive component. This is due to the fact that the wick has to be manufactured in an energy-intensive process where it is sintered, machined, evaluated, cleaned, inserted into evaporator, and sealed before the entire assembly of the LHP (Khrustalev, 2001). Other properties to consider include compatibility with working fluids and case material, material availability, and machineability.

The secondary wick is used to continuously provide fluid from the compensation chamber to the reservoir. Since its primary function is to supply fluid and not provide high capillary pressure, a much larger effective pore radius $(20 \sim 150 \mu \mathrm{m})$ is acceptable. Therefore, metal mesh structures are typically used. 


\subsubsection{Component Sizing}

Sizing of the evaporator and wick structures strongly influence the maximum heat load and pressure drop of the loop, while the length and size of the transportation lines directly influence the heat transfer between the working fluid and ambient, pressure drop of the system, and size of the reservoir. Traditionally, LHPs have employed cylindrical evaporators ranging from 12 to $28 \mathrm{~mm}$ in diameter. The shape and size of the condenser can vary significantly depending on the means and conditions of cooling. The length of vapour and liquid lines can reach up to $10 \mathrm{~m}$ while their diameter, as a rule, is in the range of 3 to $8 \mathrm{~mm}$ (Pastukhov et al., 2003). Demand for smaller devices operating in the 10 to $100 \mathrm{~W}$ ranges has pushed the development of MLHPs and has also led to a significant reduction in component sizes. For example, the length of heat transfer is typically 0.5 to $1 \mathrm{~m}$. Furthermore, the evaporator length is usually no more than $40 \mathrm{~mm}$ while the evaporator diameter is typically no more than $6 \mathrm{~mm}$. Finally, vapour and liquid lines are approximately 1 to $2 \mathrm{~mm}$ in diameter.

\subsubsection{Fluid Inventory and Compensation Chamber}

Sizing the compensation chamber and estimating the fluid charge are critical tasks in designing an LHP. Both affect a wide range of performance characteristics that can include overall heat conductance, steady-state operating temperature, maximum power, and minimum start up power. Generally, there are three design conditions to consider when developing an LHP: cold operation, hot operation, and maximum non-operating temperature. During cold operation, no heat is applied to the evaporator while the 
transport lines (condenser, liquid line, vapour line) are exposed to the coldest environmental conditions. During hot operation, maximum power is applied to the evaporator while the rest of the loop is exposed to the hottest environmental conditions. The maximum non-operating temperature is important during storage and/or transportation where the concern is that the LHP may burst due to hydrostatic pressure at elevated temperatures when there is not enough void volume in the loop. Generally, there must be enough liquid to supply the evaporator for start-up during cold case conditions while also preventing condenser blockage during hot case conditions. Furthermore, the compensation chamber should be sized to compensate for the thermal expansion of the working fluid at the different operating temperatures. It is therefore important to size the compensation chamber and fluid inventory concurrently.

Several approaches found in literature have been developed to effectively select a fluid charge and compensation chamber volume that would yield optimum performance characteristics. The techniques documented by $\mathrm{Ku}$ (1999) and TAIS Ltd (2000) are summarized below.

In the first approach, documented by Ku (1999), there is no theoretical upper limit for the compensation chamber volume. However, the volume should be optimized with the fluid inventory to accommodate space and weight constraints. Furthermore, the minimum compensation chamber volume must be able to accommodate at least the swing volume between the hot and cold case of loop operation. During cold operation, some 
small portion of the compensation chamber is liquid-filled while the rest of the loop is completely flooded. The fluid inventory must therefore satisfy the relation:

$$
M=\rho_{l, c}\left(V_{l o o p}+\beta \cdot V_{c c}\right)+\rho_{v, c}(1-\beta) V_{c c}
$$

where:

$\rho_{l, c} \quad$ is the cold-case liquid density

$\rho_{v, c} \quad$ is the cold-case vapour density

$V_{\text {loop }} \quad$ is the loop total volume excluding the compensation chamber

$\beta \quad$ is the fraction of compensation chamber volume occupied by the liquid

During hot operation, some vapour space should be available in the compensation chamber when the condenser is completely open. Thus, the fluid inventory must also satisfy the relation:

$$
M=\rho_{l, h}\left[V_{l l}+V_{p w}+V_{s w}+(1-\alpha) \cdot V_{c c}\right]+\rho_{v, h}\left(V_{\text {grooves }}+V_{v l}+V_{\text {cond }}+\alpha \cdot V_{c c}\right)
$$

where:

$$
\begin{array}{ll}
\rho_{l, h} & \text { is the hot-case liquid density } \\
\rho_{v, h} & \text { is the hot-case vapour density } \\
\alpha & \text { is the void fraction of the compensation chamber }
\end{array}
$$

$\mathrm{Ku}$ (1999) states that $\alpha$ and $\beta$ values are selected at the designer's discretion and that a careful selection of these two values will yield an optimal compensation chamber volume and fluid inventory. Finally, the fluid charge needs to be checked against the upper limit 
of the loop, imposed by the maximum non-operating temperature condition. In this case, the fluid inventory must satisfy the following relation:

$$
M \leq \rho_{l, \max }\left(V_{\text {loop }}+V_{c c}\right)
$$

where $\rho_{l, \max }$ is the liquid density at the maximum non-operating temperature.

The second technique, documented by TAIS Ltd (2000), is a more conservative approach that assumes there is always sufficient liquid in the LHP for start-up. That is, LHP start-up will always occur by supplying heat to the evaporator, even in the most unfavourable conditions and orientations. Therefore in this case, the amount of liquid in the internal volume shall be sufficient to fill the entire LHP except the reservoir and vapour grooves, as illustrated in Figure 2-8.

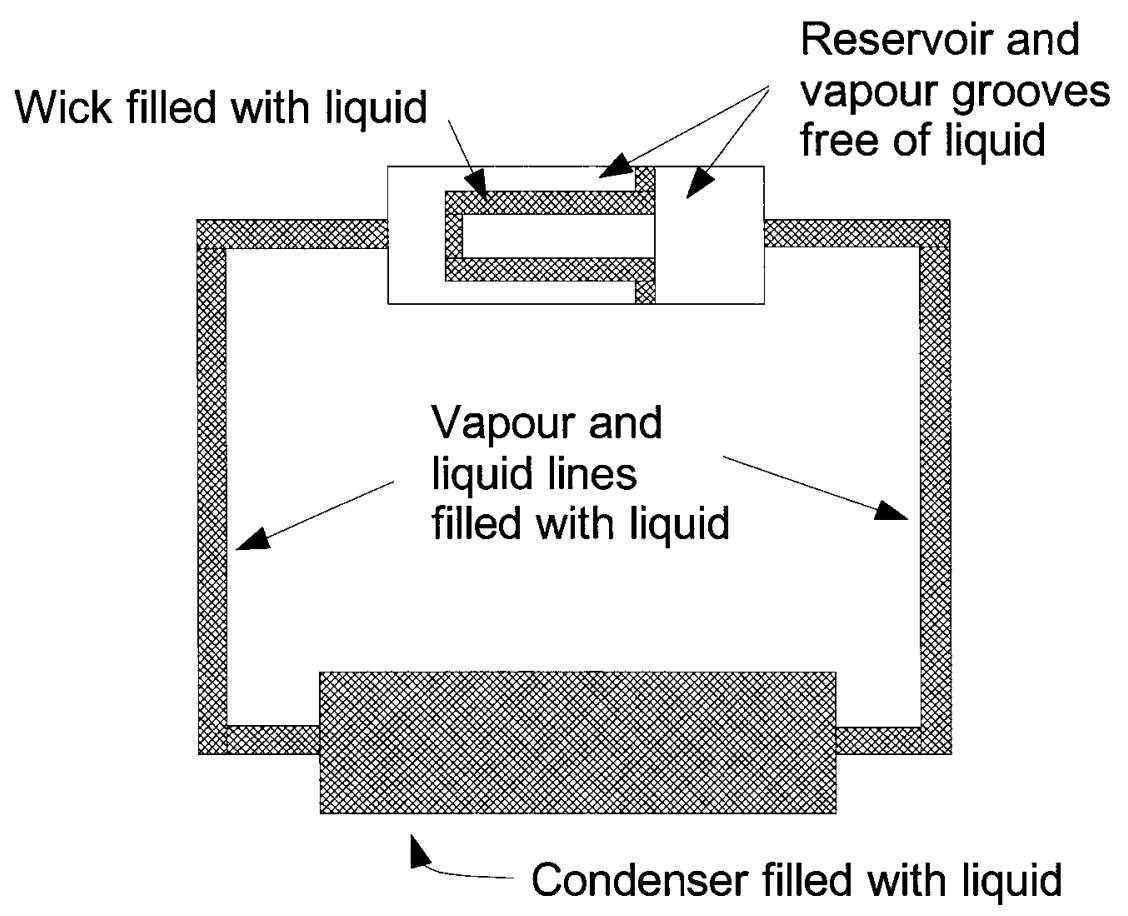

Figure 2-8: Fluid Distribution Scheme 1 
At maximum operational temperature, the compensation chamber must be sized such that it can compensate for the volume expansion of the fluid (from worst case cold to worst case hot conditions) as well as a shift of liquid from the vapour line and entire condenser. The following algorithm is used to concurrently obtain the compensation chamber volume and mass of fluid to be charged.

1. Initial approximation of working fluid volume expansion due to temperature difference between hot and cold cases:

$$
\Delta V_{l}=0
$$

2. Estimate compensation chamber volume:

$$
V_{c c}=\left(\Delta V_{l}+V_{c o n d}+V_{v l}\right) \cdot K_{v o i d}
$$

3. Calculate mass of fluid to be charged for minimum operation temperature:

$$
M=\left(V_{c c}+V_{\text {grooves }}\right) \cdot \rho_{v}+\left[V_{l h p}-\left(V_{c c}+V_{\text {grooves }}\right)\right] \cdot \rho_{l}
$$

4. Calculate the liquid phase of the working fluid at minimum operational temperature for the mass calculated in step 3:

$$
V_{l_{\text {min }}}=\frac{M-V_{l h p} \cdot \rho_{v}}{\rho_{l}-\rho_{v}}
$$

5. Calculate the liquid phase of the working fluid at maximum operational temperature for the mass calculated in step 3:

$$
V_{l_{\text {max }}}=\frac{M-V_{l h p} \cdot \rho_{v}}{\rho_{l}-\rho_{v}}
$$

6. Calculate new value for volume expansion: 


$$
\Delta V_{l}=V_{l_{\text {max }}}-V_{l_{\min }}
$$

7. Repeat steps 3 through 6 until the desired accuracy is reached

$\mathrm{K}_{\text {void }}$ is the coefficient of free volume in the compensation chamber (ie. the portion of the compensation chamber that remains liquid-free during operation). Typical values range from 1 to 1.2 , where 1.2 corresponds to $17 \%$ free volume in the compensation chamber. Variants of this method can be used to minimize the amount of working fluid necessary for operation. Such cases may exist if start-up is controlled through active cooling of the compensation chamber or if the LHP is oriented in such a way that the evaporator already has the necessary liquid supply. Additionally, it may be required that the condenser remain completely open throughout the entire LHP operating range in applications where constant conductance is required. It should be noted, however, that this may introduce some degree of risk with an increased possibility of wick dry-out and LHP deprime. 


\section{Chapter 3: LHP Design}

\subsection{Problem Statement}

As previously discussed, one of the main objectives of this study was to design and manufacture a functional loop heat pipe. The purpose of developing a LHP was twofold: to demonstrate LHPs as a reliable and robust technology; and to use the results as a stepping stone for the development of much smaller and more efficient systems. Therefore, no rigid performance or property constraints were set; however, maximizing the heat load limit while also minimizing the mass and dimensions of the LHP were a priority. As will be shown, primary components were selected based on their relative costs and availability as well as their performance in previous tests found in literature. Below is a set of parameters that, wherever possible, were employed:

- Maximum Heat Load: 20 to $100 \mathrm{~W}$

- Temperature range: 10 to $80{ }^{\circ} \mathrm{C}$

- Maximum diameter of evaporator: $25.4 \mathrm{~mm}$

- Maximum length of active evaporator $150 \mathrm{~mm}$

- Maximum diameter of transportation lines: $10 \mathrm{~mm}$

- Heat transfer distance: 200 to $500 \mathrm{~mm}$ 
- Condenser length: 100 to $200 \mathrm{~mm}$

- Cooling conditions: liquid cooling

\subsection{Design Approach}

A total of three LHPs were designed, constructed, and tested in sequence. The first LHP was designed using a similar procedure to the one described in Section 2.1. Preliminary working fluids, wick materials, and case materials were chosen based on flight heritage, cost, availability, and performance characteristics. Mathematical models were then used to estimate working fluid properties, reservoir volume, fluid inventory, overall mass, pressure losses, and maximum heat load. Based on these results, transportation lines were optimized to minimize pressure losses and therefore maximize the potential heat load limit. Similarly, the wick structure was designed to maximize efficiency of fluid flow through the wick. Material selection was then finalized based primarily on compatibility and method of loop sealing. Each subsequent LHP was developed with only minor modifications to address any performance issues of the previous unit tested. The following sections summarize the design and selection process. A brief overview of the final sizes and properties of all three LHP's is presented in section 3.10.

\subsection{Wick Material Selection}

Two wick materials were considered for this study: ultra high molecular weight (UHMW) polyethylene tubing and copper mesh. UHMW polyethylene tubing has been used considerably and is well documented as a wicking material for capillary pumped 
loops. Recently, polyethylene has also been applied and tested for use in LHPs with success. For example, Khrustalev (2001) reported manufacturing an inexpensive ammonia LHP with a UHMW polyethylene wick operated in vertical and horizontal orientations transporting $200 \mathrm{~W}$ with a transport length of about one meter. The operating temperature range was from $20^{\circ} \mathrm{C}$ to $50{ }^{\circ} \mathrm{C}$. Polyethylene is an excellent wicking material due to its low thermal conductivity, machineability and compatibility to most working fluids and all case materials. It is also widely available as a commercial off the shelf (COTS) product in bulk quantities thus reducing procurement time and costs. One drawback, however, is that the effective pore size and porosity is relatively large (15-20 microns and $20-35 \%$ respectively) in comparison to established sintered metal wicks. More desirable properties can be obtained but with significant increases to tooling costs. Copper mesh has also been well documented in literature. However, its use has been limited to conventional heat pipes due to very large pore sizes. The surface pore size of mesh wicks is inversely proportional to the mesh number, which is defined as the number of pores per inch (Chi, 1976). For example, a typical mesh number of 100 corresponds to a pore size of 0.01 inches or 254 microns. Therefore, it was not a viable option for use as a primary wick but was considered for use as a secondary wick. It should be noted that sintered metals and ceramics were initially considered. Sintered nickel, titanium, and copper wicks have been used predominantly as a primary wicking material in LHPs because of the ability to manufacture excellent properties $(<1 \mu m$ pore size and $>50 \%$ porosity). Unfortunately, costs for these materials are quite high and 
suppliers are limited. Similarly, ceramics have the potential to be excellent wicking materials with very low pore sizes, relatively high porosity, and very low thermal conductivity. Unfortunately, there has not been a lot of research conducted in this area and suppliers are also scarce. Therefore, of the two remaining choices, UHMW polyethylene was selected as the primary wick material mainly due to its availability and extensive use in CPLs. Two polyethylene tubes were obtained and rated by the manufacturer to have an effective pore size of $\sim 20 \mu \mathrm{m}$ and porosity of approximately $35 \%$. The first tube was 36 in $(910 \mathrm{~mm})$ long with a 1 in $(25.4 \mathrm{~mm})$ outer diameter and a $1 / 2$ in $(12.7 \mathrm{~mm})$ inner diameter while the second tube was 36 in $(910 \mathrm{~mm})$ long with a $1 / 2$ in $(12.7 \mathrm{~mm})$ outer diameter and a $1 / 4$ in $(6.35 \mathrm{~mm})$ inner diameter. The material density was estimated to be $965 \mathrm{~kg} / \mathrm{m}^{3}$ while the material conductivity was approximately at 0.45 $\mathrm{W} / \mathrm{mK}$.

\subsection{Working Fluid Selection}

As specified in the problem statement, the operational temperature range of the LHP should be approximately 10 to $80^{\circ} \mathrm{C}$. Potential working fluids that meet this requirement and were considered for the study include acetone, methanol, and water. Details of each fluid are provided in Table 3-1. 
Table 3-1: Potential Working Fluids and their Properties ${ }^{1}$

\begin{tabular}{ccccc}
\hline & $\begin{array}{c}\text { Surface } \\
\text { Tension } \\
(\mathbf{N} / \mathbf{m})\end{array}$ & $\begin{array}{c}\text { Latent } \\
\text { Heat } \\
(\mathbf{J} / \mathbf{k g})\end{array}$ & $\begin{array}{c}\text { Liquid } \\
\text { Density } \\
\left(\mathbf{k g} / \mathbf{m}^{3}\right)\end{array}$ & $\begin{array}{c}\text { Liquid } \\
\text { Viscosity } \\
\left(\mathbf{m}^{2} / \mathbf{s}^{\mathbf{2}}\right)\end{array}$ \\
\hline \hline Acetone & 0.0227757 & 530450 & 787.847 & 0.000322475 \\
Methanol & 0.0233655 & 1190470 & 794.63 & 0.000591358 \\
Water & 0.0727734 & 2443540 & 995.683 & 0.00100148 \\
Ammonia & 0.0212896 & 1182620 & 604.834 & 0.000146047 \\
\hline
\end{tabular}

Traditionally, ammonia has been used for many space and electronics applications due to its wide operating temperature range and outstanding merit number in comparison to other working fluids. However, due to its relative high vapour pressure and toxicity at room temperature, it was not considered for this application. Instead, it was used as a baseline for performance. Water has a very high latent heat and surface tension compared to the other fluids, and is non toxic. Its advantages manifest themselves at higher temperatures and reach a maximum at 100 to $150{ }^{\circ} \mathrm{C}$ (Maidanik et al., 2005). However, at elevated temperatures, water has a tendency to generate NCGs in the presence of oxides with the most common case materials: aluminum and stainless steel. The selection of UHMW polyethylene as the primary wicking material produces another compatibility issue since it is hydrophobic. Polyethylene can be rendered hydrophilic through a chemical process; however, such a method may produce NCGs within the loop. Since the required heat dissipation is relatively low, other fluids such as acetone and methanol were other interesting options. They present several advantages such as sub-

\footnotetext{
${ }^{1}$ All working fluid properties evaluated at a temperature of $20^{\circ} \mathrm{C}$
} 
atmospheric working pressure for operation temperatures from -60 to $80{ }^{\circ} \mathrm{C}$. They also have reduced handling risks, are less expensive, and unlike water, reduce the probability of freezing in space conditions. Acetone has been well documented in literature for use in LHPs. Some studies have reported results comparing the performance of acetone and ammonia. For low power applications (up to $70 \mathrm{~W}$ ), Riehl et al. (2005) verified that both working fluids present close performance characteristics, despite a higher superheat (temperature difference between the reservoir and evaporator) obtained when acetone was used as the working fluid. Tests have also shown stable long-term operation between acetone and stainless steel for a wide range of applied power. For these reasons, acetone was selected as the primary working fluid. Methanol was selected as an alternative working fluid to compare performance characteristics against acetone for the same LHP design.

\subsection{Case Material Selection}

Various factors including the operating temperature range of the proposed device, compatibility with the working fluid, evaporator and condenser sizes, and internal operating pressure were considered during the selection of the case material. Internal operating pressure was not as great of a concern since potential working fluids, as described in Section 3.3, have sufficiently low vapour pressures between the anticipated loop operating temperatures of 10 to $80{ }^{\circ} \mathrm{C}$. As a result, aluminum and stainless steel (316L) were selected as potential case materials. Due to its high thermal conductivity $(237 \mathrm{~W} / \mathrm{mK}$ ), aluminum reduces the thermal resistance between the heat source and wick 
material thus increasing the LHP efficiency. However, high thermal conductivity also yields high parasitic heating of the reservoir which in turn increases the loop operating temperature. Aluminum also has a much lower density $\left(2700 \mathrm{~kg} / \mathrm{m}^{3}\right)$ compared to stainless steel $\left(7800 \mathrm{~kg} / \mathrm{m}^{3}\right)$ thus reducing the overall mass. In comparison, stainless steel has been used much more frequently in literature. It is also more responsive to different kinds of welding techniques and possesses high strength (tensile strength of approximately $485 \mathrm{MPa}$ ). Stainless steel is also compatible with a wider range of working fluids. Specifically, stainless steel has been successfully demonstrated with working fluids such as water, acetone, ammonia, and methanol. Aluminum is not recommended for use with methanol and is incompatible with water due to generation of non-condensible gases (Peterson, 1994).

\subsection{Loop Sealing}

Loop sealing was also of primary concern during the design phase of this study since this process can potentially determine success or failure of the LHP. A review of several techniques traditionally used for welding highly conductive materials was undertaken. It was found that electron beam (EB) welding and tungsten inert gas (TIG) welding are the most commonly used processes for stainless steel and aluminum respectively. However, by permanently sealing the loop, it would be difficult to perform experimental studies such as analyzing the effect of fluid inventory and wick design on loop performance. By welding the loop for sealing, construction of a new loop would be required for each fluid charge and wick design. Welding also increases the likelihood of exceeding the 
maximum allowable temperature of UHMW polyethylene thus greatly increasing the complexity of sealing the loop. Therefore, an alternative means of sealing the loop was selected. Swagelok tube fittings were used to provide an efficient and time savings way of connecting each section of the loop while a vacuum-tight valve was used to completely seal the loop after fluid charging. This approach facilitates testing of several fluid charges while also allowing easy insertion and removal of the wick structure. However, in order to maintain the vacuum in the loop after assembly, this approach confines selection of the case material to stainless steel. Ideally, this approach reduces the time required for assembly.

\subsection{Component Sizing}

As a starting point the evaporator, condenser, liquid line, and vapour line sizes were selected based on values found in literature for use in LHPs with similar requirements. Then, based on the specific requirements defined in the problem statement, sizes were further constrained. Tolerance-matching with the wick material and compatibility with the Swagelok fittings were also considered. Sizes for each component were finalized after analyzing the predicted performance based on mathematical models for a given design.

To ease machining and insertion of the wick, a sufficiently large evaporator was required. Also, due to the low tolerance of the polyethylene tubes, the inner diameter of the stainless steel tubing was required to be slightly smaller than the outer diameter of the wick material. Accordingly, standard stainless steel tubing of $1 / 2$ in $(12.7 \mathrm{~mm})$ and 1 in 
(25.4 mm) outer diameters with lengths ranging from 50 to $130 \mathrm{~mm}$ were selected for analysis. Initial sizing of the transportation lines was determined relative to the size of the evaporator. Standard stainless steel tubing ranging from 150 to $300 \mathrm{~mm}$ in length and $1 / 8,1 / 4$ and $3 / 8$ inches $(3.18,6.35$, and $9.53 \mathrm{~mm})$ in diameter was investigated. As discussed in the problem statement, the overall size of the LHP had to be minimized. To meet this requirement and minimize the mass of the tube fittings, stainless steel tubing with similar dimensions to that of the vapour and liquid transportation lines were selected for the condenser. The compensation chamber is essentially an extension of the evaporator, sharing the same material properties and radial dimensions. It is therefore thermally and mechanically connected to the evaporator. Its specific volume was estimated concurrently with the fluid inventory and was based on the volumes of all other LHP components.

\subsection{Wick Structure Design}

Loop heat pipe performance greatly depends on the wick structure and evaporator design. Modifying various wick characteristics such as length, diameter, thickness, number of axial grooves, and number of circumferential grooves can result in differences in heating area (interface between wick and evaporator body), heat transfer coefficient across the heating area, and vapour pressure drop in the vapour channel (Chuang, 2003). Traditionally, the primary wick consists of axial grooves extruded down the length of the body, similar to that shown in Figure 3-1, to provide vapour flow to the vapour line. 
Circumferential grooves are threaded around the body to provide vapour flow to the main axial vapour channels as shown in Figure 3-1.

Similar to component selection, initial wick designs were based on existing systems with proven success. A total of four axial grooves and four circumferential grooves were chosen. Specific dimensions of each as well as the thickness between the inner and outer diameter of the wick were optimized to minimize the pressure drop of the fluid flow (both liquid and vapour) while also maximizing the heat transfer capacity. Since it was determined that polyethylene would be used as the primary wicking material, vapour grooves were machined directly on the wick structure instead of the evaporator tubing. A solid model of the wick structure is shown in Figure $3-2$. The 1 in $(25.4 \mathrm{~mm})$ OD plastic tubing was chosen due to the size of the evaporator case. For a simplified assembly process and reduced manufacturing costs, it was decided that no secondary wick was required. It is noted that such a design may degrade LHP performance in certain testing conditions such as adverse orientations. 


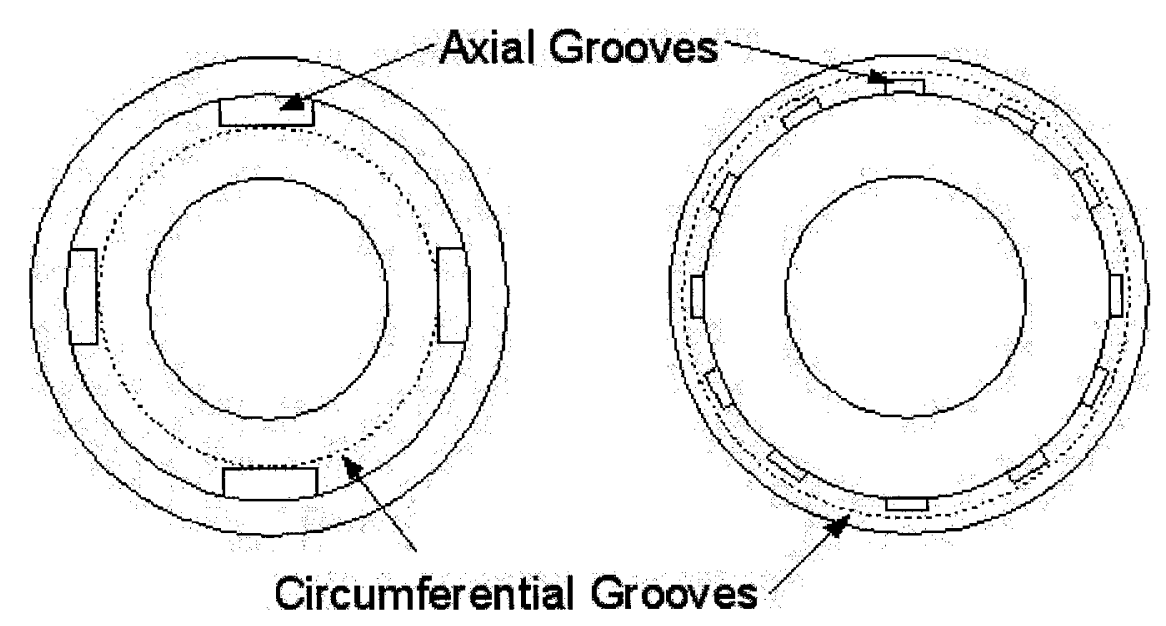

Figure 3-1: Design of Evaporator and Primary Wick Interface

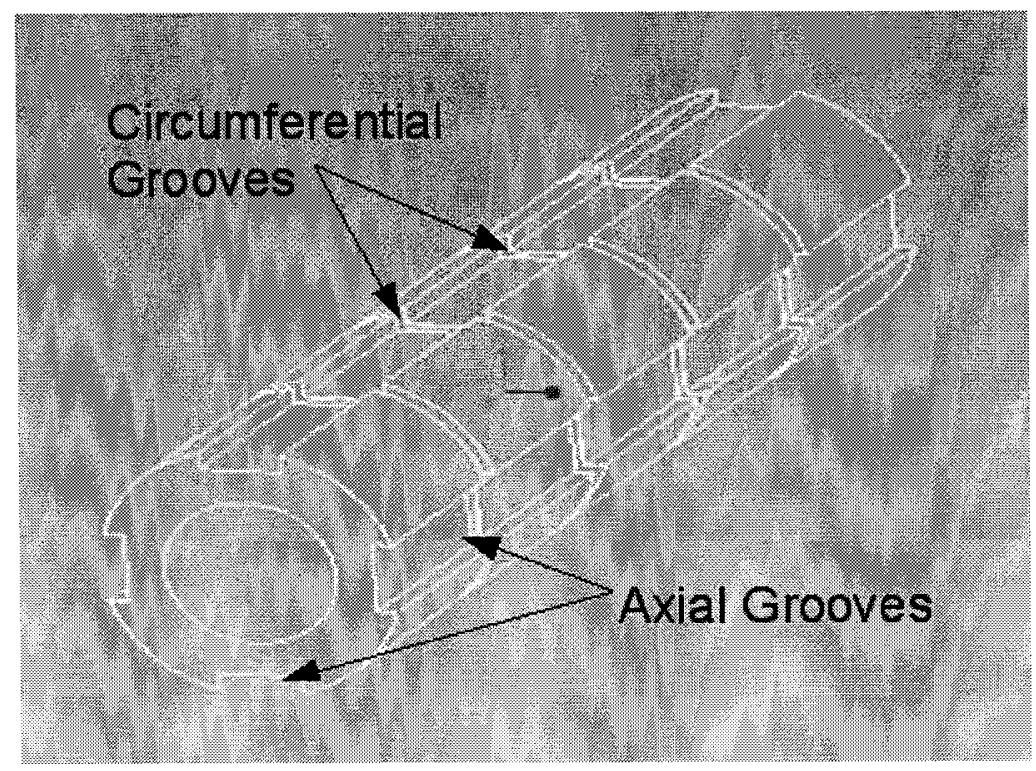

Figure 3-2: Solid Model of Wick Structure with Vapour Grooves

\subsection{Mathematical Modeling}

Mathematical models developed by the Russian company TAIS Ltd. were initially used to help size components, such as the transportation lines and wick structure, by 
estimating the system pressure drop and maximum heat flux. The models were available in a bundled demo software package called EASY 2000. The package consists of four blocks:

1. Data input (creation, reading, editing, recording, printing);

2. Calculation of working fluid parameters such as latent heat, surface tension, liquid and vapour viscosity...etc;

3. Calculation of LHP parameters such as fluid inventory, reservoir size, and component masses;

4. Calculation of LHP processes such as maximum heat flux and steady state loop operation temperature.

The EASY 2000 demo was bundled with three applications which were used in the development of the first two LHPs. The first program, Idprep, allows the user to input all physical properties such as length, diameter, pore size, porosity etc. Conditions such as ambient temperature and sink temperature for all major junctions are also available for input. Figure 3-3 illustrates a sample of the graphical user interface (GUI) with the properties and dimensions of an iteration of the first LHP design. 


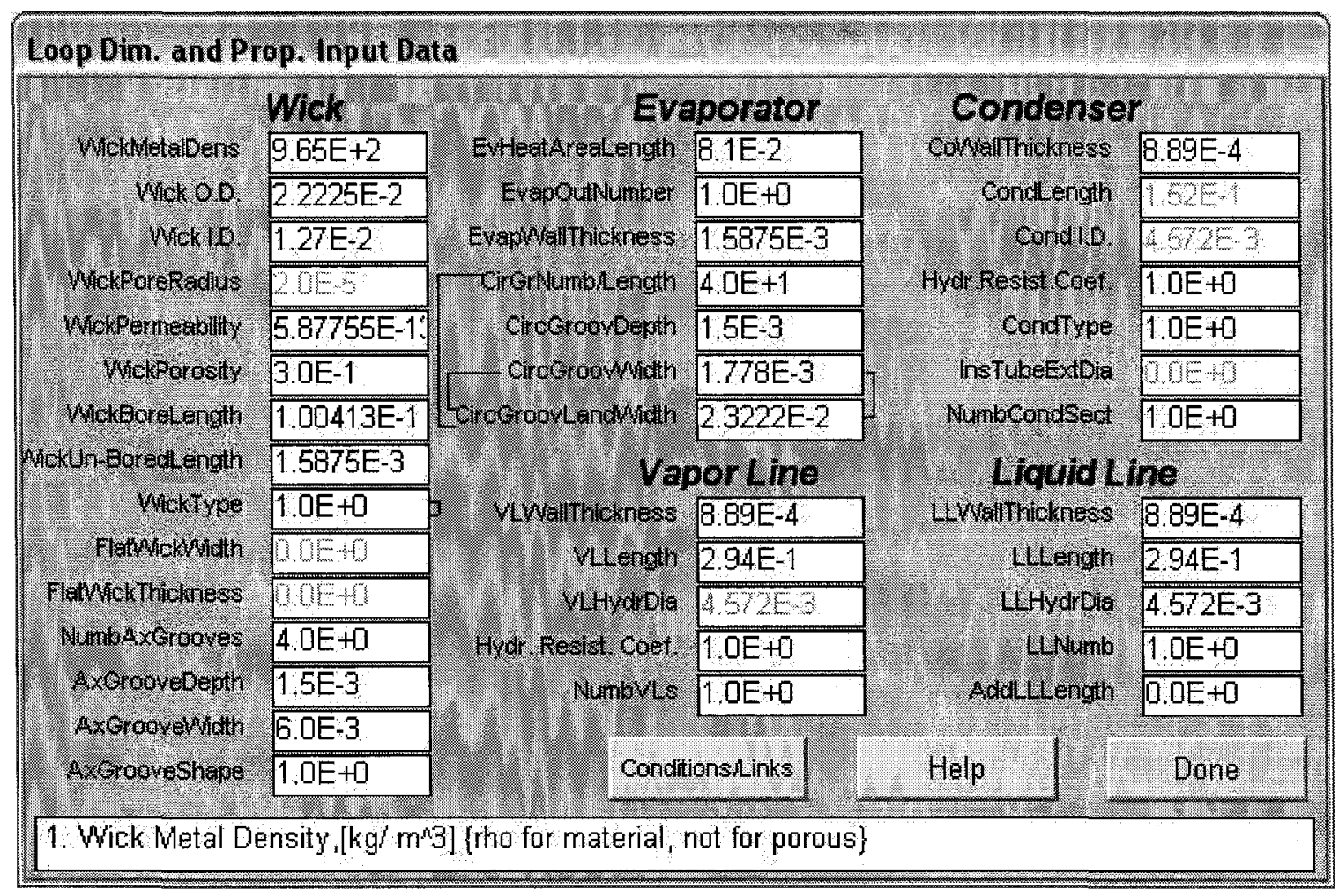

Figure 3-3: EASY 2000 User Interface and Input Parameters

The second application, Charge1, calculates the mass of the working fluid to be charged, compensation chamber volume, and mass of LHP components. The program uses the physical properties specified in Idprep to simultaneously calculate fluid inventory and compensation chamber volume using the technique described in Section 2.3.4. Then, by specifying the density of the case material and wick structure, the approximate mass of the LHP and each individual component is estimated. Figure 3-4 illustrates a sample of the results obtained for the properties specified in Figure 3-3, using water as the working fluid. 


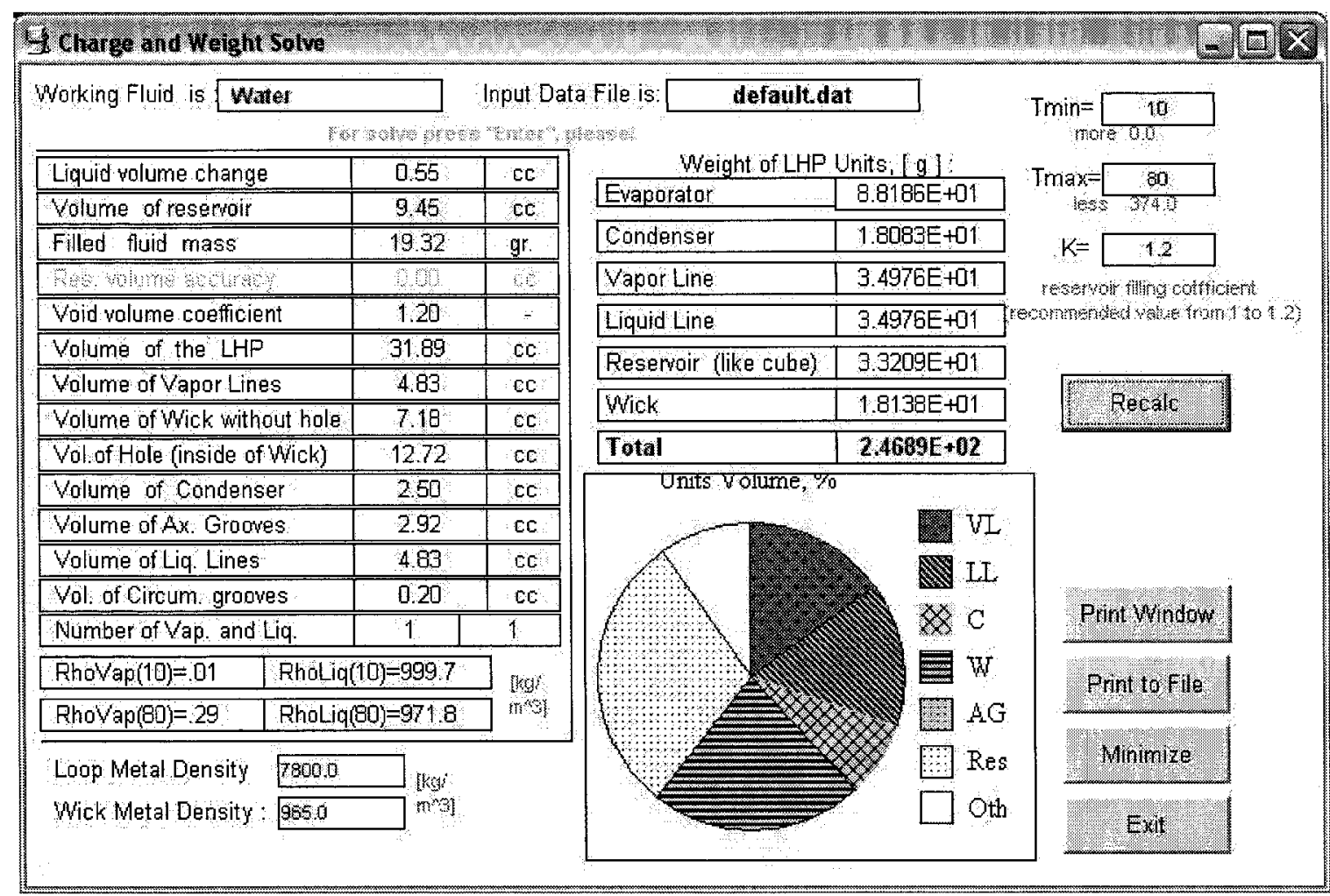

Figure 3-4: Calculation of Fluid Inventory, Reservoir Volume, and LHP Mass

The third application, Cqmax, calculates the maximum heat flux which is determined by the maximum capillary pressure developed by the wick and the pressure balance in the LHP. Details of the method of calculation is provided in the EASY2000 User's Manual (TAIS, 2000). Figure 3-5 provides a sample calculation of the estimated pressure drop for the properties specified in Figure 3-3, with water as the working fluid. In this example, the maximum pressure drop occurs in the condenser line and the maximum heat flux is estimated to be $285.9 \mathrm{~W}$, well above the range specified in the problem statement. Using acetone and methanol as the working fluid will lower this value, especially at lower temperatures. It should also be noted that the software uses many assumptions that 
do not directly apply to the given design such as the use of a secondary wick and bayonet tube.

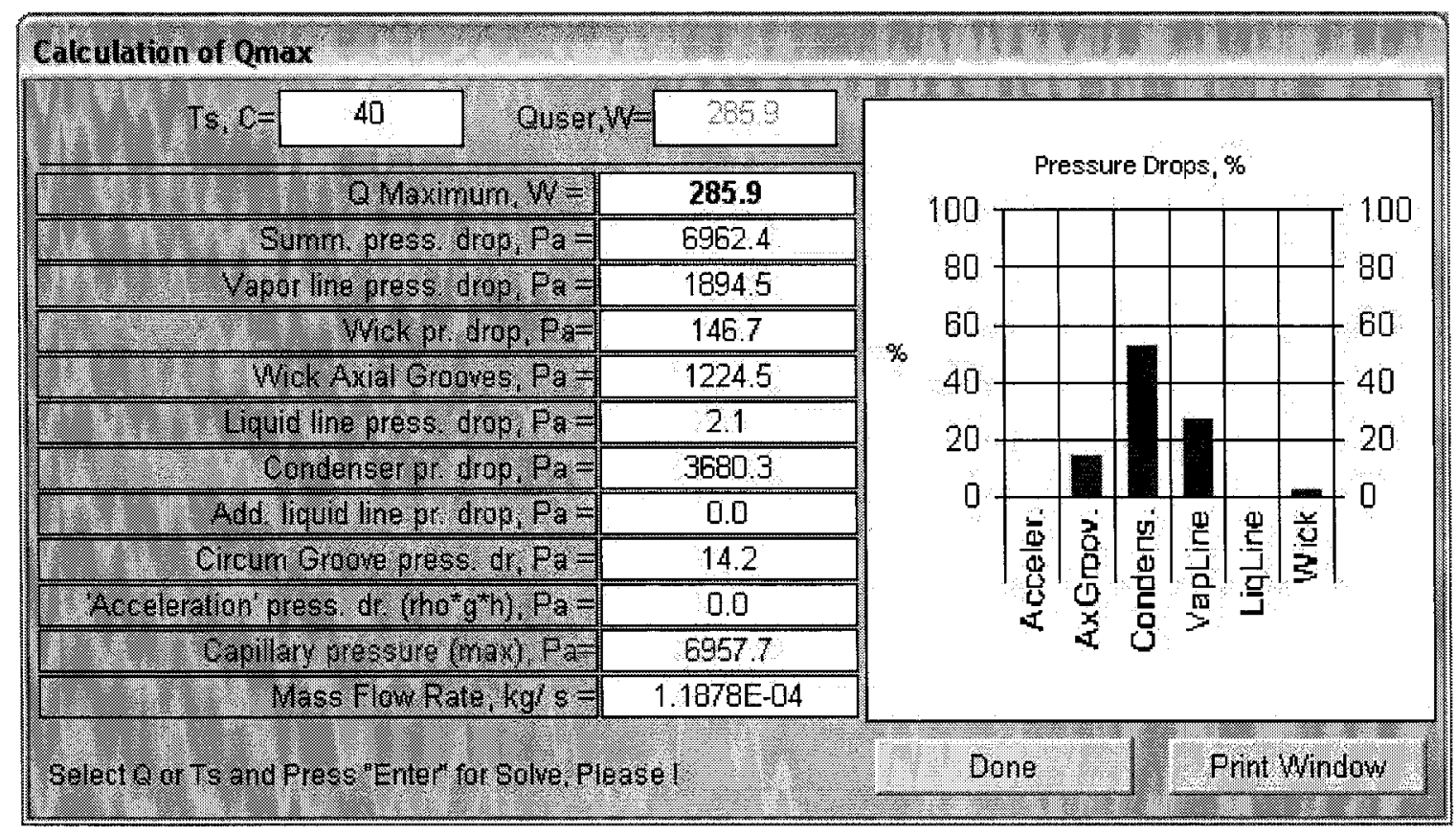

Figure 3-5: Pressure Balance and Maximum Heat Flux Estimate for Given Design

Unfortunately, the demo version of EASY 2000 was limited in many aspects; working fluid selections were restricted to water and ammonia while documentation of mathematical methods and examples of experimental validation were insufficient. It is therefore noted here that while EASY 2000 was helpful in optimizing the sizes of each LHP component, models with increased flexibility and functionality were required to provide more accurate predictions of fluid inventory, compensation chamber sizing, working fluid properties as well as operational characteristics such as steady-state temperatures, system pressure drop and mass flow rate for any given design. As a result, 
'in-house' software was developed in parallel with the final LHP design. The models were developed in Matlab and are reported in Chapter 6.

\subsection{Final LHP Design and Layout}

After optimizing the sizes and properties of each component, the final design was selected. It is again emphasized that each LHP was designed, manufactured, and tested sequentially. That is, after successfully manufacturing and testing the first LHP, two subsequent designs were created with small variations to increase performance or to address any issues of the previous design. Design changes for each LHP are addressed in Chapter 5, where test results of each unit are also presented and analyzed. A summary of all properties and dimensions of the three designs is provided in

Table 3-2.

Table 3-2: Detailed Properties of each Test Unit

\begin{tabular}{llll}
\hline & \multicolumn{1}{c}{ LHP 1 } & \multicolumn{1}{c}{ LHP 2 } & \multicolumn{1}{c}{ LHP 3 } \\
\hline \hline Working Fluid & Acetone & Acetone, Methanol & Acetone \\
Designed Temperature & 5 to $75^{\circ} \mathrm{C}$ & 5 to $75^{\circ} \mathrm{C}$ & 5 to $75^{\circ} \mathrm{C}$ \\
Range & Stainless Steel & Stainless Steel & Stainless Steel \\
Evaporator & $8.1 \mathrm{~cm}$ & $8.1 \mathrm{~cm}$ & $8.1 \mathrm{~cm}$ \\
Heated Length & $1.59 \mathrm{~mm}$ & $1.59 \mathrm{~mm}$ & $2.11 \mathrm{~mm}$ \\
Wall Thickness & UHMW Polyethylene & UHMW Polyethylene & UHMW Polyethylene \\
Primary Wick & $965 \mathrm{~m}^{3}$ & $965 \mathrm{~m}^{3}$ & $965 \mathrm{~m}^{3}$ \\
Density & $2.2225 \mathrm{~cm}$ & $2.2225 \mathrm{~cm}$ & $2.12 \mathrm{~cm}$ \\
Outer Diameter & $1.27 \mathrm{~cm}$ & $1.27 \mathrm{~cm}$ & $1.27 \mathrm{~cm}$ \\
Inner Diameter & $10 \mathrm{~cm}$ & $18 \mathrm{~cm}$ & $9 \mathrm{~cm}$ \\
Length & $20 \mu \mathrm{m}$ & $20 \mu \mathrm{m}$ & $20 \mu \mathrm{m}$ \\
Effective Pore Radius & $5.88 \mathrm{E}-13 \mathrm{~m}^{2}$ & $5.88 \mathrm{E}-13 \mathrm{~m}^{2}$ & $5.88 \mathrm{E}-13 \mathrm{~m}^{2}$ \\
Permeability & & &
\end{tabular}




\begin{tabular}{clll} 
Porosity & 0.35 & 0.35 & 0.35 \\
Number of Axial Grooves & 4 & 4 & 4 \\
Number of Circ. Grooves & 4 & 4 & 4 \\
Compensation Chamber & Stainless Steel & Stainless Steel & Stainless Steel \\
Inner Diameter & $2.2225 \mathrm{~cm}$ & $1.91 \mathrm{~cm}$ & $2.2225 \mathrm{~cm}$ \\
Length & $4.25 \mathrm{~cm}$ & $6 \mathrm{~cm}$ & $5.25 \mathrm{~cm}$ \\
Vapour Line & Stainless Steel & Stainless Steel & Stainless Steel \\
Line Inner Diameter & $4.6 \mathrm{~mm}$ & $4.6 \mathrm{~mm}$ & $4.6 \mathrm{~mm}$ \\
Line Length & $29.4 \mathrm{~cm}$ & $40.24 \mathrm{~cm}$ & $26.4 \mathrm{~cm}$ \\
Wall Thickness & $0.9 \mathrm{~mm}$ & $0.9 \mathrm{~mm}$ & $0.9 \mathrm{~mm}$ \\
Liquid Line & Stainless Steel & Stainless Steel & Stainless Steel \\
Line Inner Diameter & $4.6 \mathrm{~mm}$ & $4.6 \mathrm{~mm}$ & $4.6 \mathrm{~mm}$ \\
Line Length & $29.4 \mathrm{~cm}$ & $36.2 \mathrm{~cm}$ & $26.4 \mathrm{~cm}$ \\
Wall Thickness & $0.9 \mathrm{~mm}$ & $0.9 \mathrm{~mm}$ & $0.9 \mathrm{~mm}$ \\
Condenser & Stainless Steel & Stainless Steel & Stainless Steel \\
Line Inner Diameter & $4.6 \mathrm{~mm}$ & $4.6 \mathrm{~mm}$ & $4.6 \mathrm{~mm}$ \\
Line Length & $15.2 \mathrm{~cm}$ & $26.2 \mathrm{~cm}$ & $15.2 \mathrm{~cm}$ \\
Wall Thickness & $0.9 \mathrm{~mm}$ & $0.9 \mathrm{~mm}$ & $0.9 \mathrm{~mm}$ \\
\hline
\end{tabular}




\section{Chapter 4: LHP Manufacturing}

\subsection{Fabrication}

A loop heat pipe is essentially composed of four basic components; working fluid, wick structure, case materials, and a sealing mechanism. Selection and design of each component was discussed in detail in the previous chapter. In the following chapter, LHP manufacturing techniques are discussed. Figure 4-1 illustrates the basic operations involved in manufacturing. The basic elements, as can be seen from the figure, are parts manufacturing, cleaning, assembly, evacuation and charging, sealing, and validation/acceptance testing. 


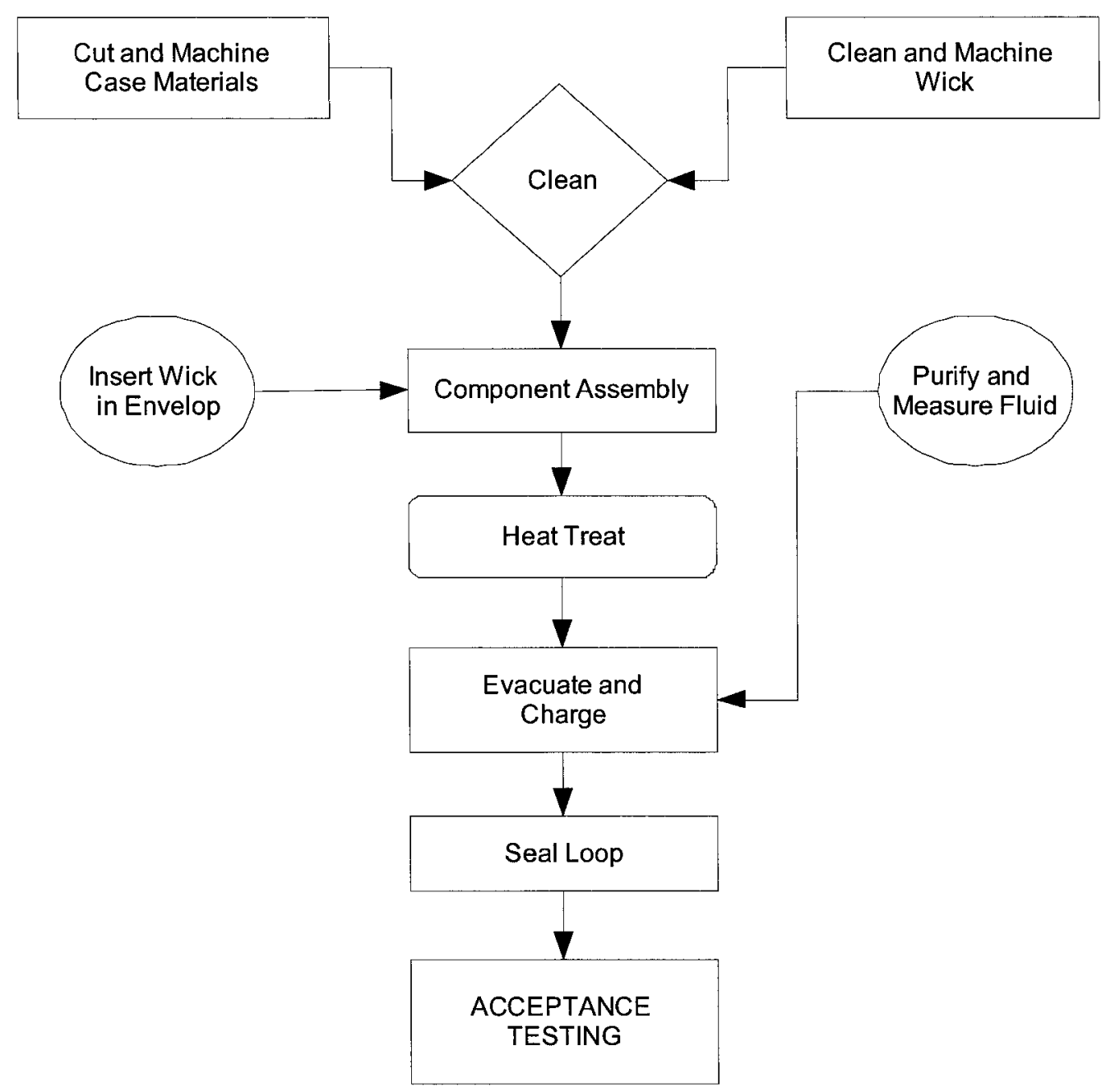

Figure 4-1: Loop Heat Pipe Manufacturing Process Adapted from (Chi, 1976)

\subsubsection{Case Materials}

The first step in fabrication involved cutting both 1 in $(25.4 \mathrm{~mm})$ and $1 / 4$ in $(6.35 \mathrm{~mm})$ stainless steel tubing to the required lengths for each section of the LHP. The tubing was first cut with a band saw, as shown in Figure 4-2, to the approximate lengths required plus some small margin. Then, using a lathe, shown in Figure 4-3, both ends of each tube were squared off and machined to a more accurate length. Care was taken to avoid 
distorting the tube ends to ensure a vacuum-tight fit with the Swagelok unions during assembly. The lathe was also used to debur the inner and outer edges at each end of the tubes to safeguard against any debris that may damage LHP operation and to allow for easy insertion of the wick.
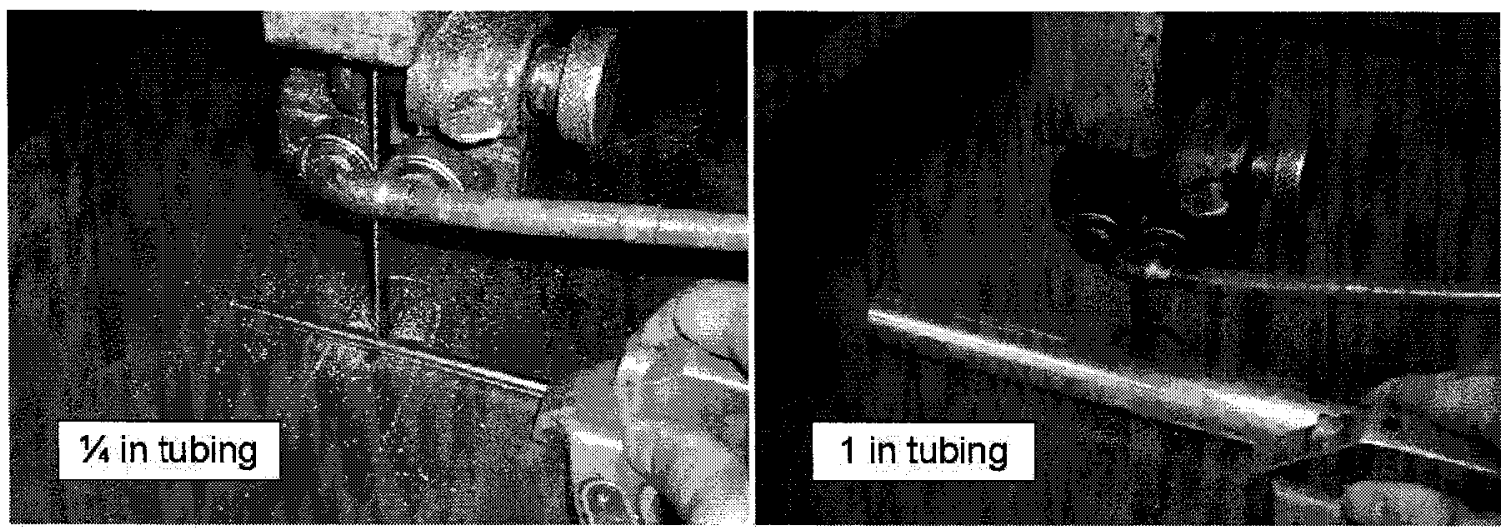

Figure 4-2: Band Saw used to Cut Stainless Steel Tubing
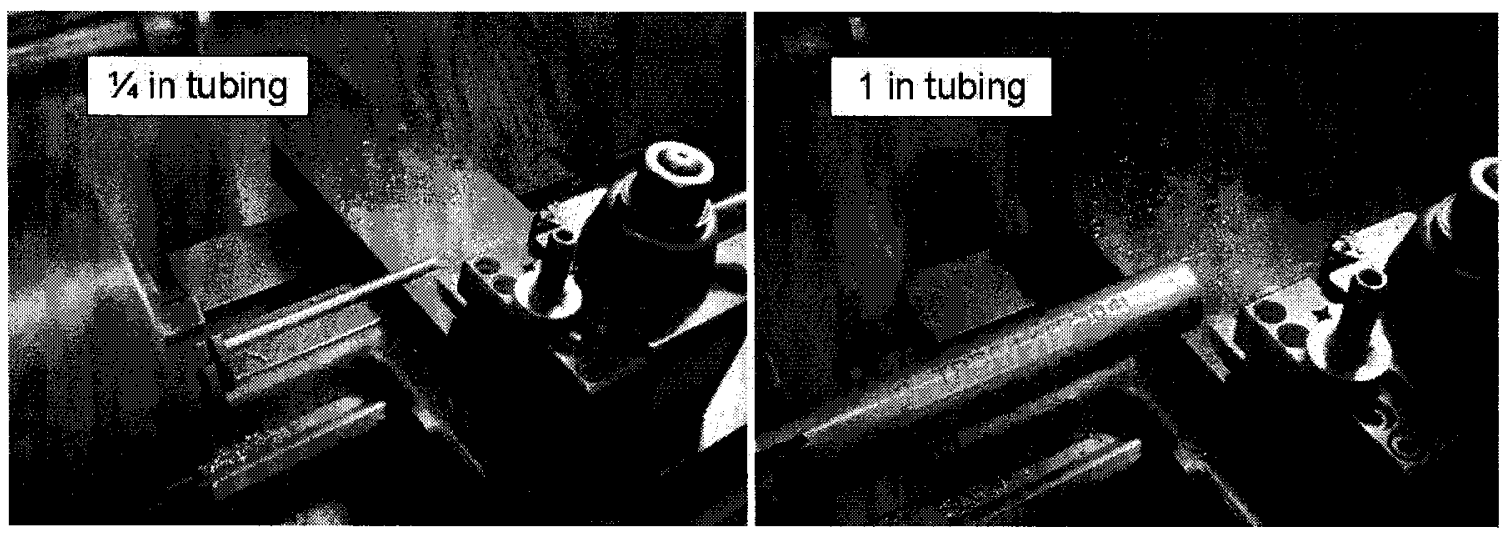

Figure 4-3: Lathe used to Round-Off Edges of Tubing

It should be noted that the 1 in $(25.4 \mathrm{~mm})$ tubing, used for the evaporator casing, was cut to a length $2.5 \mathrm{~cm}$ greater than the length of the reservoir and wick combined. This is due to the fact that the Swagelok reducers, used to join the evaporator tubing to the vapour 
and liquid lines, create a slight bend around the circumference of the tubing and may damage the wick or reduce wick-wall contact which should be avoided. Further details of the Swagelok unions, reducers, and valves used for assembly are presented in Section 4.3.1.

\subsubsection{Wick}

The next step in fabrication involved machining the wick structure. As discussed in Section 3.3, a UHMW polyethylene wicking material with a 1 in $(22.23 \mathrm{~mm})$ outer diameter and a $1 / 2$ in $(12.7 \mathrm{~mm})$ inner diameter was obtained. Since the diameter of the plastic tubing was larger than that of the stainless steel body, the outer diameter of the wick was machined to reduce its dimensions and allow for insertion of the wick. It is noted that the wick structure was machined to a diameter slightly larger than the internal diameter of the stainless steel case to ensure constant wick contact with the evaporator wall (throughout the entire length of the wick) after insertion. Since the resistance between the heat pipe case material and the wicking structure can make up a significant portion of the overall LHP thermal resistance, it is necessary to maintain good contact between the two. A lathe machine was used to reduce the outer diameter of the wick, as shown in Figure 4-4. The lathe was also used to machine four circumferential grooves on the wick. A bit with the required width of $1.5 \mathrm{~mm}$ was placed at intervals of $2 \mathrm{~cm}$ along the length of the wick and machined to a depth of $1.5 \mathrm{~mm}$ thus reducing the diameter at each groove to $19.2 \mathrm{~cm}$. Finally, the lathe was used to machine the wick to the required length and round off any edges. Care was taken to minimize any damage or 
contamination to the wick from metal filings that may have been left over from the previous user of the machine.
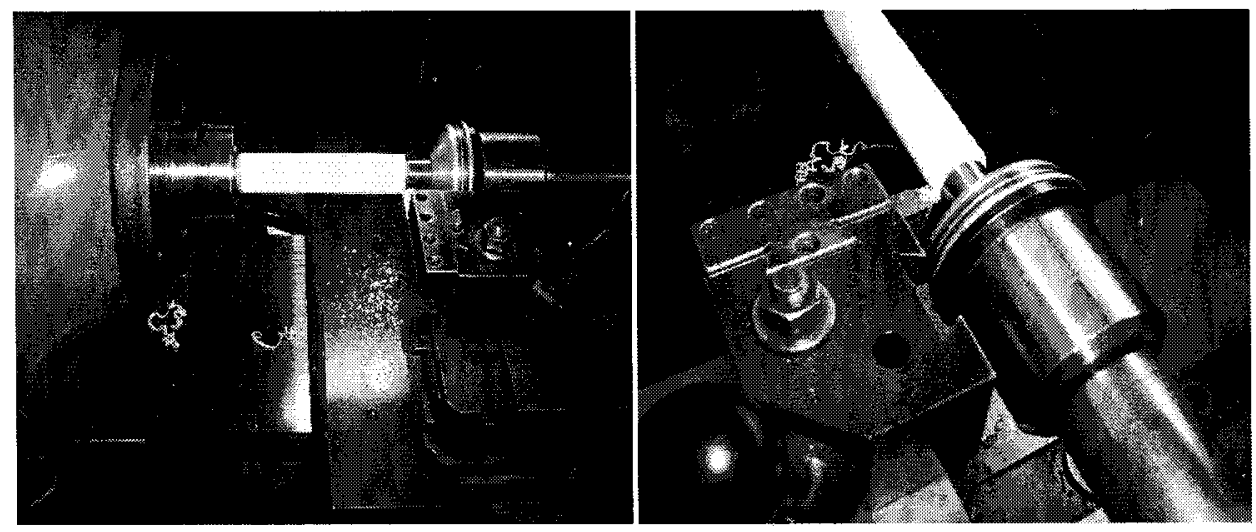

Figure 4-4: Lathe used to Reduce Diameter and Machine Four Circumferential Grooves

Next, a milling machine was used to mill four axial grooves, shown in Figure 4-5. The grooves were $6 \mathrm{~mm}$ in width and $1.5 \mathrm{~mm}$ in depth and were machined along the length of the tubing. At one end, a small section $5 \mathrm{~mm}$ long was left untouched to stop vapour flow to the compensation chamber. At the opposite end, as shown in Figure 4-6, a plastic cap was installed to prevent liquid from flowing to the vapour line. The cap consisted of polyethylene filler that was sintered to existing wick material. Care was taken to ensure that the filler did not interfere with any of the vapour grooves. The depth of the filler was limited to $2 \mathrm{~mm}$ to minimize damage to surrounding pores thus maximizing the active length of the wick. 


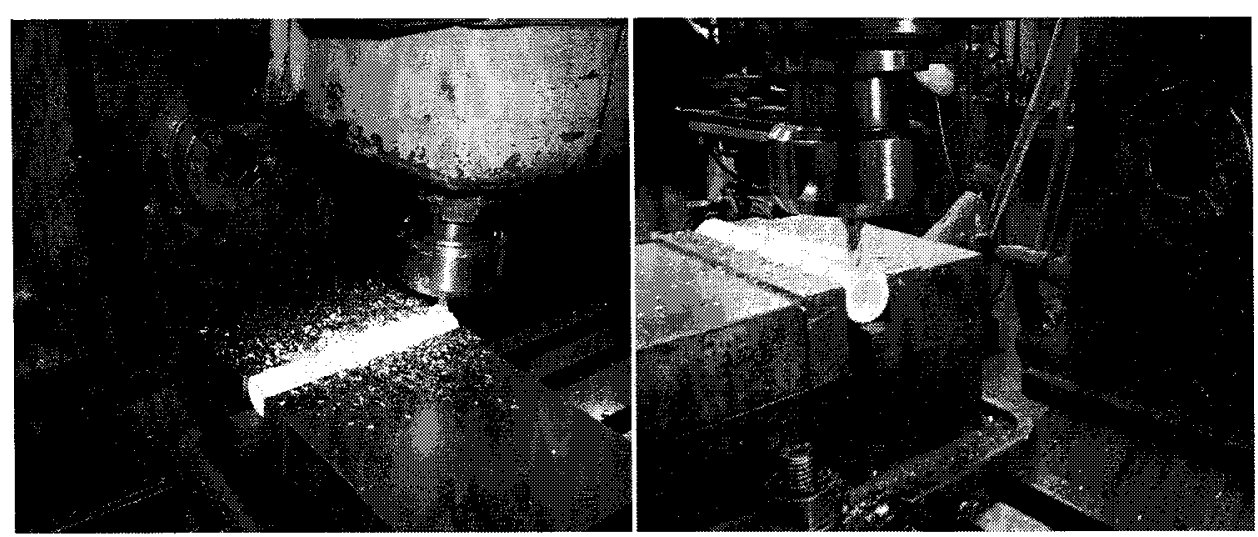

Figure 4-5: Mill used to Machine Four Wick Axial Grooves

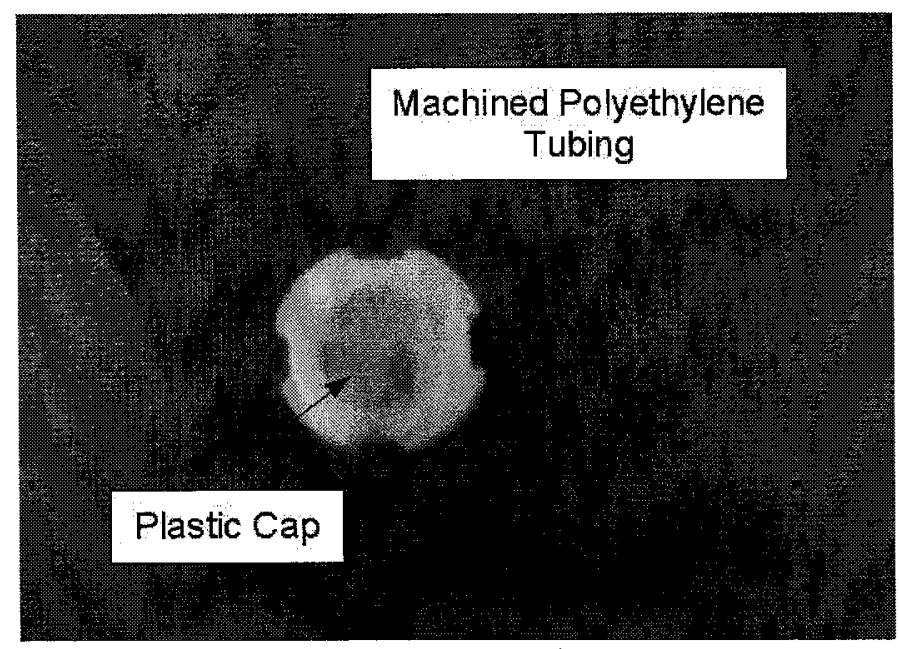

Figure 4-6: Wick Plastic Cap

\subsubsection{Heat Source and Heat Sink Saddles}

The evaporator saddle consisted of an aluminum base plate with approximate dimensions of $75 \mathrm{~mm}$ by $50 \mathrm{~mm}$ by $20 \mathrm{~mm}$ and a stainless steel base plate with dimensions of $75 \mathrm{~mm}$ by $50 \mathrm{~mm}$ by $3 \mathrm{~mm}$. As shown in Figure 4-7, a $1 / 2$ in $(12.7 \mathrm{~mm})$ semi-circular groove was machined along the length of the base plate. A drill press, also shown in Figure 4-7, was then used to machine four holes through the cover plate and halfway through the base 
plate. Then, using a hole tap shown Figure 4-8, 10-32 threads were introduced in the base plate. The final assembly, shown in Figure 4-9 required four screws torqued to 45 in-lb $(5 \mathrm{~N}-\mathrm{m})$. Similar to the evaporator saddle, the first heat sink and subcooler saddle was constructed by milling a $1 / 4$ in $(6.35 \mathrm{~mm})$ semi-circular groove across the length of a $150 \mathrm{~mm}$ by $50 \mathrm{~mm}$ by $6.35 \mathrm{~mm}$ copper plate. A total of 10 holes were machined through both the base plate and cover plate. The final assembly of each saddle, as shown in Figure 4-10, required ten screws torqued to 45 in-lb $(5 \mathrm{~N}-\mathrm{m})$.

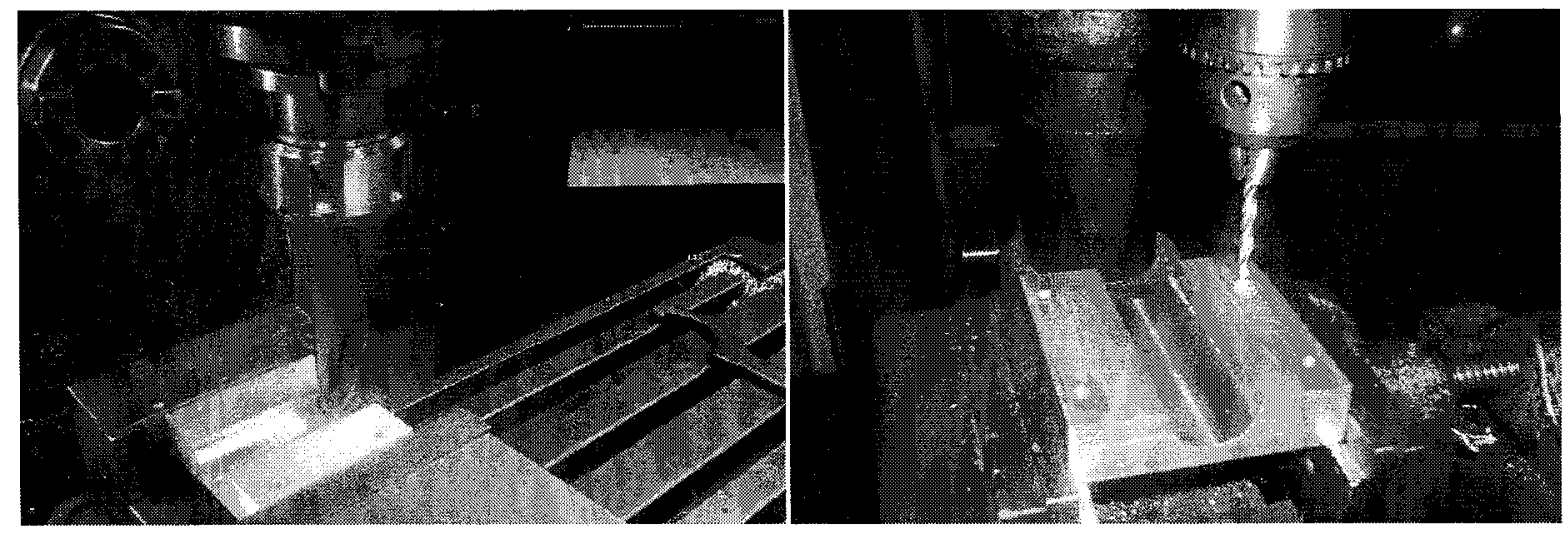

Figure 4-7: Milling Machine and Drill Press used for Manufacturing Saddles

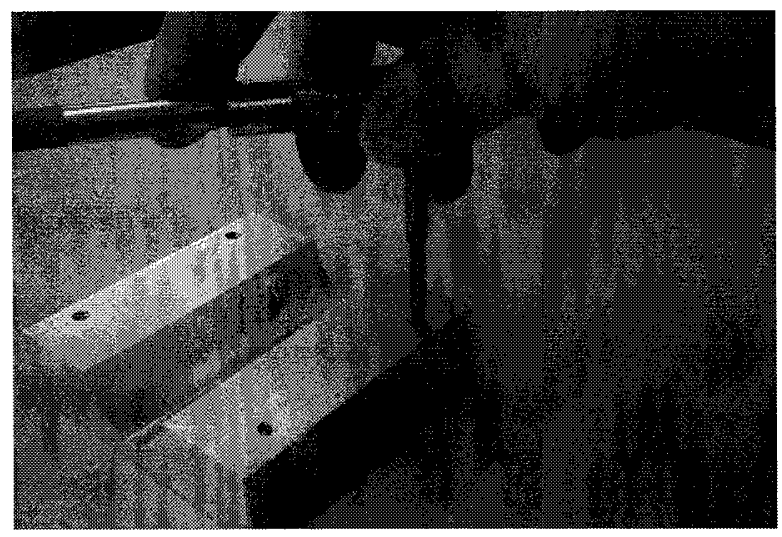

Figure 4-8: Threads Machined using a 10-32 Hole Tap 


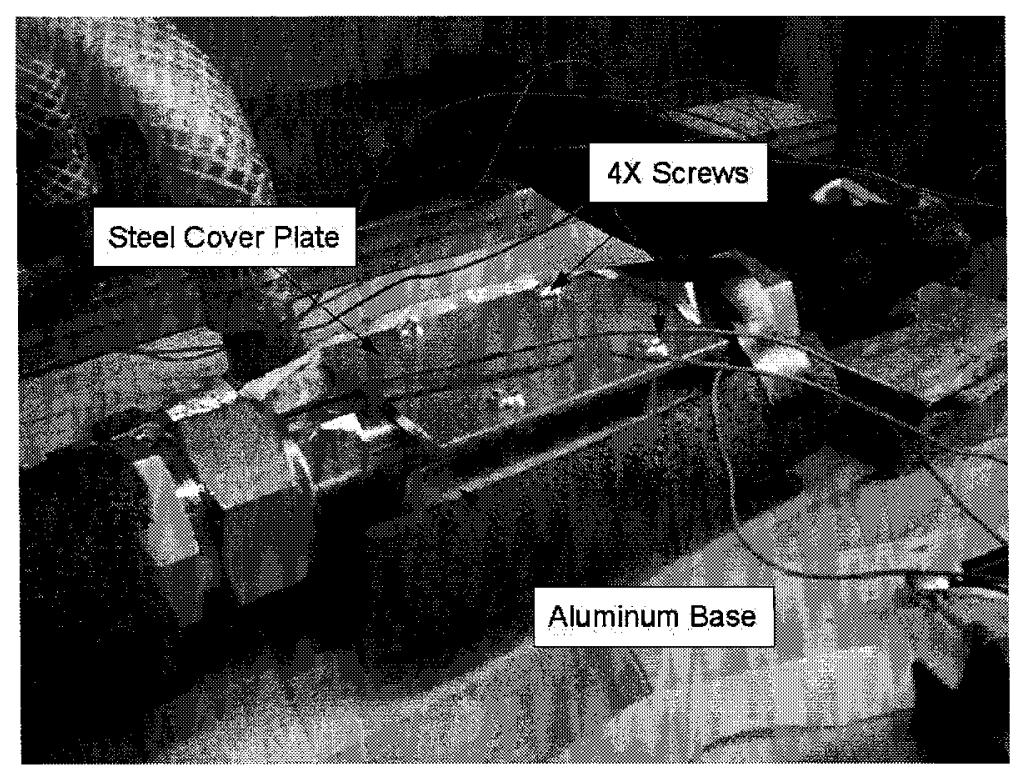

Figure 4-9: Final Evaporator Saddle Assembly
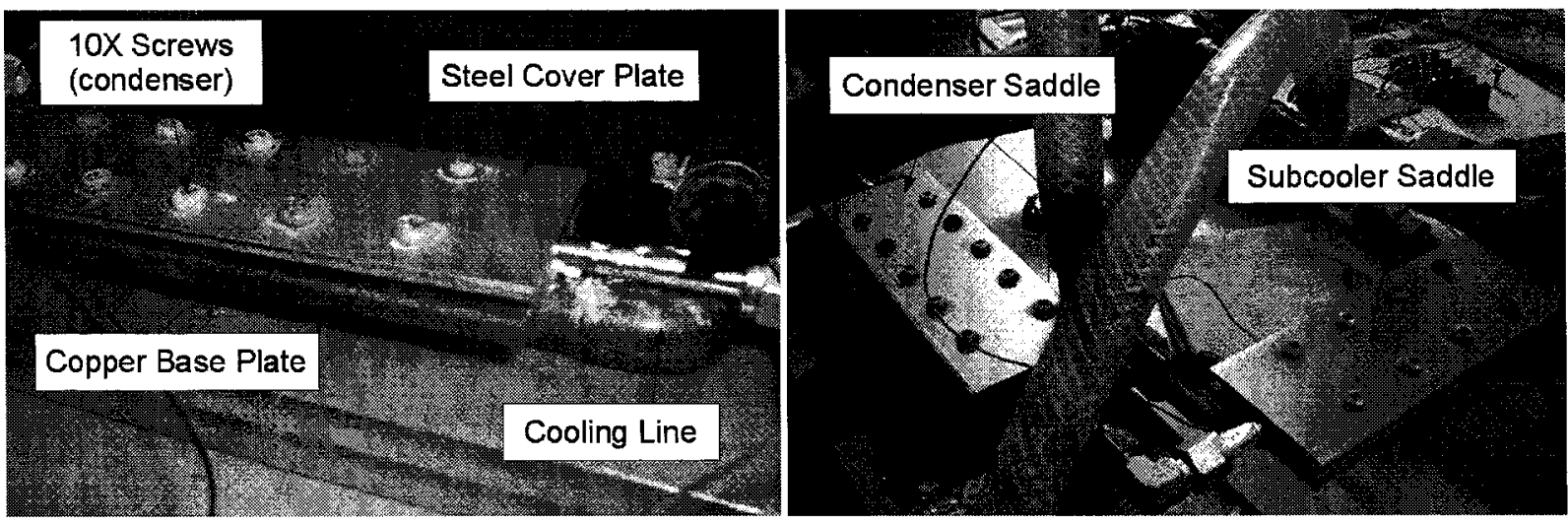

Figure 4-10: Final Condenser and Subcooler Saddle Assembly

A second heat sink was designed and manufactured using acrylic tubing, as shown in Figure 4-11. First, 1' $(25.4 \mathrm{~mm})$ and $1 / 2 ",(12.7 \mathrm{~mm})$ plastic tubing was cut using a band saw to the appropriate lengths. Then, similar to the techniques used for machining the stainless steel transportation lines, a lathe was used to round off the ends to help secure a liquid-tight seal at the ends. Plastic adhesive was used to fasten the end caps and 
inlet/outlet tubing to the main body. Finally, caulking was applied between the end cap and steel tubing to avoid leaking of the cooling fluid.
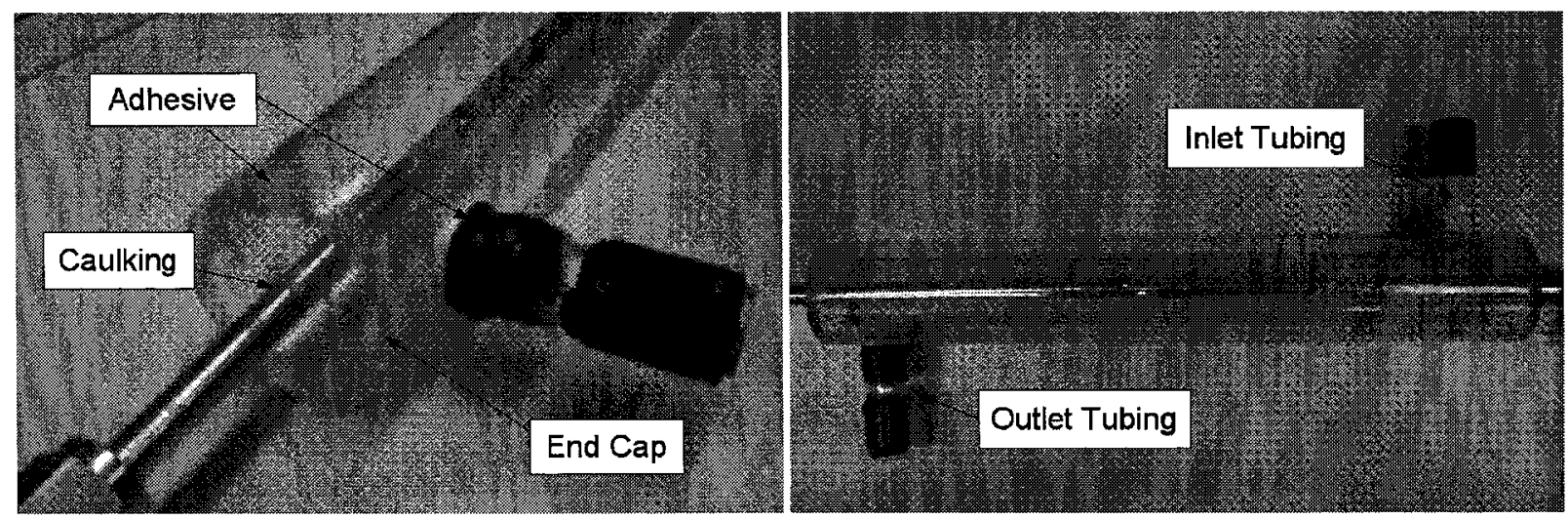

Figure 4-11: Tube-in-Tube Parallel Flow Heat Exchanger

\subsection{Component Cleaning}

As previously discussed, the presence of contaminants within the LHP may degrade performance over time. Therefore, thorough cleaning of all components before assembly is required. The particular cleaning procedure employed for a given LHP is greatly dependent upon the case material, wicking structure, and working fluid combination being used. There are numerous references available that describe various cleaning procedures for a wide variety of combinations ((Chi, 1976) and (Peterson, 1994)). The basic steps involve the following: initial cleaning to remove any debris, metal fillings...etc; chemical cleaning process to remove any water, oils, or films on the case or wick materials; a series a final rinse processes to remove any remaining solvent; and in some cases a vacuum bakeout. The best methods for cleaning stainless steels use passivation techniques to remove or eliminate any steel particles embedded in or near the 
surface from the machining process (Peterson, 1994). In addition, common passivation treatments including nitric acid $\left(\mathrm{HNO}_{3}\right)$ solutions or pastes enhance the formation of the protective film thus increasing resistance to corrosion.

The following procedure was used to clean the stainless steel tubes (adapted from (Peterson, 1994)):

1. Soak and brush the surfaces with a wire brush and acetone to remove oil and dirt.

2. Flush parts with acetone.

3. Soak in a solution of $15 \%$ nitric acid, $5 \%$ hydrochloric acid, and $80 \%$ water for 15 minutes.

4. Soak in a $15 \%$ nitric acid, $85 \%$ water solution at $65{ }^{\circ} \mathrm{C}$ for 15 minutes to dissolve any iron or steel particles.

5. Flush parts with acetone or isopropyl alcohol.

6. Dry thoroughly with clean, dry air.

This procedure is compatible with both acetone and methanol working fluids. Acetone was used to clean the wick structure of any remaining contaminants left over from machining. A bakeout was also performed on the LHP, and is discussed in the evacuation and charging procedures.

\subsection{Assembly Procedure}

Assembly of each LHP component should occur immediately after cleaning, where applicable. Typically, assembly of loop heat pipe parts includes welding of the end cap, welding of the case sections and wick insertion. For this particular study, the wick 
structure was first inserted, as shown in Figure 4-12, into the evaporator section immediately after uniformly heating the evaporator to a temperature of $80^{\circ} \mathrm{C}$. After insertion, the evaporator-wick assembly was visually inspected to confirm that the wick was in direct contact with the evaporator wall, as shown in Figure 4-13. The evaporator and transportation lines were then connected via Swagelok unions and the loop was sealed with a Swagelok valve. After assembly, the apparatus was weighed for comparison to the mass after fluid charging.

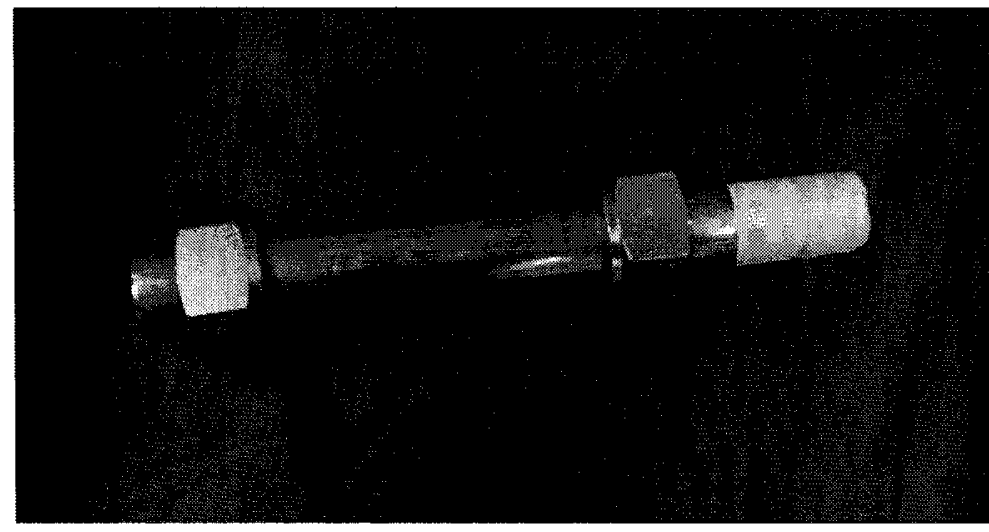

Figure 4-12: Wick-Evaporator Insertion

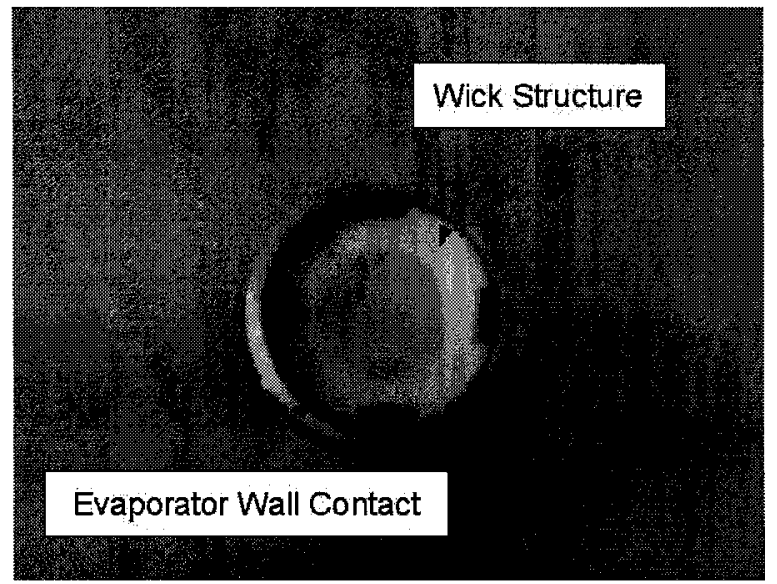

Figure 4-13: Evaporator Wall-Wick Contact after Insertion 


\subsubsection{Swagelok Fittings}

Swagelok fittings were chosen as an easy and efficient way of assembling and sealing LHP components. The fittings use a two ferrule design that provides leak-tight seals up to a pressure of $10^{-7}$ Torr $\left(1.33 \times 10^{-5} \mathrm{~Pa}\right)$. The two ferrule design separates sealing and tube retaining functions. As shown in Figure 4-14, the front ferrule creates a seal against the fitting body and tube $\mathrm{OD}$, while the back ferrule provides a radial tube grip that can withstand vibrations and temperature variations.

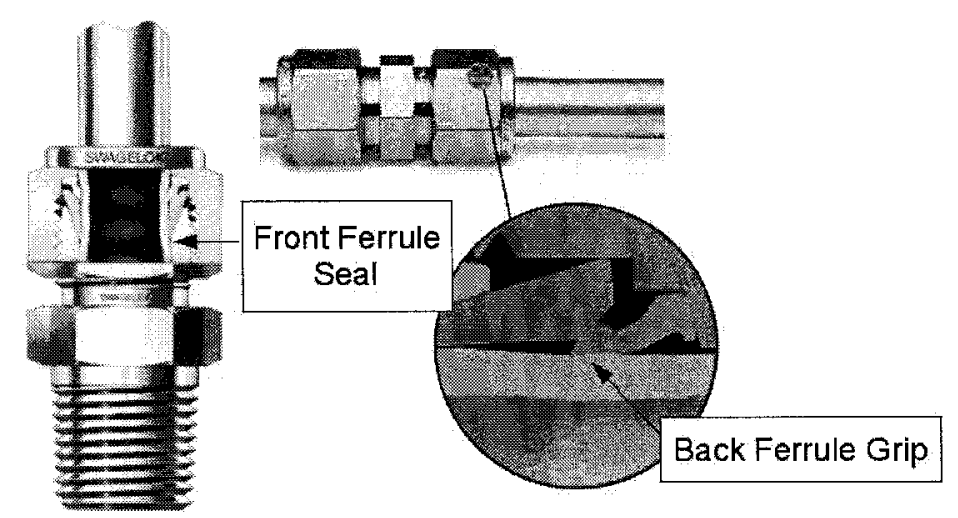

Figure 4-14: Swagelok Two-Ferrule Design (Swagelok Tube Fittings, 2004)

Nine fittings were used for assembly of the first and third LHP and are illustrated in Figure $4-15$. Two reducing unions (1 in $(25.4 \mathrm{~mm})$ OD to $1 / 4$ in $(6.35 \mathrm{~mm})$ OD) were used to connect the evaporator section to both the vapour and liquid lines. A union tee $(1 / 4$ in $(6.35 \mathrm{~mm})$ OD) was used to connect the liquid line to the fill-tube and sealing valve. A Bellows valve was used for fluid charging and sealing the system. Three union elbows $(1 / 4$ in $(6.35 \mathrm{~mm})$ OD) were installed at three of the four right angles of the loop. The second LHP was assembled in the same manner as LHP 1 and 3 with the exception 
of the top two union elbows. These two fittings were replaced with $90^{\circ}$ degree bends in the tubing. The purpose of replacing the fittings was to reduce pressure losses introduced by the fittings.

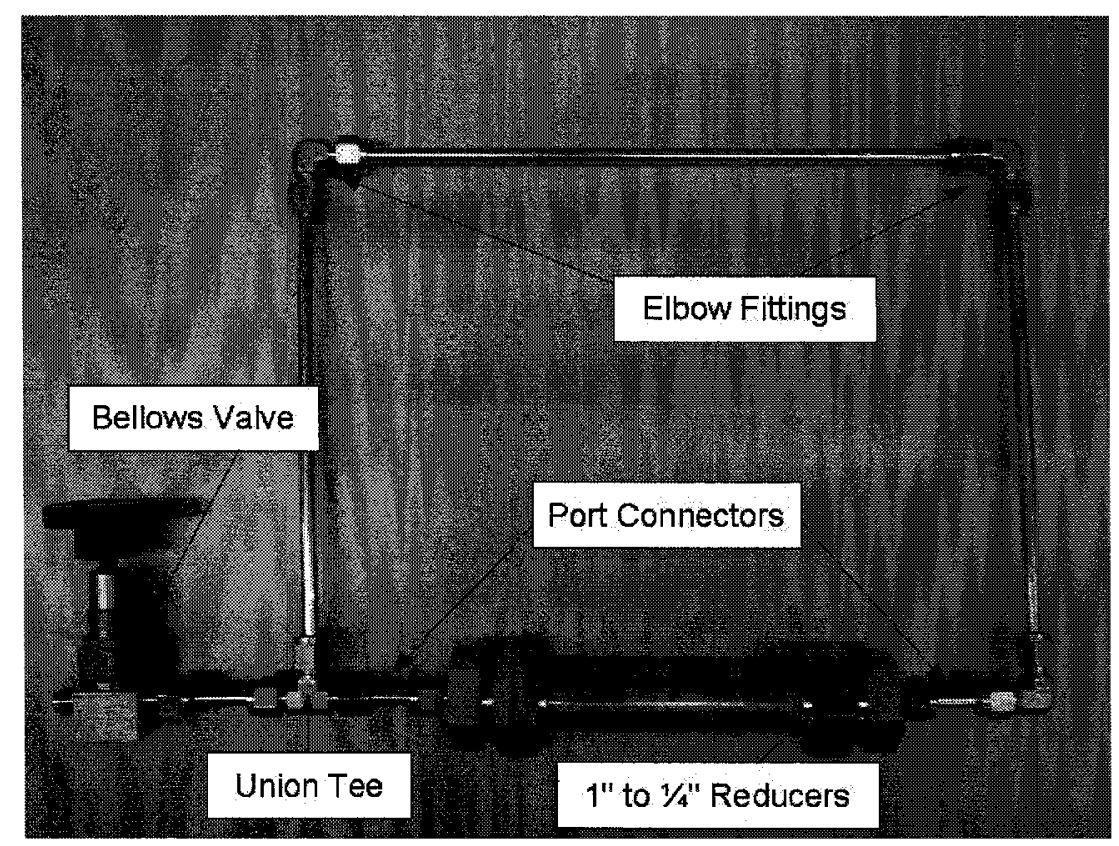

Figure 4-15: Swagelok Fittings

The following are installation procedures of all Swagelok fittings under 1 in OD:

1. Insert tubing into the Swagelok tube fitting.

2. Make sure that the stainless steel tubing rests firmly on the shoulder of the tube fitting body and that the nut is finger-tight.

3. Scribe the nut at the 6 o'clock position.

4. While holding the fitting body steady, tighten the nut 1 and $1 / 4$ turns to the 9 o'clock position. 
One of the main advantages of using Swagelok fittings is that each fitting may be disassembled and reassembled several times. This function permits easy access to the wick structure for inspection. It also enables testing of varying fluid inventories in the same loop without the requirement of manufacturing a new prototype for every charge. Reassembly instructions are as follows: first, insert the tubing with preswaged ferrules into the fitting body until the front ferrule sits flush with the fitting, then rotate the nut with a wrench to the previously pulled-up position, at which point a significant increase in resistance will be encountered; tighten slightly with a wrench.

It is noted that in some instances, port connectors were used as a substitute to regular stainless steel tubing in areas where only a small length of tubing was required. The location of each port connector used in LHP 1 and 3 is shown in Figure 4-15, while Figure 4-16 illustrates the component before assembly. The tube end of the port connectors are installed the same way as regular stainless steel tubing. On the machined ferrule end, the procedures are as follows: remove the nut and ferrules from one the tube fittings; then, place the nut of the machined ferrule end of the port connector; turn the nut onto the fitting so that it is finger tight; scribe the nut at the 6 o'clock position; while holding fitting body steady, tighten the nut $1 / 4$ of a turn to the 9 o'clock position. 


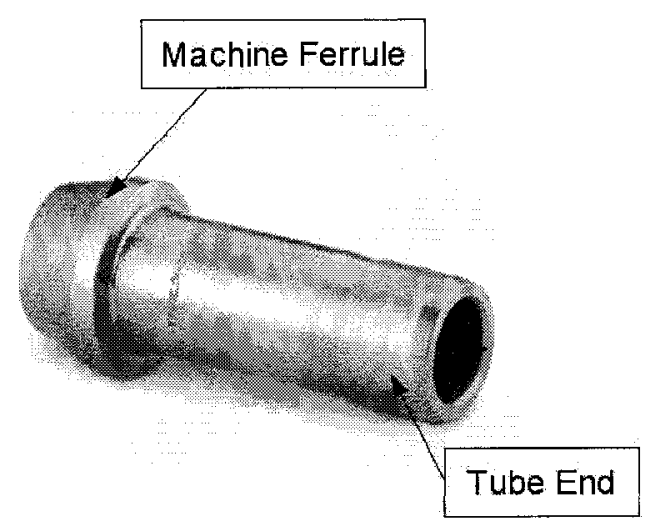

Figure 4-16: Port Connector

\subsection{Evacuation and Charging Procedures}

Particular attention to loop evacuation and fluid charging is necessary as it is a critical stage in LHP manufacturing. The requirement of evacuating the LHP relates to the evaporation process of the working fluid. Based on the ideal gas law expressed in Eq. (4.1), temperature of a gas is directly proportional to its pressure.

$$
p V=n R T
$$

where $\mathrm{P}$ is the absolute pressure; $\mathrm{V}$ is the volume; $\mathrm{n}$ is the number of moles; $\mathrm{R}$ is the universal gas constant $=8.3145 \mathrm{~J} / \mathrm{mol} \mathrm{K}$; $\mathrm{T}$ is the absolute temperature. Therefore, if the pressure in a constant volume is decreased then the temperature at which evaporation occurs in a liquid is also decreased. For example, at atmospheric pressure $(101.33 \mathrm{kPa})$, water boils at approximately $100{ }^{\circ} \mathrm{C}$. If the pressure is reduced to $3.17 \mathrm{kPa}$, water will instead boil at approximately $25^{\circ} \mathrm{C}$. Similarly, acetone and methanol both boil at $25^{\circ} \mathrm{C}$ for pressures of $26.66 \mathrm{kPa}$ and $16.85 \mathrm{kPa}$ respectively. Thus, start-up at low temperatures is partly established by reducing the pressure in the LHP. 
Another important factor for evacuation is the need to remove any remaining particulates that may damage LHP operation. More specifically, a LHP should be evacuated and heated prior to charging to remove any foreign materials that may subsequently appear as unwanted non-condensibles, or that chemically react with the working fluid forming undesirable corrosion products. A general rule is to evacuate the pipe at a temperature greater than the heat pipe operating temperature (Chi, 1976). This process is sometimes referred to as bakeout.

Figure 4-17 illustrates the apparatus used for evacuation and charging. The system is composed of a six primary components: vacuum pump, trap, flow lines, pressure gauge, valves, and fluid container.

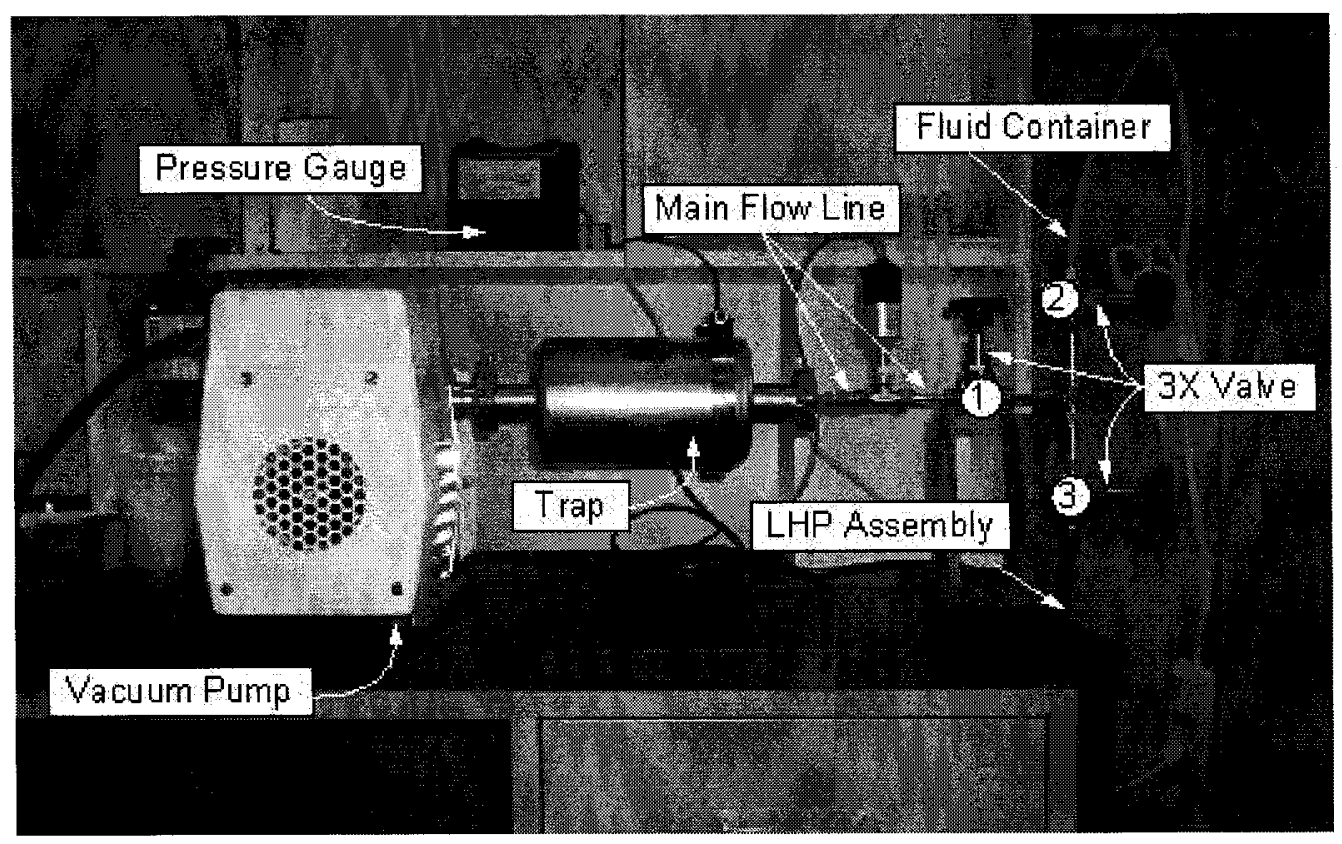

Figure 4-17: Evacuation and Charging System Assembly 
The vaccum pump is an Alcatel SD series rotary vane pump. It has a nominal flow rate of $6.5 \mathrm{~m}^{3} / \mathrm{h}$ or $1.8 \mathrm{~L} / \mathrm{s}$ and produces a minimum pressure of $1.5 \times 10^{-3}$ Torr $(0.2 \mathrm{~Pa})$, suitable for many LHP applications. The flow line system consisted of $1 / 4$ in $(6.35 \mathrm{~mm})$ stainless steel tubing connected with Swagelok fittings similar to those used in assembly of each LHP. A trap was installed at the pump inlet to help prevent entry of pump oils and condensable gases. A Kurt J. Lesker pressure gauge was installed directly after the trap, between the vacuum pump and the LHP, and has a minimum pressure reading of $10^{-}$ ${ }^{3}$ Torr $(0.133 \mathrm{~Pa})$. Three Swagelok Bellows valves were installed in the indicated location, shown in Figure 4-17. Valve 1 controls the main line to the vacuum pump. It is opened to connect the vacuum pump to the LHP for evacuation. During fluid charging, valve 1 is closed to halt any fluid from entering and damaging the vacuum pump, trap, or pressure gauge. Valve 2 controls the flow of the working fluid and is therefore closed during the entire evacuation process. It is only slightly opened while charging the necessary amount of fluid to the LHP. Valve 3 is first installed on the LHP and then placed directly below the fluid flow line for access to both the vacuum and fluid charge lines. It remains open during evacuation and fluid charging procedures and is closed for final sealing of the LHP. The fluid container provides the required amount of working fluid. It is essentially a graduated cylinder permanently installed on the end of valve 2 . A summary of the standard evacuation and charging procedures are provided below:

1. Assemble the LHP and attach to valve 3 .

2. Seal valve 3 and attach to the vacuum assembly. 
3. Fill the fluid container with the required volume of working fluid (at ambient temperature); ensure no air bubbles are trapped in the valve.

4. Seal valve 2 and attach to the vacuum assembly.

5. Confirm valves 1,2 , and 3 are closed and then turn on the vacuum pump.

6. Once the pressure gauge has stabilized, open valve 1 .

7. Let the system stabilize for 20 minutes then check the pressure reading; the pressure gauge should read a maximum of $10 \mathrm{mTorr}$. If this is not the case, then the system may contain some residual liquid in the flow lines. The entire assembly must then be heated to an elevated temperature to boil off the remaining liquid. As the lines are heated there should be a sudden jump in the pressure reading, indicating vaporization of the residual liquid.

8. After heating, let the system cool to ambient temperature. It may be necessary to repeat this process several times over the course of several hours until the appropriate pressure reading is obtained.

9. Open valve 3 to evacuate the LHP. The loop assembly may also contain residual liquid left over from the cleaning process. In such a case, repeat the same process described in Steps 7 and 8 until the required pressure is obtained. Care should be taken to avoid heating the evaporator to significant levels since the wick structure may be damaged at temperatures above $80^{\circ} \mathrm{C}$.

10. Once the pressure has stabilized at approximately 3 to 5 mTorr, close valve 3 and turn off the pump. Record the pressure reading and leave system as is over night. 
11. Repeat steps 5 through 8 . Open valve 3 while watching the pressure gauge. The pressure should be maintained at the same pressure recorded the day before. If this is the case, then proceed to the next step. If this is not the case then there may be a leak in the loop assembly. Remove the loop assembly from the system and check all Swagelok connections. Repeat steps 5 through 8 again.

12. Close valve 1 and make sure valve 3 is open. Slowly open valve 2 while inspecting the fluid container. Close valve 2 when the required volume is charged.

13. Apply a cold source, such as an ice pack, to the loop assembly to ensure that all of the fluid is charged to the loop.

14. Close valve 3 and detach from the vacuum assembly.

15. Turn off the vacuum pump and seal all outlets.

\subsection{LHP Sealing}

After evacuation and fluid charging, the LHP was sealed by closing the Swagelok Bellows valve. The apparatus was then removed from the vacuum system and a cap was placed on the end of the valve. The LHP was then weighed to verify that the correct amount of fluid was charged. Performance verification tests were performed and are described in detail in the following chapter. The final LHP assembly is shown below in Figure 4-18. 


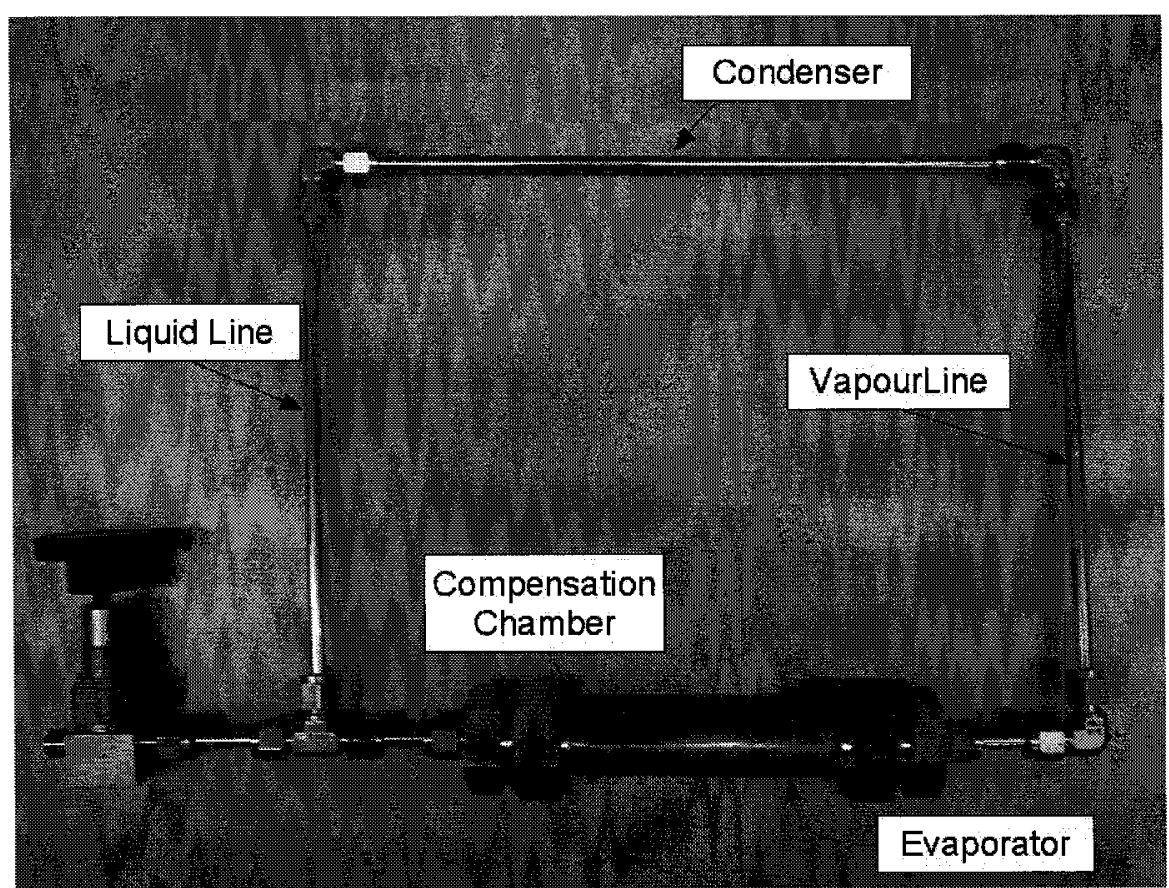

Figure 4-18: Final LHP Assembly 


\section{Chapter 5: LHP Testing}

\subsection{Experimental Approach}

Preliminary LHP testing of each apparatus was required as part of the evaluation procedure necessary for selecting an optimum design that meets the problem specifications. All three LHPs were tested in succession to verify performance and stable operation. The first phase of testing focused on loop start-up and steady-state operating temperatures in comparison to 'baseline' results obtained from each LHP without working fluid. After testing each unit, design changes were implemented in each subsequent LHP to increase performance, with the final LHP producing the best results. As a result, the final LHP was selected for further analysis. The second phase of testing studied the effect of fluid inventory on LHP start-up, steady-state operating temperature, effective thermal resistance, and heat transfer coefficient. The final phase of testing was used to measure the effect of orientation and periodic heating on thermal performance. Temperature hysteresis was also investigated during the final phase of testing.

\subsection{Test Specimen and Experimental Setup}

All three test articles in this study were constructed primarily of stainless steel, with UHMW polyethylene as the wick material. A summary of the specifications of each test 
unit is provided in Table 3-2. All tests were performed at the Carleton University Heat Pipe Laboratory in Ottawa, Ontario. A test platform was constructed for the purpose of LHP performance verification and characterization of properties. The overall test platform is illustrated in Figure 5-1. A reference coordinate system fixed to the test board, also shown in Figure 5-1, was used to describe different orientations of the LHP. The evaporator and condenser sections were aligned with the $\mathrm{X}$ axis while the vapour and liquid lines were aligned with the $\mathrm{Y}$ axis. The $\mathrm{Z}$ axis was parallel but opposite in direction to the gravity vector (coming out of the page in Figure 5-1).

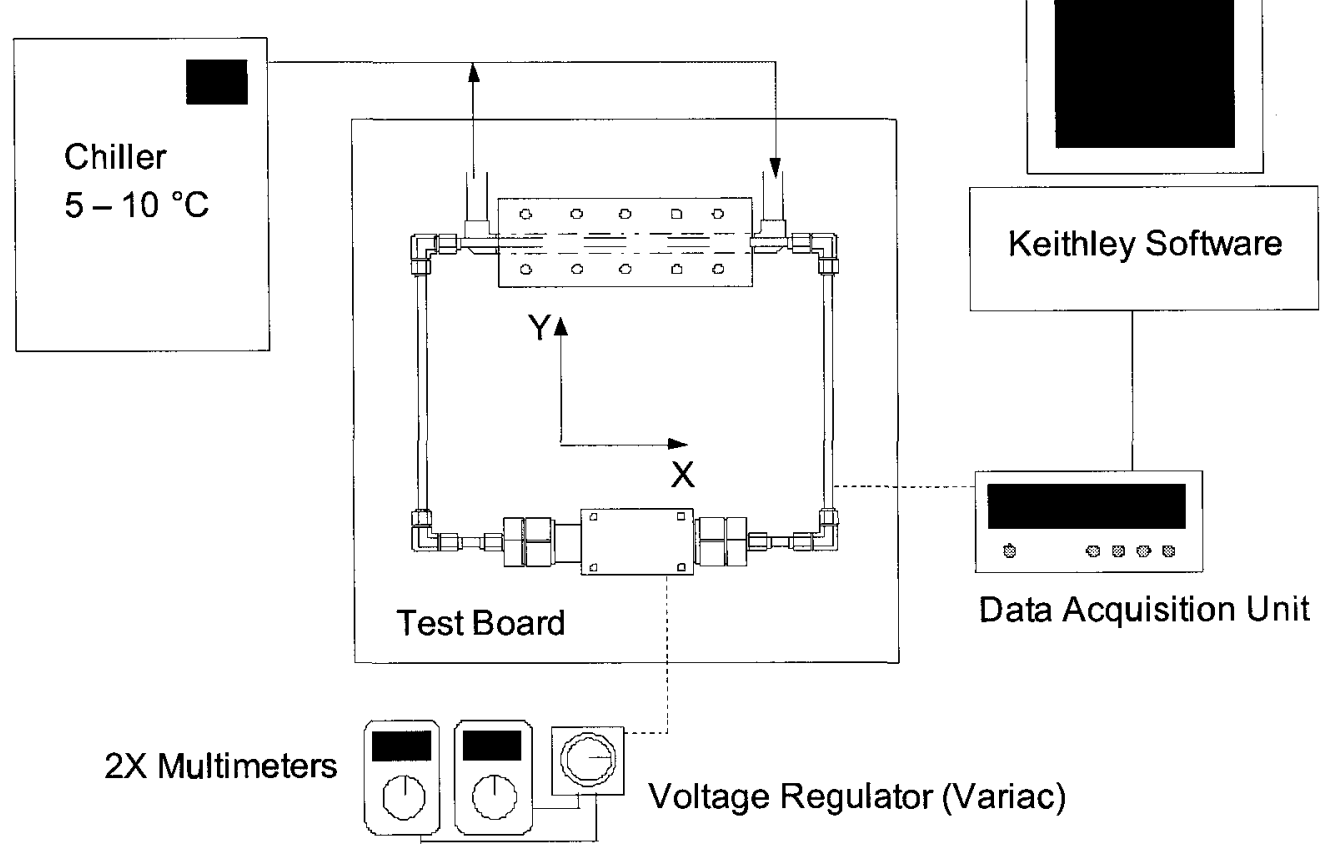

Figure 5-1: Schematic of Test Platform in Heat Pipe Laboratory 


\subsubsection{Orientation of Test Unit}

Nominal testing of each unit proceeded with a fixed elevation. That is, the liquid and vapour lines were fixed horizontally in the y-axis. The elevation refers to the vertical distance between the centre of the evaporator and the centre of the condenser line. The evaporator and reservoir were also fixed in the horizontal position (in the x-axis), producing no adverse tilt. The tilt refers to the vertical distance between the centre of the evaporator and the centre of the reservoir.

\subsubsection{Instrumentation}

\section{Temperature Sensors}

A minimum of 11 Omega T-type copper/constantan thermocouples were used to monitor LHP temperatures. Thermocouples were placed at critical points along the LHP, including the evaporator, vapour line inlet, centre of vapour line, condenser, liquid line inlet, centre of liquid line, and compensation chamber. Thermocouples were also used to monitor ambient temperature, as well as the temperature of the cooling liquid entering and exiting the condenser heat exchanger. The uncertainty of the thermocouple readings were estimated to be approximately $+/-0.5^{\circ} \mathrm{C}$. Aluminum adhesive tape was used to fix the thermocouples to all testing surfaces and had a maximum operating temperature of $120{ }^{\circ} \mathrm{C}$. Figure 5-2 illustrates the location of thermocouples for two condenser configurations used during testing. 

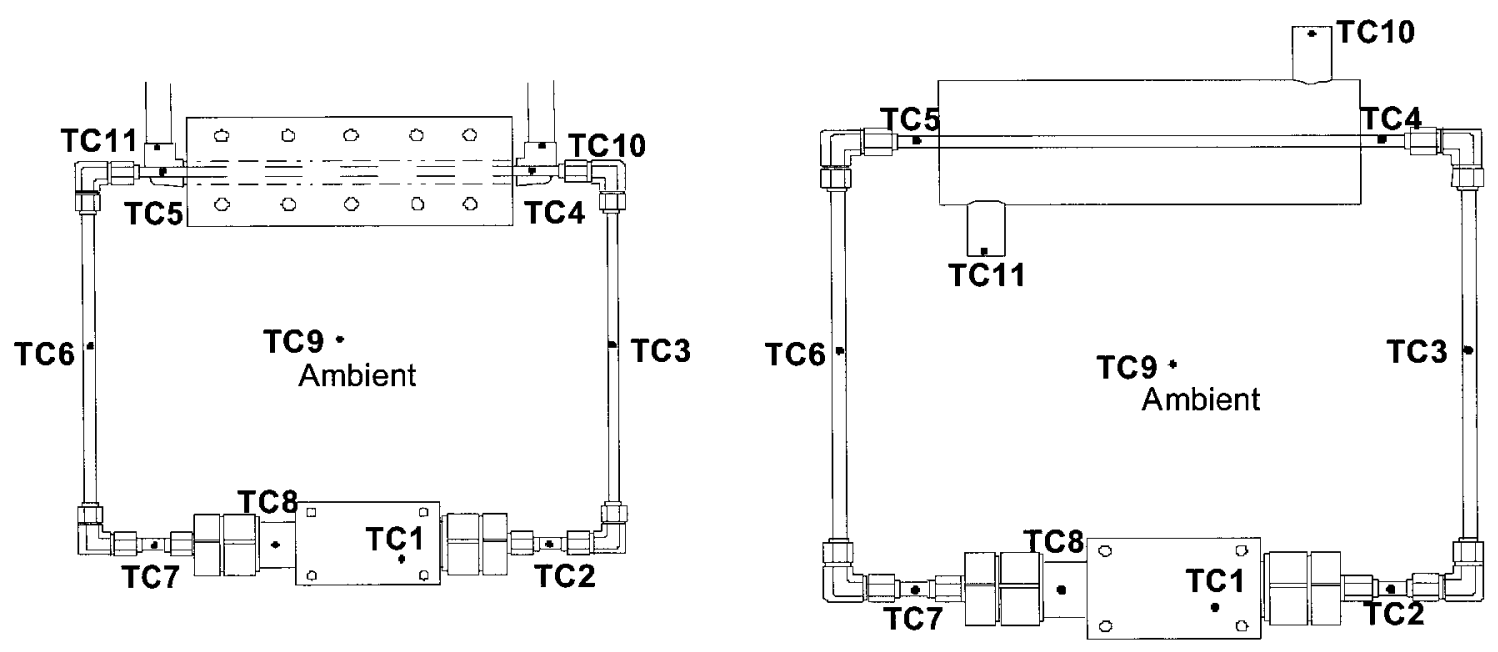

Figure 5-2: Thermocouple Placement for both Configurations

\section{Data Acquisition System}

A Keithley Model 2700 data acquisition system was employed during LHP testing and used a built-in digital input board to read the potential from the thermocouples. The temperatures were recorded and displayed in real time through a direct interface card to a personal computer using Keithley Integra Series Software. All data was automatically output as .dat files at the end of each test procedure. Matlab scripts were used for postprocessing of data.

\section{Heat Source \& Power Control System}

An Omega kapton flexible heater provided up to $60 \mathrm{~W}$ of power to the LHP evaporator. The voltage supplied to the heater was controlled by a $110 \mathrm{~V}$ variac. One multimeter monitored the voltage input to the heater while another multimeter monitored the amperage. The resolution of the voltage reading was $0.1 \mathrm{~V}$ while the resolution of the 
amperage reading was $0.01 \mathrm{~A}$. The uncertainty for the power input was estimated to be approximately $+/-2 \%$ of the reading.

\section{Cooling System}

A Lytron recirculation chiller was used to provide a continuous supply of cooling liquid at a constant temperature and volumetric flow rate. During operation, a minimum sink plate temperature of $5{ }^{\circ} \mathrm{C}$ was achieved and maintained within $+/-0.5{ }^{\circ} \mathrm{C}$ using an internal thermostat. The cooling fluid used during operation was a mixture of $70 \%$ water and $30 \%$ ethylene glycol. The maximum operating volume flow rate is $6.8 \mathrm{~L} / \mathrm{min}$. The nominal volume flow rate during testing was $9 \mathrm{~L} / \mathrm{min}$.

\subsubsection{Insulation and Test Frame}

Nomex piping insulation $\left(3 / 8^{\prime \prime}(9.5 \mathrm{~mm})\right.$ thick) was wrapped around the evaporator, condenser, compensation chamber, and liquid and vapour lines to minimize the influence of the environment (ie. to control parasitic heating and cooling during testing). All LHP components were insulated separately to reduce any external heat paths between them. This was vitally important between the evaporator and $\mathrm{CC}$ since heat leak to the $\mathrm{CC}$ must be minimized in each design.

Two test stands were built to support the LHP for levelled testing and to minimize the effects of small vibrations. The first test stand consisted of a large table with wooden mounting blocks. The mounting block heights were adjusted for tilt and elevation tests. The second test stand was constructed of steel frames and supported a conventional heat 
exchanger type condenser. However, this design did not support tilt or elevation tests. During levelled testing, both test stands ensured that the evaporator was at the same level as the condenser within $+/-1 \mathrm{~mm}$. The evaporator was also maintained at the same elevation as the $\mathrm{CC}$ within $+/-2 \mathrm{~mm}$ to minimize any gravitational effect on pressure gradient across the wick.

\subsubsection{Evaporator-Heat Source Assembly}

An aluminum saddle was constructed to house to the evaporator and effectively provide the required heat input. Figure 5-3 provides a schematic of the evaporator-heat source assembly.

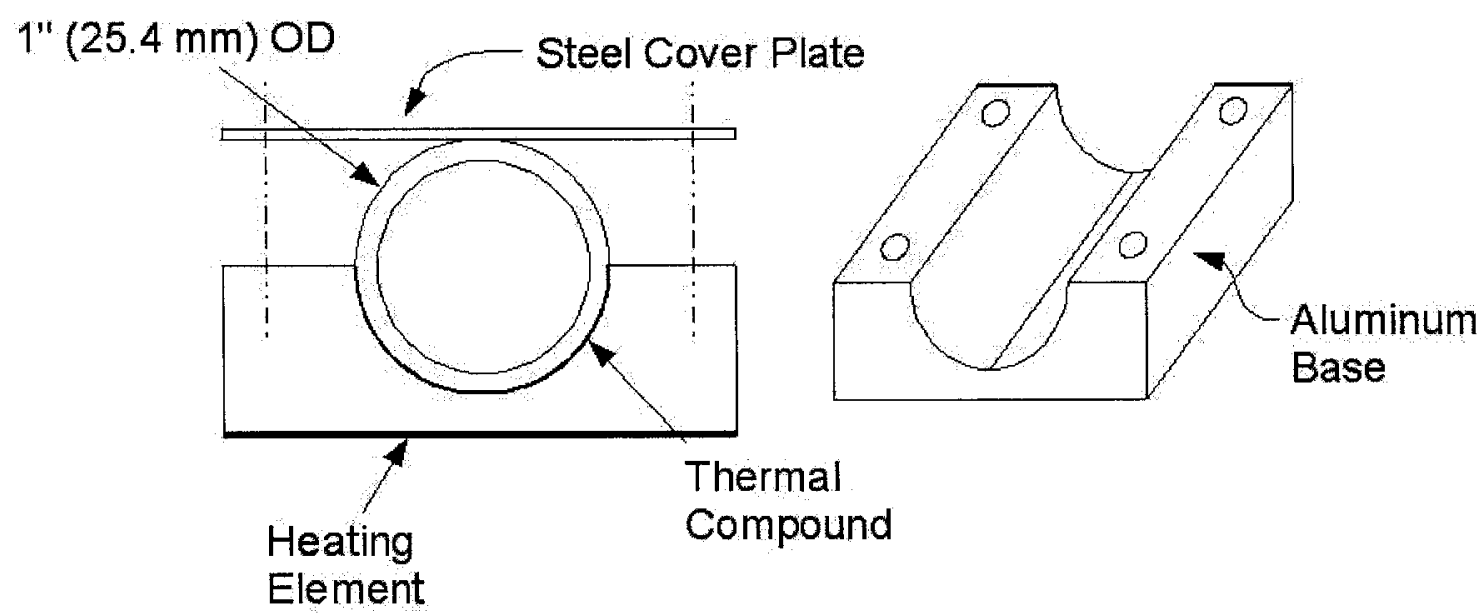

Figure 5-3: Evaporator-Heat Source Assembly

As shown in Figure 5-3, the saddle consists of a base and a cover plate. A flexible heating element was permanently attached to the flat surface of the saddle base using a thin and consistent layer of thermal epoxy. The selected thermal epoxy had a relatively high thermal conductivity $(1.05 \mathrm{~W} / \mathrm{mK})$ to minimize the thermal resistance between the 
heating element and saddle. The aluminum base simulated a typical thermal mass that may be encountered during normal operation of the LHP. The relatively high thermal conductivity of aluminum also ensured a uniform heat flux was applied to the evaporator. The stainless steel saddle cover was also used to ensure a uniform heat flux was applied to the evaporator. By torquing the four screws to 45 in-lb $(5 \mathrm{~N}-\mathrm{m})$, the cover provided good contact between the evaporator outer wall and the saddle base, thus increasing the thermal conductance between the two. To maximize the thermal conductance between the evaporator wall and saddle base and ensure a uniform temperature distribution, a thermal joint compound (Wakefield Engineering 120 Series: $0.735 \mathrm{~W} / \mathrm{mK}$ ) was applied between contact surfaces.

\subsubsection{Sink Assembly}

Active cooling of the condenser region during testing was necessary due to a relatively small heat transfer area in the condenser and low operating temperature of the wick material. As a result, two heat exchangers were constructed for the condenser. Figures Figure 5-4 and Figure 5-5 illustrate both designs. 


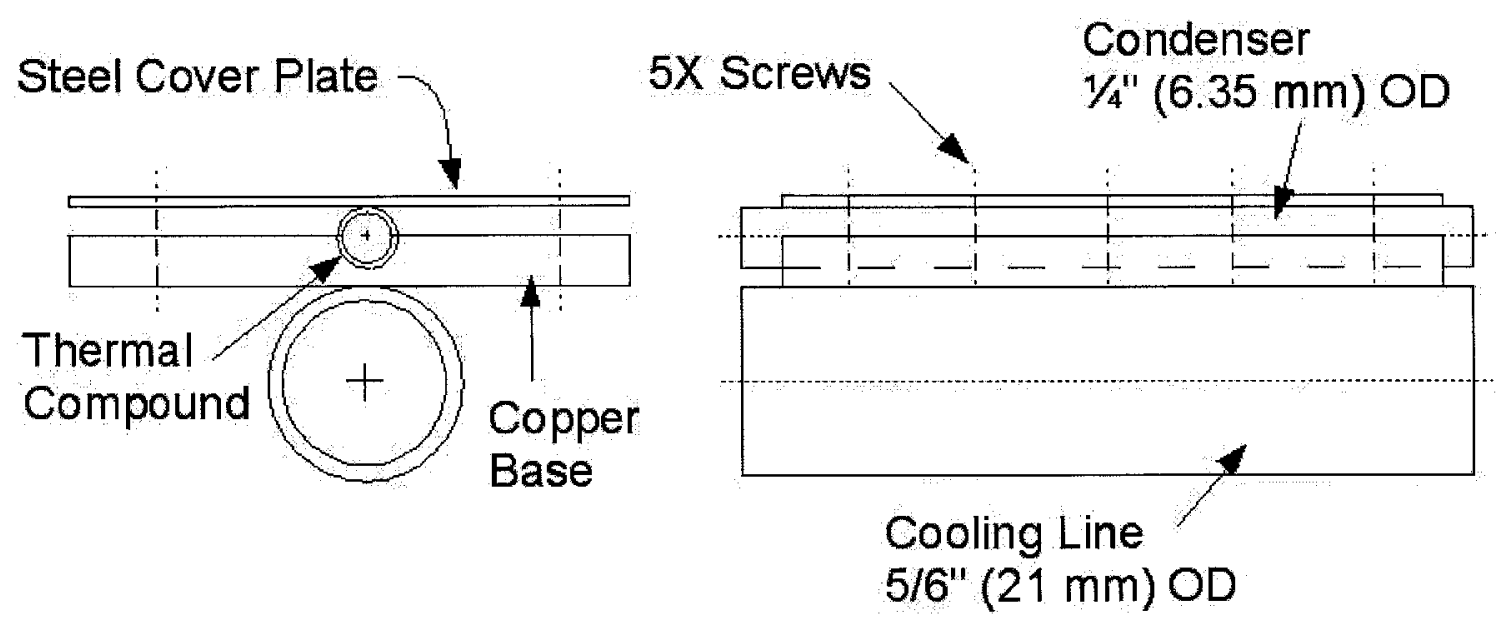

Figure 5-4: Condenser-Heat Exchanger Assembly 1

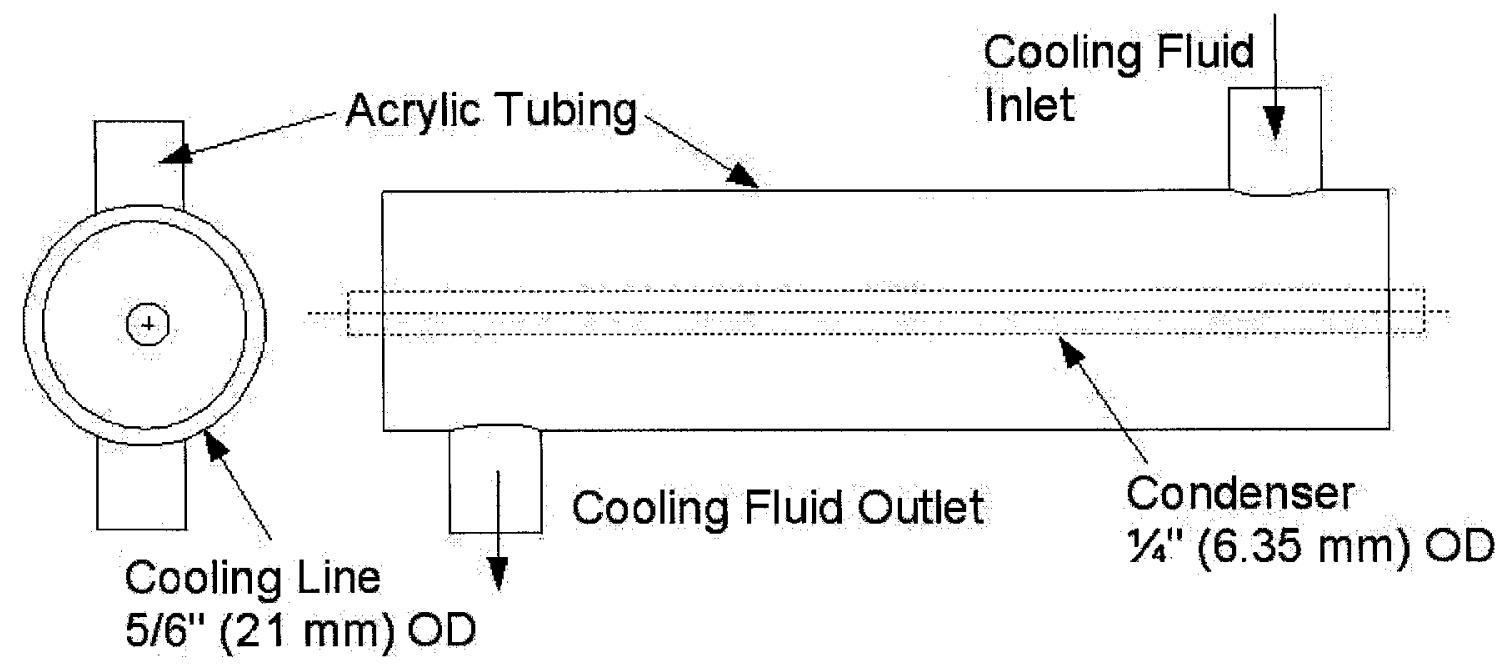

Figure 5-5: Condenser-Heat Exchanger Assembly 2

The first sink design is similar to that of the heater assembly. The condenser tubing is sandwiched between a copper base plate with a $1 / 4 "$ " $(6.35 \mathrm{~mm})$ wide groove and a stainless steel cover. To maintain good contact between the condenser and the copper base plate, 10 screws were torqued to 45 in-lb $(5 \mathrm{~N}-\mathrm{m})$. A thermal joint compound 
(Wakefield Engineering 120 Series) was applied between contact surfaces to maximize thermal conductance. To regulate the sink temperature, the Lytron chiller was used to circulate the cooling fluid in copper lines below the base plate. These copper lines were permanently soldered to the base plate to reduce thermal resistance.

The second sink design is a conventional tube-in-tube parallel-flow heat exchanger. This design is compact and has a comparatively simple design. In this case, the cooling fluid is in direct contact with the condenser tubing thus greatly increasing the heat transfer from the condenser to the cooling fluid.

The chiller temperature was maintained at its minimum temperature of $5{ }^{\circ} \mathrm{C}$ for the duration of each test procedure. In some cases, further subcooling of the liquid line was required in order to perform tests over a wider range of applied powers and operating temperatures. Therefore, a subcooler with an equivalent design to that of the first heat exchanger was attached to the liquid line of the LHP. In this case, the cooling liquid exiting the condenser heat exchanger was diverted to the subcooler before returning to the chiller as illustrated in Figure 5-6. 


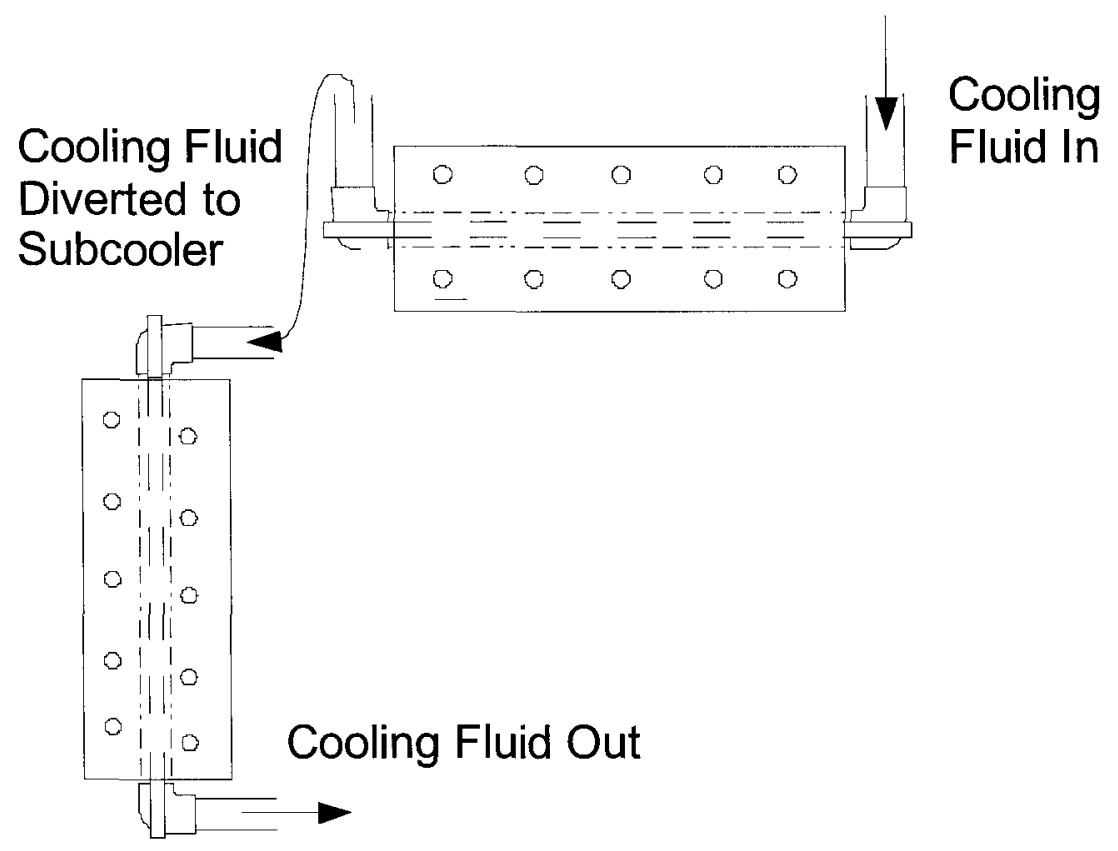

Figure 5-6: Addition of Subcooler to Liquid Line

\subsection{Operating Procedure}

To obtain consistent and reliable experimental results, a standard procedure was implemented, as listed below:

1. Leave the test apparatus sit idle overnight for at least 12 hours $^{2}$.

2. Adjust tilt and elevation of the apparatus to obtain the required orientation.

3. Ensure all thermocouples are properly connected

4. Adjust insulation of all critical areas of the apparatus.

5. Connect heating element power cord. 
6. Turn on the computer and run Keithley 2700 Software; start collecting data.

7. Turn on the chiller and set chiller temperature to required sink temperature, 5-10 ${ }^{\circ} \mathrm{C}$.

8. Adjust the cooling water volume flow rate to $9 \mathrm{~L} / \mathrm{min}$.

9. Wait until all temperatures including cooling fluid temperature, loop temperature, and ambient temperature reach steady state. This takes approximately 20-30 minutes.

10. Adjust the variac to the desired heat load. Note: variac controls the heater voltage. The desired heat load is obtained by adjusting the voltage based on the readings of voltage and amperage from both multimeters; where power applied in Watts is, $P=V \cdot A$.

11. Wait until all loop temperatures reach steady-state values. That is, no more than a $0.5^{\circ} \mathrm{C}$ variation over 20 minutes.

12. Adjust heat load to a desired intensity and repeat steps 11 and 12 for all required heat loads for the current test. Record heat load and scan number at time of adjustment.

13. Turn off heater and chiller, disconnect all power cords.

14. Terminate data acquisition software and export .dat file for post-processing.

\footnotetext{
${ }^{2}$ To obtain consistent results, it is required that each test be started with similar initial conditions in the evaporator. In particular, the initial state of the working fluid in the wick structure should be consistent as explained in Section 2.2.2.
} 
It is noted that for safety reasons, testing was terminated and all power disconnected if the evaporator temperature exceeded $75^{\circ} \mathrm{C}$, chiller volumetric flow rate dropped below 2 $\mathrm{L} / \mathrm{min}$, or sink temperature dropped below $5{ }^{\circ} \mathrm{C}$. These were constraints specified by the wick and chiller manufacturers respectively.

\subsection{Test Phase 1: Preliminary Testing}

As discussed in Section 5.1, preliminary tests were carried out on each test unit to investigate functionality. In particular, LHP start-up and stable operation were verified under steady-state conditions. The following sections discuss the test results for each unit and summarize the subsequent design changes for each.

\subsubsection{Baseline Tests}

Each unit was tested with no working fluid charged in the loop. These tests were considered 'baseline' tests, and used to compare against results obtained from each apparatus after fluid charging. In particular, the results were used to ascertain whether or not loop start-up occurred, as well as to quickly establish how much energy was transferred through LHP operation in comparison to pure conduction. Figure 5-7 presents the results obtained from testing the third LHP with no working fluid. It illustrates the average temperature of the evaporator, vapour line, liquid line, and compensation chamber for a power input of 5 and $15 \mathrm{~W}$ and a sink temperature of $5{ }^{\circ} \mathrm{C}$. 


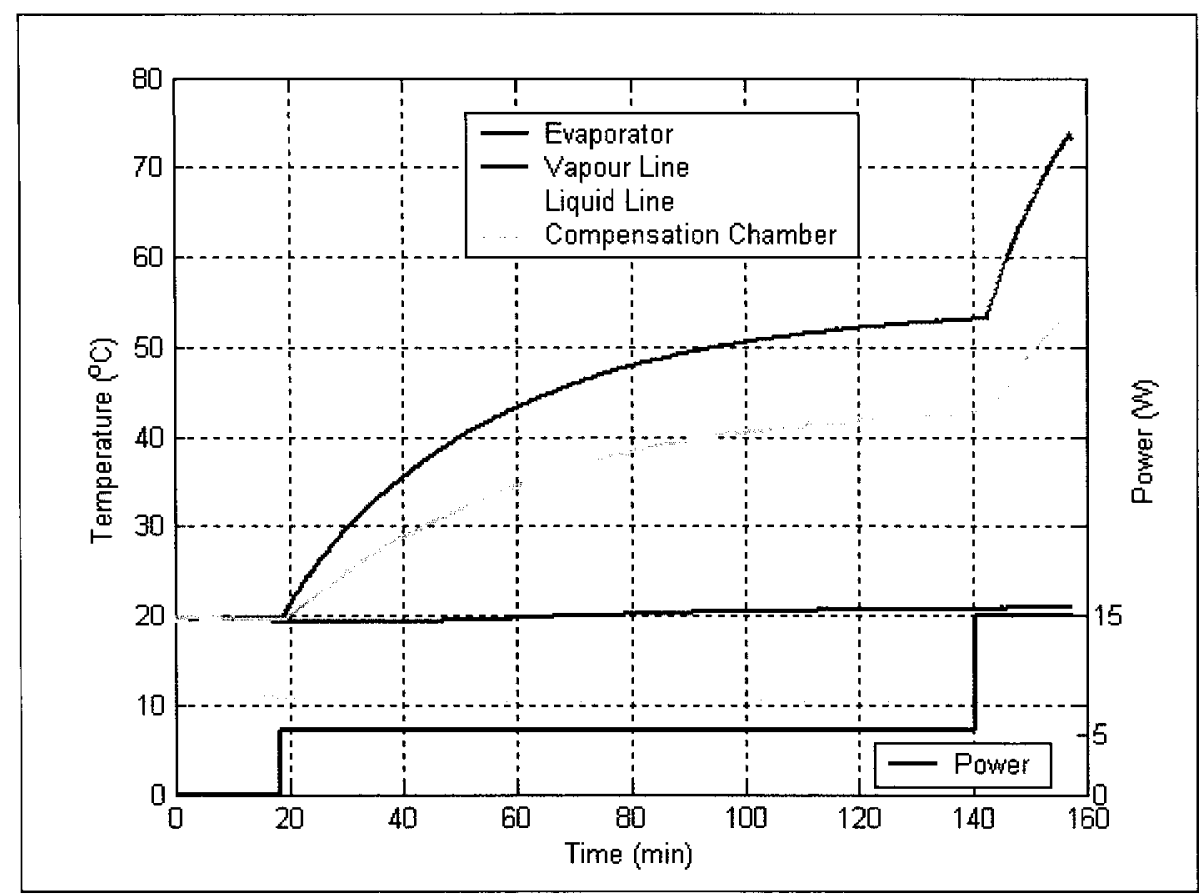

Figure 5-7: Baseline Results for 5 and 10W Power Inputs

Since heat transfer is achieved primarily through conduction, the temperature of each section closest to the heat source (evaporator and compensation chamber) rose steadily without any abrupt fluctuations. Components located further away from the heat source (vapour line and liquid line) also rose in temperature but at a much slower rate due to the relatively low thermal conductivity of stainless steel. It should be noted that since the steady-state temperature is a function of thermal conductivity and ambient conditions, the ambient temperature and insulation were kept constant throughout all baseline tests to ensure consistent results between tests. The steady-state temperature of the evaporator for a range of power loads for each unit was compiled and is shown in Figure 5-8. The 
trendline demonstrates the linear relationship between the applied power and resulting steady-state temperature of the evaporator.

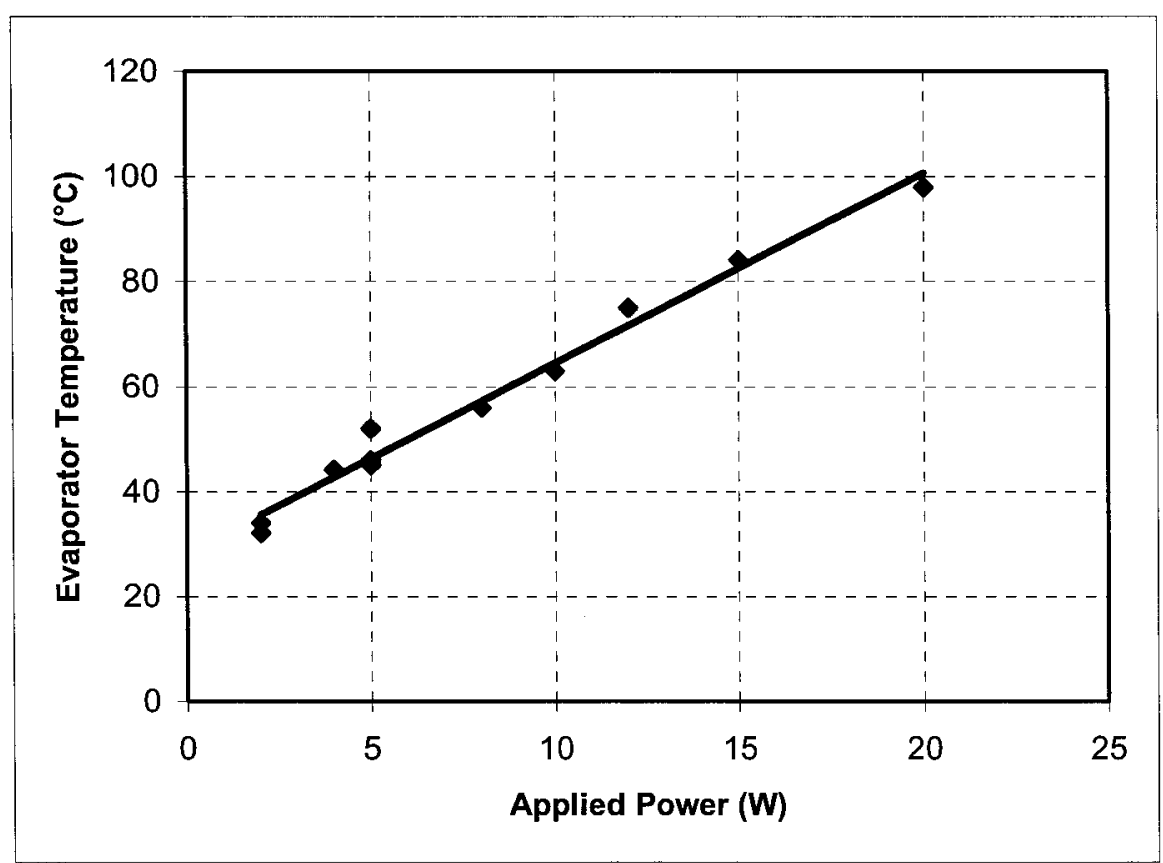

Figure 5-8: Steady-State Evaporator Temperatures for a Given Power Input (Baseline)

\subsubsection{Test Apparatus \#1}

The dimensions and properties of the first LHP are provided in Table 3-2. The first set of tests was performed to demonstrate the start-up capabilities of the LHP at low power levels. Start-up is identified by a sudden rise in vapour line temperature as superheated vapour is pushed from the evaporator to the vapour line, followed by a sudden drop in the liquid line temperature as cold liquid is pushed from the condenser to the liquid line. These features are clearly illustrated in Figure 5-9 for a $5 \mathrm{~W}$ start-up with a sink temperature of $5{ }^{\circ} \mathrm{C}$, thus demonstrating successful LHP operation of the test unit. A 
slight temperature overshoot of $1.2{ }^{\circ} \mathrm{C}$ was also observed. Several start-ups at various applied heat loads were attempted while maintaining the sink temperature at $5{ }^{\circ} \mathrm{C}$. The LHP demonstrated successful start-up for power inputs ranging from $2.5 \mathrm{~W}$ to $20 \mathrm{~W}$. The minimum power threshold for start-up was found to be approximately $2.5 \mathrm{~W}$ for this particular design.

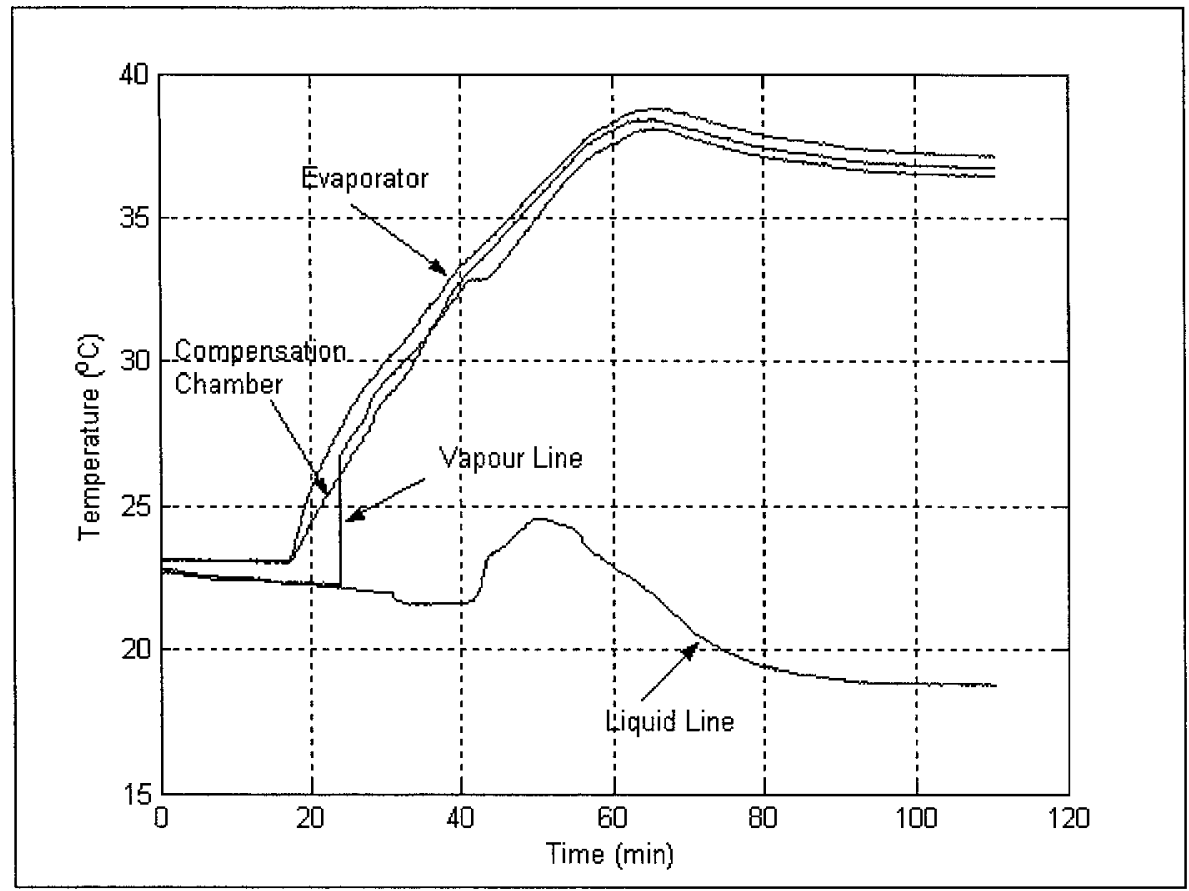

Figure 5-9: Temperature Profile for a 5 W Start-Up

In the second set of tests, power cycling was performed to analyze the ability of the LHP to handle sudden changes in applied heat load. Tests involved successive application of various heat loads with a sink temperature of $5{ }^{\circ} \mathrm{C}$. As discussed in the operating procedures, temperatures were allowed to reach steady state before applying a new power input to the evaporator. Figure 5-10 and Figure 5-11 show the temperature 
profiles of the test unit with respect to time during power cycling tests. These tests revealed that the LHP was able to sufficiently handle abrupt changes in the applied power without de-priming. Furthermore, no significant temperature overshoot was observed while cycling the power.

Additional testing was performed to investigate consistent LHP operation over time. These tests revealed significant degradation of loop performance, and after two weeks of thorough testing, the unit completely failed. As shown in Figure 5-12, start-up did not occur for a power input of $20 \mathrm{~W}$. The temperature of both the evaporator and compensation chamber increased rapidly and did not reach steady-state before the critical cut-off temperature of $75^{\circ} \mathrm{C}$. Further testing of the LHP was halted and the fluid inventory was discharged. Inspection of the wick revealed some minor damage to the outer layer of the material. As a result, a second LHP was manufactured and assembled with some minor modifications to the first design. 


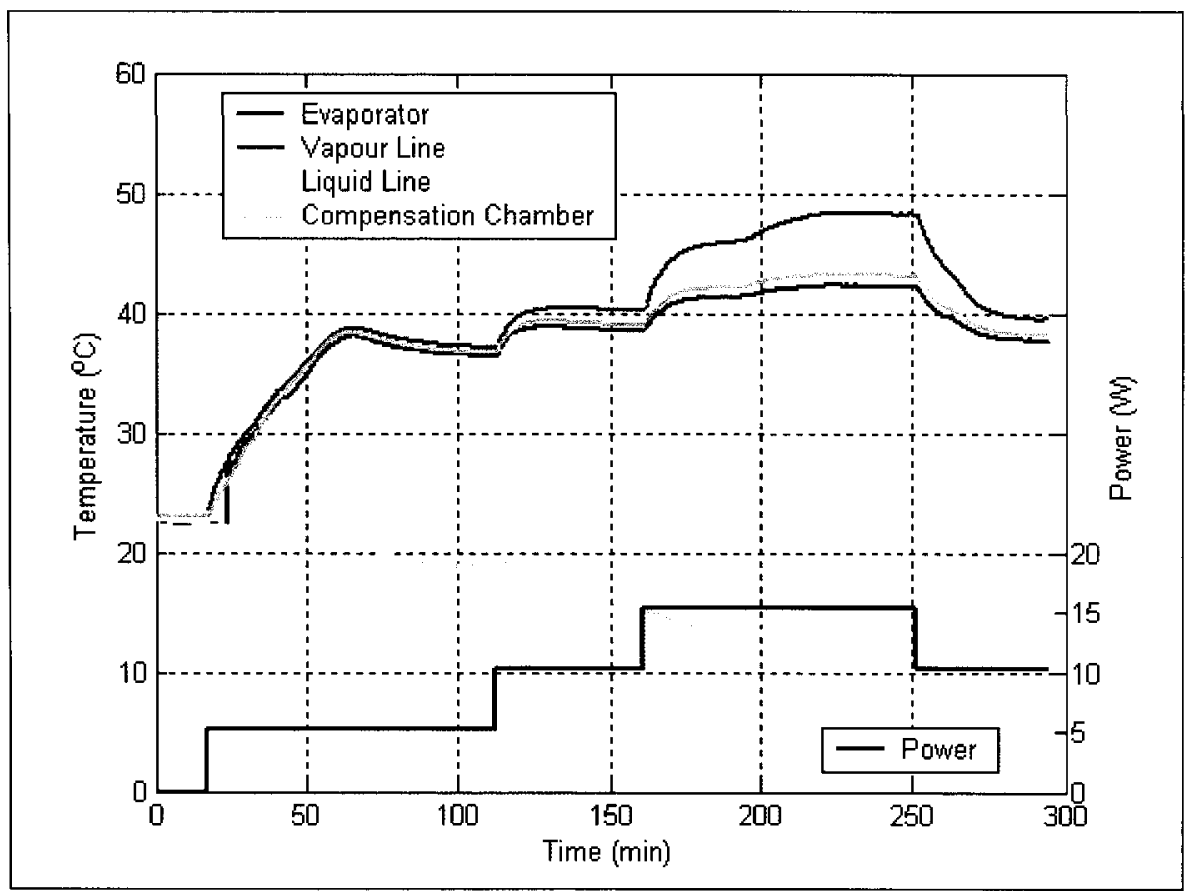

Figure 5-10: Power Cycling (5-10-15-10 W)

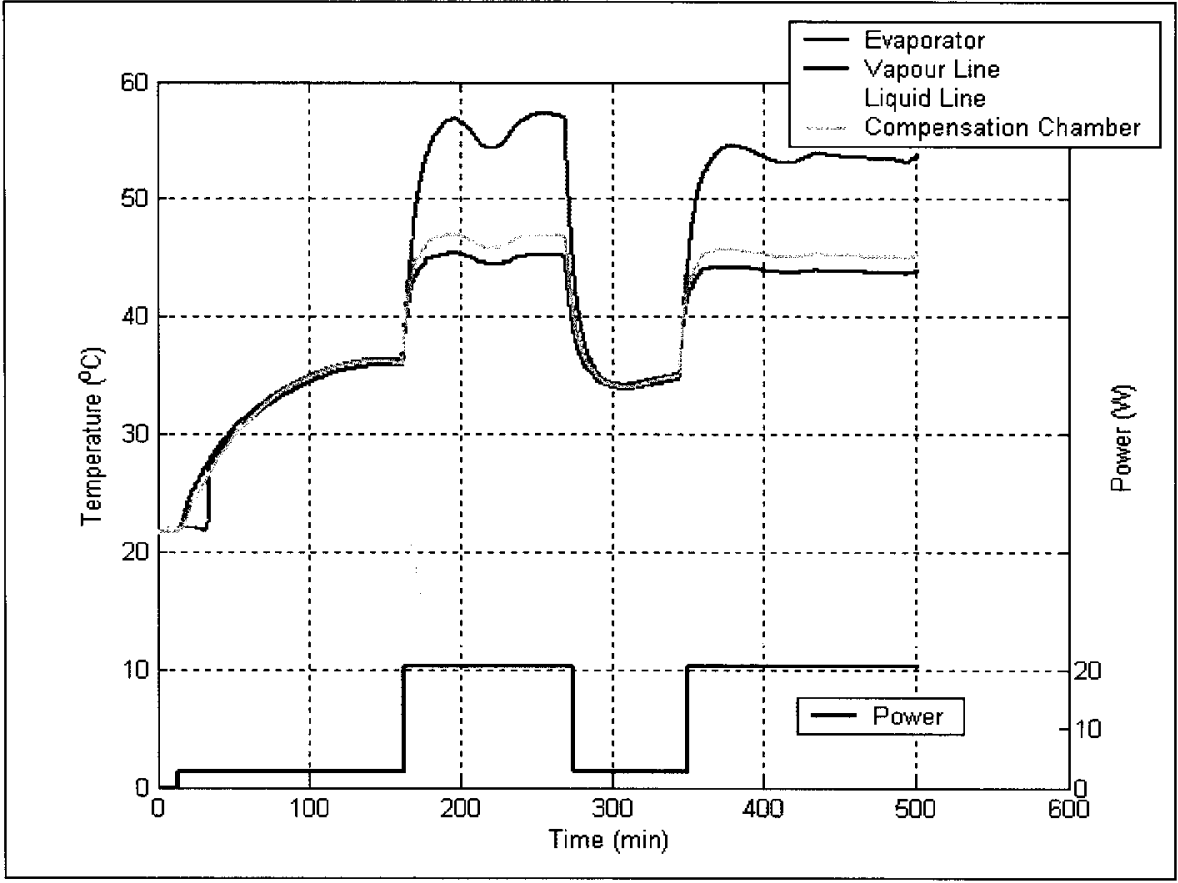

Figure 5-11: Power Cycling (2-20-2-20 W) 


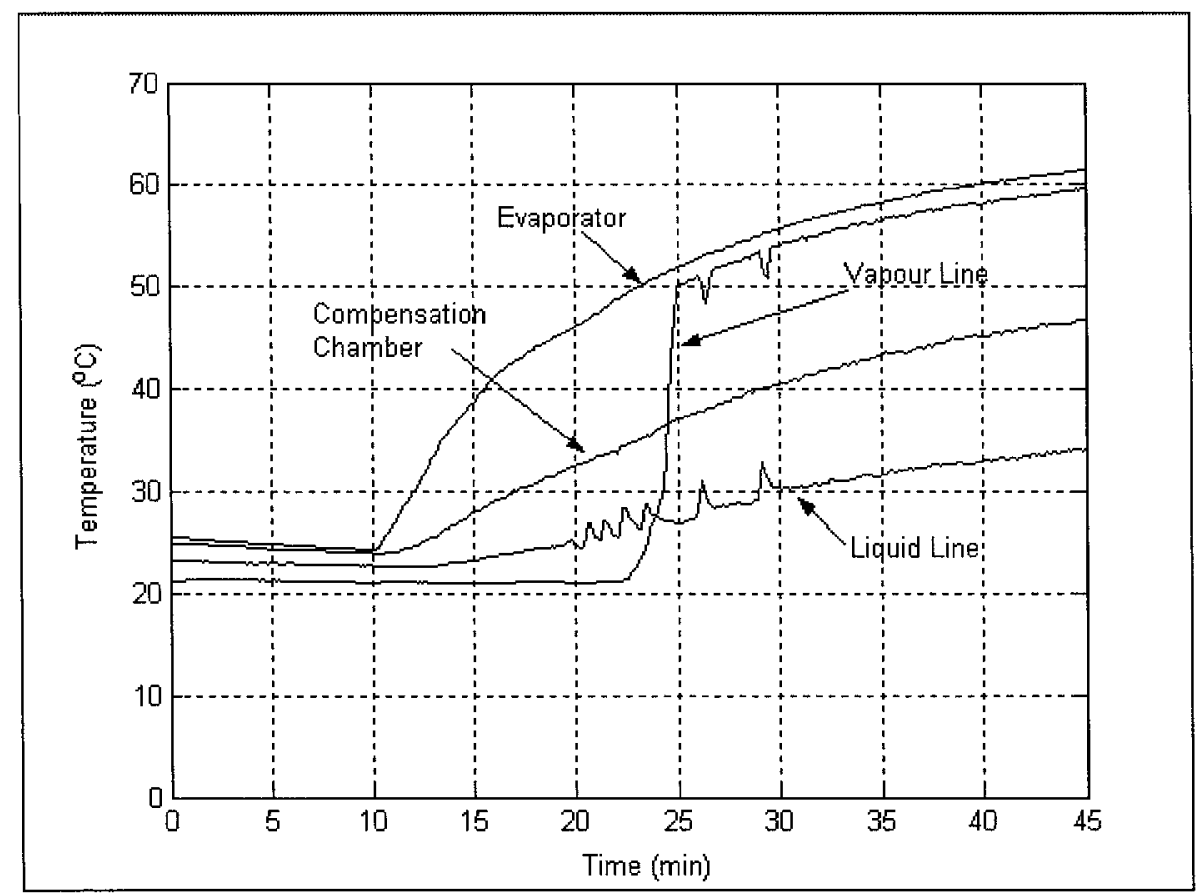

Figure 5-12: LHP Failure, 20 W Initial Input Power

\subsubsection{Test Apparatus \#2}

After reviewing the results from the first LHP, it was found that the length of the condenser limited the heat transfer capacity of the apparatus, thus also limiting the available power range for testing. Therefore, a more efficient condenser-heat exchanger interface was designed for the second LHP and is shown in Figure 4-11. This design greatly increases the heat transfer coefficient between the cooling fluid and the working fluid since the cooling fluid is in direct contact with the condenser thus minimizing the thermal resistance between the two fluids. To accommodate the new interface, the condenser was lengthened. Consequently, the length of the vapour line, liquid line, and evaporator were also slightly increased, as summarized in Table 3-2. In addition to the 
condenser-sink interface, the wick structure was also redesigned. The new wick extended $8 \mathrm{~cm}$ past the vapour grooves, spanning the length of the compensation chamber. The purpose of the new wick design was twofold: to maintain a consistent supply of working fluid to the primary wick even at high heat loads or adverse orientations thus maximizing LHP efficiency; to help reduce heat leak from the evaporator to the compensation chamber thus reducing the LHP operating temperature.

Similar to the previous device, the second LHP was initially tested to verify functionality. The primary goal was to clearly demonstrate loop start-up. Correspondingly, the unit was tested at power loads of $5,10,20,30$ and $40 \mathrm{~W}$. Unfortunately, as illustrated in Figure 5-13, no significant cooling in the liquid line was visible. In most cases, the temperature of the evaporator and compensation chamber did not reach steady-state before the maximum operating temperature of $75^{\circ} \mathrm{C}$. Steady-state temperatures were only achieved with power loads of less than $5 \mathrm{~W}$. However, these results were comparable to those derived from the baseline tests, suggesting that the dominant mode of heat transfer was conduction. The primary mechanism for operational failure was not immediately evident; it was therefore decided to revert to a design similar to the first LHP. The wick structure was replaced with a wick comprised of the same dimensions as the one used in the first test unit. Furthermore, the new condenser-sink interface was replaced with the saddle used on the first test unit. The overall dimensions of the LHP remained the same and the fluid inventory was adjusted accordingly. Subsequent tests to verify performance produced the same results, suggesting that 
operational failure was caused by a small leak in one of the lines at a Swagelok connection. A leak was confirmed through vacuum testing of the apparatus.

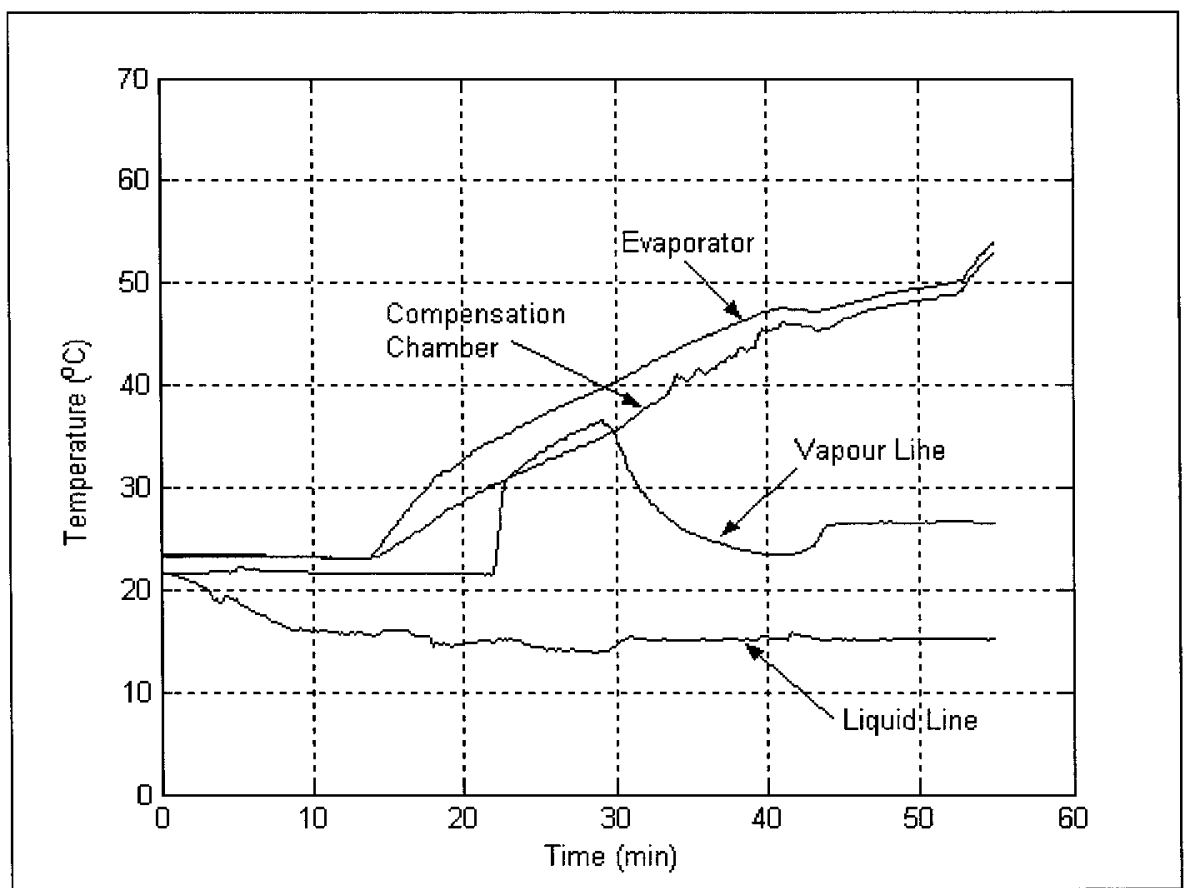

Figure 5-13: LHP Failure, 10 W Initial Input Power

\subsubsection{Test Apparatus \#3}

The third LHP was assembled using seamless stainless steel with higher tolerances to help protect against small leaks at the Swagelok connections. It was fabricated with similar physical properties to that of the first LHP, including the wick structure. Furthermore, the condenser-heat exchanger interface used in the first LHP was again used. A sub-cooler was added to the liquid line for additional heat transfer thus enabling testing throughout a wider range of applied powers. Figure 4-18 demonstrates the final design; component volumes are approximately the same as the first LHP. A summary of 
the dimensions and properties is provided in Table 3-2. Preliminary test results showed clear start-up at powers of $5,10,20,30$ and $40 \mathrm{~W}$. Continuous and stable operation was also observed over the same power range. The final LHP was therefore selected for the second phase of testing.

\subsection{Test Phase 2: Experimental Study of the Effect of Fluid Inventory on LHP Performance}

The primary objective of the second phase of testing was to determine the LHPs sensitivity to fluid charge. In particular, sensitivity studies were conducted to evaluate the effect of fluid inventory on LHP efficiency measured by start-up, steady-state operating temperature, maximum transport capacity, effective thermal resistance, and heat transfer coefficient. Based on the results obtained from the sensitivity studies, an optimal fluid charge was selected and used for the final phase of testing and analysis.

\subsubsection{Fluid Inventory}

In order to effectively study the impact of fluid inventory on loop performance, four fluid charges over a sufficient range were selected for analysis. Furthermore, to ensure test results were comparable, the overall LHP design and in particular the volume of the compensation chamber remained constant for all fluid charges. The compensation chamber volume and fluid charges were estimated using the alpha/beta approach described in Section 2.3.4. Each fluid charge corresponds to a specific void fraction in the compensation chamber, $\alpha$, for worst case hot conditions and a specific liquid-filled 
fraction in the compensation chamber, $\beta$, for worst case cold conditions. A summary of all four fluid inventories is provided in Table 5-1.

Table 5-1: Summary of Fluid Charges

\begin{tabular}{ccc}
\hline Fluid Inventory (g) & $\begin{array}{c}\text { Hot Case Void } \\
\text { Fraction, } \alpha\end{array}$ & $\begin{array}{c}\text { Cold Case Liquid-Filled } \\
\text { Fraction, } \beta\end{array}$ \\
\hline 28 & 0 & 0.7 \\
23 & 0.3 & 0.4 \\
20 & 0.5 & 0.2 \\
15 & 0.9 & 0 \\
\hline
\end{tabular}

\subsubsection{Start-Up}

The first set of tests was performed to study the effect of fluid inventory on LHP start-up. As previously discussed, start-up is characterized by the initialization of fluid circulation in the loop and is typically identified by a sudden rise in the vapour line temperature followed by a sudden drop in the liquid line temperature. Additionally, start-up can sometimes be identified by a sudden drop in temperature difference between the compensation chamber and evaporator. Start-up was attempted primarily for low power loads in the range of 2 to $20 \mathrm{~W}$ for all four fluid charges. An overview of the start-up results obtained for each fluid charge is presented below, followed by a comparative analysis of the experimental data.

\section{Fluid Inventory 1: $23 \mathrm{~g}$}

In each test, the LHP initially demonstrated characteristics of a typical start-up. Figure 5-1 illustrates a $20 \mathrm{~W}$ start-up. After 28 minutes of testing the vapour line experienced a 
sudden rise in temperature and continued to rise until its temperature was approximately equal to the temperature of the evaporator. Shortly thereafter, the liquid line experienced a slight drop in temperature, indicating circulation of the working fluid within the loop. However, its temperature was not sustained and began to rise at the same rate of the evaporator and compensation chamber. Power to the evaporator heater was subsequently turned off before the temperature of the evaporator rose above the maximum allowable temperature of the wick. Power to the heater was not returned until the temperature of the evaporator and compensation chamber dropped below $40{ }^{\circ} \mathrm{C}$. Interestingly, only after re-applying the power did the LHP temperatures reach steady-state. As shown in Figure $5-15$, the temperature of the evaporator quickly stabilized around $50{ }^{\circ} \mathrm{C}$ after re-applying $20 \mathrm{~W}$.

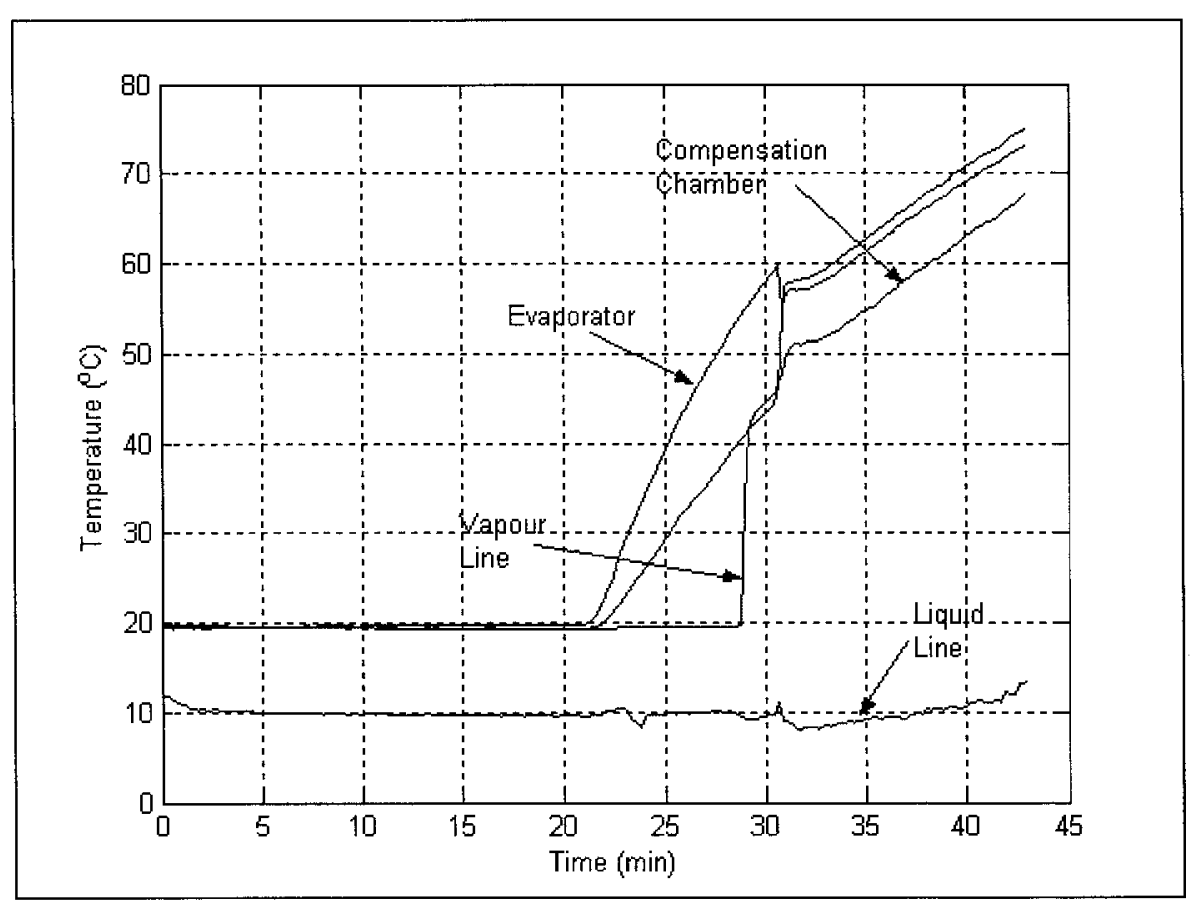

Figure 5-14: 20 W Start-Up, 24 g Fluid Inventory 


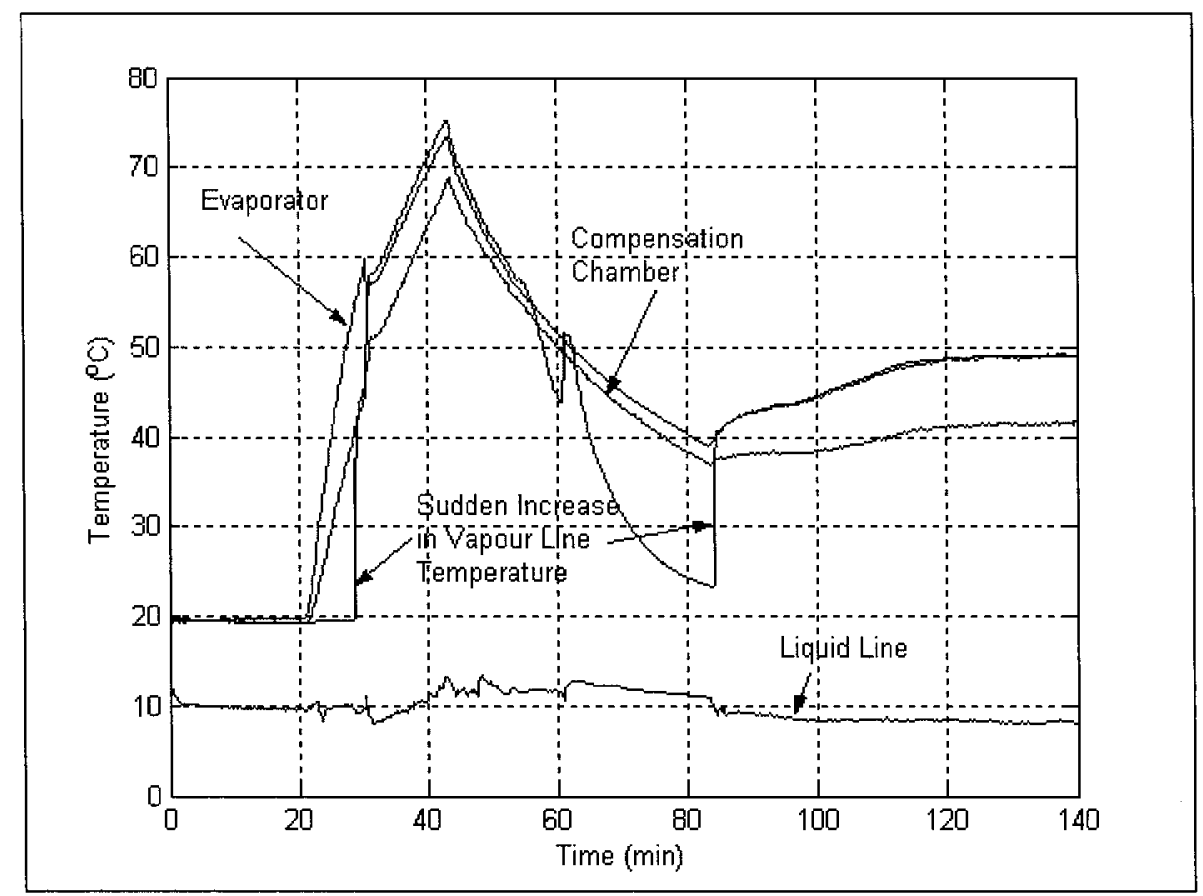

Figure 5-15: Temperature Profile for 20 W Start-Up, 24 g Fluid Inventory

\section{Fluid Inventory 2: $15 \mathrm{~g}$}

Similar results were obtained for a fluid inventory of $15 \mathrm{~g}$ for power loads of $10 \mathrm{~W}$ and greater. An example of a $20 \mathrm{~W}$ start-up is shown in Figure 5-16. For power loads of $5 \mathrm{~W}$ or less, the evaporator and compensation chamber temperature reached steady-state immediately following start-up, as shown in Figure 5-17. It is pointed out that in this example there was no visible subcooling in the liquid line. The temperature in the liquid line actually increases slightly and is slow to reach steady-state. At low powers, the mass flow rate is slow and the liquid has a longer residence time in the liquid line, resulting in parasitic heating from ambient and low subcooling. In comparison to the baseline results, 
the evaporator temperature is visibly cooler (approximately $5^{\circ} \mathrm{C}$ ) for the same power load. This suggests that there was some heat transfer due to fluid flow in the loop.

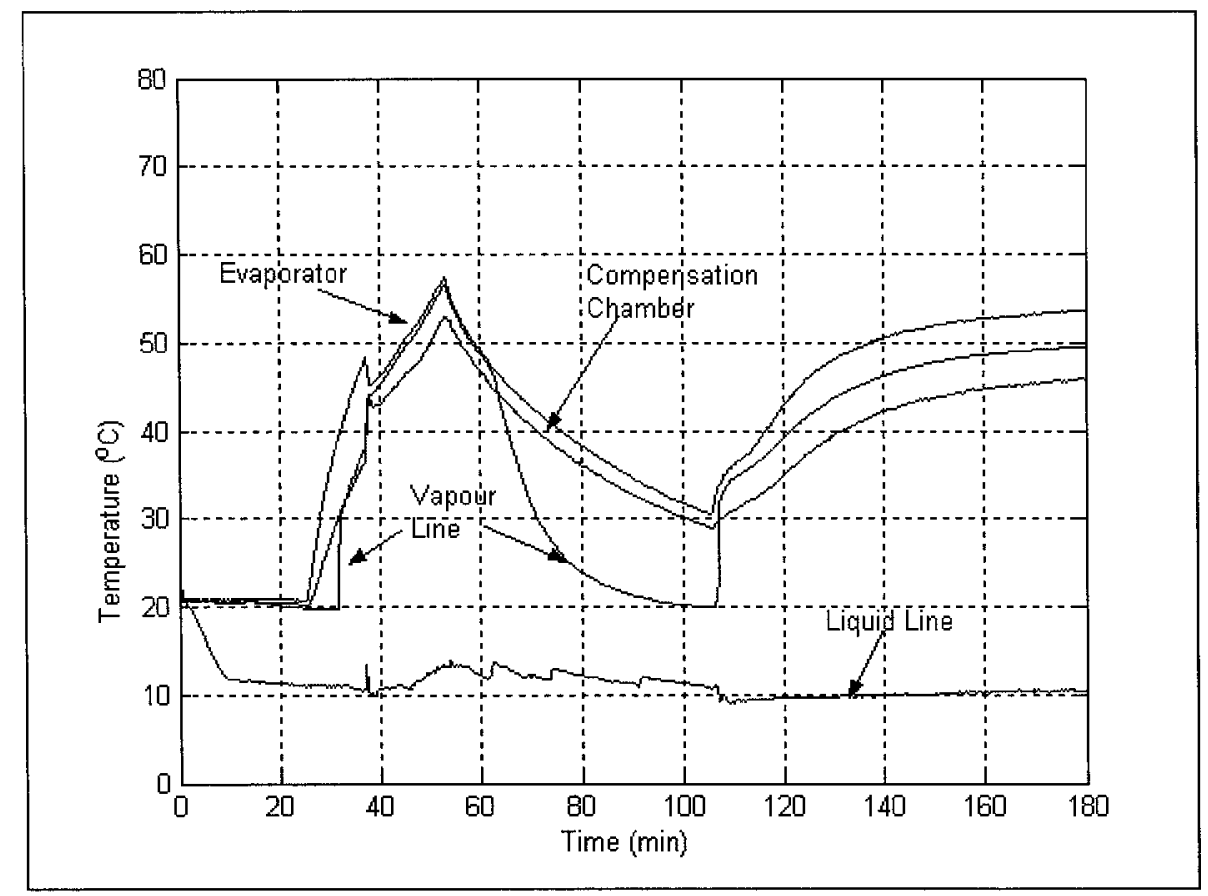

Figure 5-16: Temperature Profile for $20 \mathrm{~W}$ Start-Up, $15 \mathrm{~g}$ Fluid Inventory 


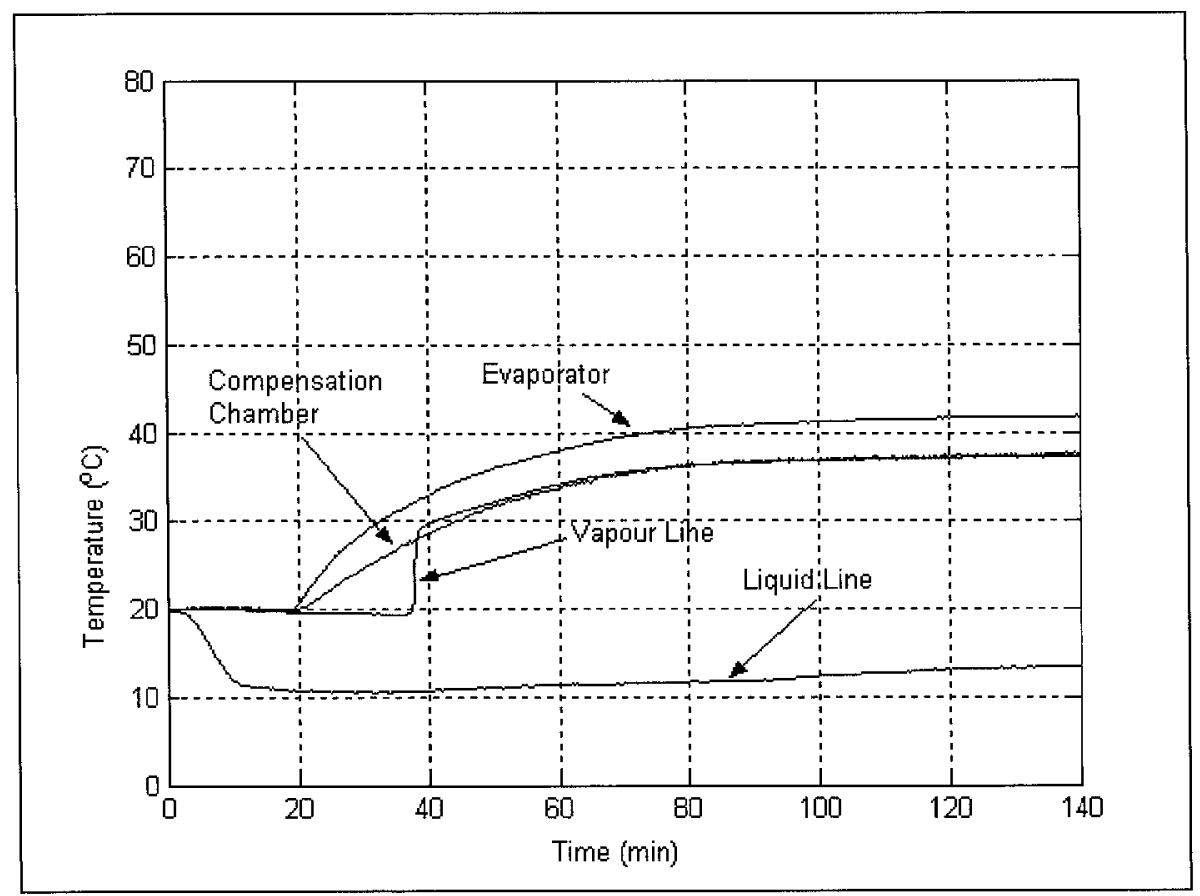

Figure 5-17: 5 W Start-Up, 15 g Fluid Inventory

\section{Fluid Inventory 3: $28 \mathrm{~g}$}

The third fluid charge tested produced more reliable and consistent results compared to the first two fluid charges. As shown in Figure 5-18 for a power input of $15 \mathrm{~W}$, steadystate temperatures were obtained immediately following start-up. An interesting result is that the temperature of the evaporator was consistently 5 to $10{ }^{\circ} \mathrm{C}$ higher than the vapour line and approximately 10 to $15^{\circ} \mathrm{C}$ higher than the compensation chamber. These results indicate a higher thermal resistance in the evaporator compared to previous tests. A higher thermal resistance in the evaporator is usually attributed to vapour bubbles in the wick structure. Trapped vapour bubbles in the wick can block some of the liquid return paths resulting in less cooling at the inner surface of the evaporator section. 


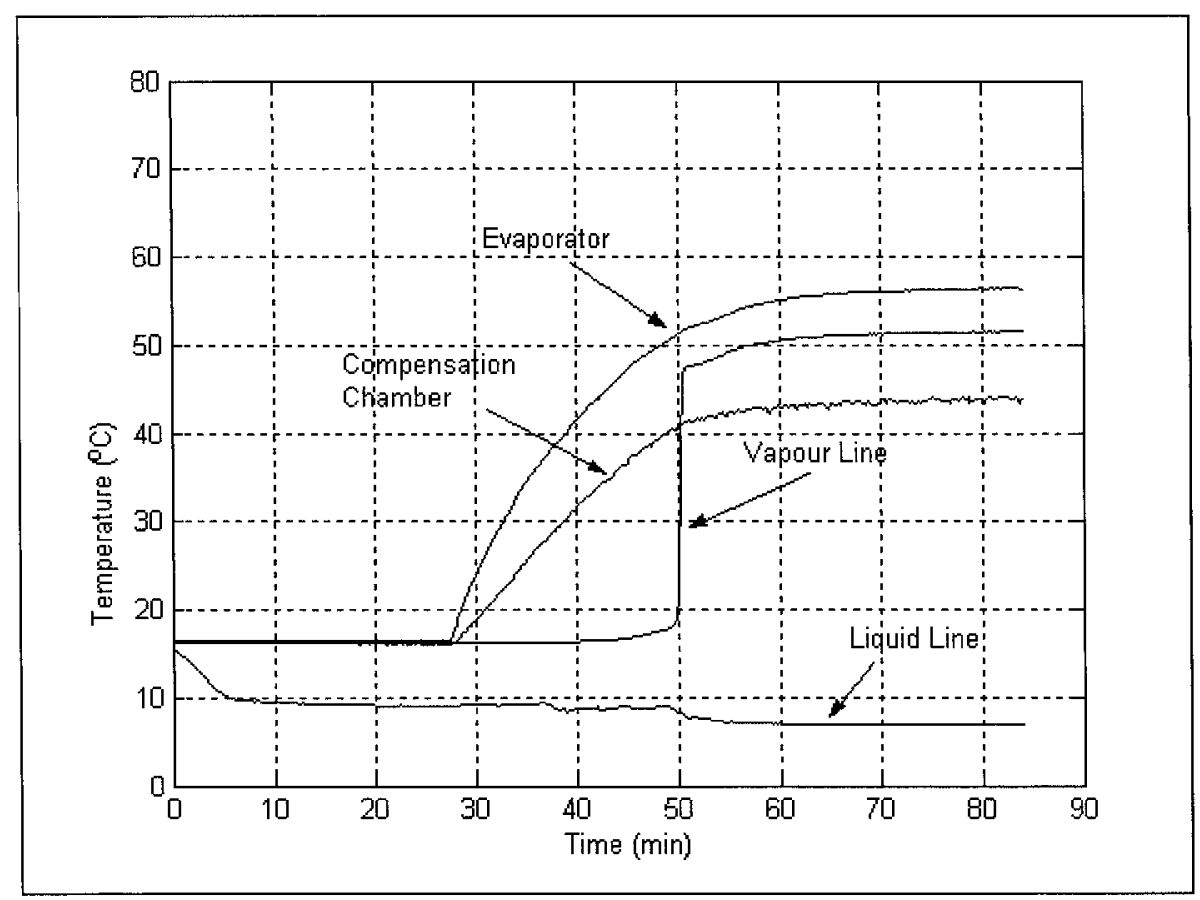

Figure 5-18: 15 W Start-Up, 28 g Fluid Inventory

\section{Fluid Inventory 4: $20 \mathrm{~g}$}

The final fluid charge tested produced the most reliable and consistent results for start-up. Fluid flow in both the vapour and liquid lines were clearly visible for a range of power loads from $5 \mathrm{~W}$ to $45 \mathrm{~W}$. Table $5-1$ provides a summary of the start-up tests conducted for a power range of 5 to $20 \mathrm{~W}$. It also includes the steady-state temperature of the evaporator after start-up. Figure 5-19 illustrates a typical $15 \mathrm{~W}$ start-up for a fluid inventory of $20 \mathrm{~g}$. 
Table 5-2: Summary of Start-up Results for a Fluid Charge of $20 \mathrm{~g}$

\begin{tabular}{ccccc}
\hline Applied Power $(\mathrm{W})$ & $\begin{array}{c}\text { Average Sink } \\
\text { Temperature } \\
\left({ }^{\circ} \mathrm{C}\right)\end{array}$ & $\begin{array}{c}\text { Average } \\
\text { Ambient } \\
\text { Temperature } \\
\left({ }^{\circ} \mathrm{C}\right)\end{array}$ & $\begin{array}{c}\text { Time to Start-up } \\
(\mathrm{hr}: \text { min:s) }\end{array}$ & $\begin{array}{c}\mathrm{T}_{\text {max }} \text { of } \\
\text { Evaporator } \\
\text { Block }\left({ }^{\circ} \mathrm{C}\right)\end{array}$ \\
\hline \hline 5 & 5.2 & 18.3 & $0: 24: 36$ & 44.8 \\
10 & 5.5 & 19.0 & $0: 19: 11$ & 45.3 \\
15 & 5.3 & 18.1 & $0: 10: 06$ & 48.5 \\
20 & 5.0 & 18.5 & $0: 04: 54$ & 50.1 \\
\hline
\end{tabular}

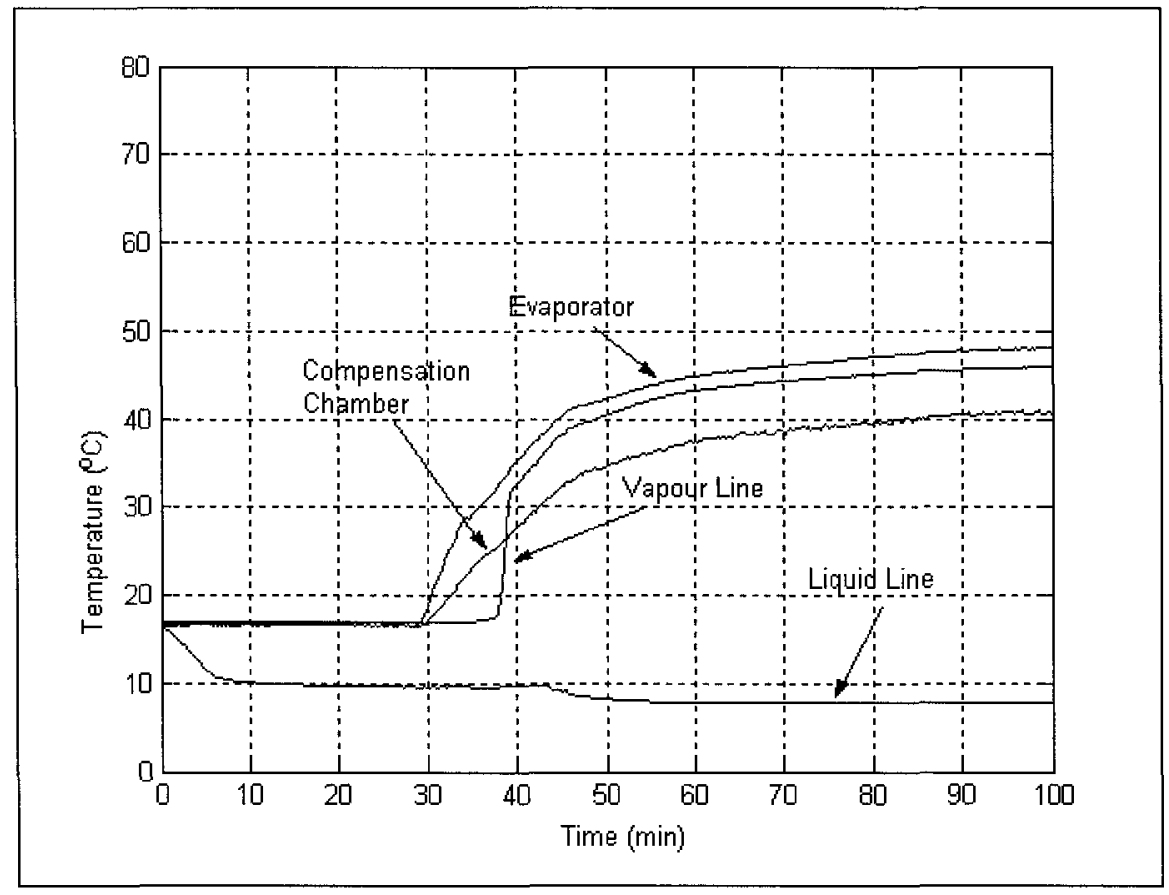

Figure 5-19: 15 W Start-Up, 20 g Fluid Inventory

\section{Analysis of Experimental Data}

LHP start-up represents one of the most complex transient phenomenons in LHP operation. Start-up is a function of evaporator and compensation chamber construction, 
and is not only dependent on fluid inventory but also on initial conditions inside the evaporator core and wick, as well as operation immediately prior to start-up. To that end, a strong effort was made to keep the initial states of the fluid within the loop as similar as possible between tests by following the same procedure and setup, as described in Section 5.3. It is however difficult to completely control the states of the fluid in each section of the LHP prior to start-up, and is taken into account when examining the data.

The results of the first two fluid charges show a high degree of instability within the loop during start-up as vapour begins to flow through the vapour line. Figure 5-15 and Figure 5-16 both indicate that shortly after vapour begins to flow through the vapour line, the evaporator experiences a sudden cooling effect of 2 to $3^{\circ} \mathrm{C}$ from cool liquid arriving from the liquid line. At the same time, the liquid line experiences a similar cooling effect due to liquid being pushed from the condenser. However, the cooling effect is not sustained and temperatures of all components then begin to rise. Steady-state temperatures were only achieved by re-applying power after allowing the system to cool below a temperature of $40^{\circ} \mathrm{C}$. It is possible that such characteristics may be a result of a large temperature overshoot caused by vapour phase in the evaporator core, liquid phase in the vapour line, or both. If the vapour line is flooded with liquid, a relatively large superheat is required to initiate nucleate boiling and displace the liquid in the grooves. If on the other hand, there is a significant amount of vapour in the evaporator core, the temperature of the evaporator and compensation chamber will rise until cold liquid from the condenser can compensate for the increased heat leak. Another possible explanation 
is that vapour blockage in the pores of the wick may be limiting the available area of vaporization. This would not only increase the effective thermal resistance of the system but also reduce the flow of vapour in the vapour line and mass flow rate of fluid in the system. A reduced mass flow rate would result in less subcooling, which is necessary for offsetting the heat leak from the evaporator to the compensation chamber. This in turn would increase the LHP operation temperature beyond the maximum allowable temperature. The results of the last two fluid charges $(20 \mathrm{~g}, 28 \mathrm{~g})$ produced more reliable and consistent results in comparison to the first two fluid charges $(15 \mathrm{~g}, 23 \mathrm{~g})$. A fluid charge of $28 \mathrm{~g}$ indicated some degree of vapour blockage in the wick since the temperature of the evaporator was relatively high in comparison to the temperature of the vapour line and compensation chamber over the entire range of applied power. However, there was still sufficient fluid flow in the loop to provide the necessary amount of subcooling to achieve steady-state temperatures. A fluid charge of $20 \mathrm{~g}$ appeared to produce the most desirable results. No significant temperature overshoot was observed and generally, steady-state temperatures immediately after start-up appeared to be lower compared to the other fluid charges. The only significant difference found between each fluid charge was the time required for initiation of circulation of the fluid. For example, it took approximately 10 minutes from the time power was turned on $(15 \mathrm{~W})$ to circulation within the loop for a fluid charge of $20 \mathrm{~g}$. In comparison, circulation of fluid in the loop was initiated 22 minutes after applying the same power for a fluid charge of 28 g. In general, it was found that start-up times were shorter for smaller fluid 
inventories. A summary of start-up times for three of the four fluid charges is provided in Table 5-3. It is suggested that start-up times are reduced because a smaller mass flow rate is required to displace liquid within the lines since there is less liquid to displace for smaller fluid inventories.

Table 5-3: Summary of Start-up Times

\begin{tabular}{ccccc}
\hline \multirow{2}{*}{ Applied Power (W) } & $\begin{array}{c}\text { 15 g, Start-up } \\
\text { Time (hr:min:s) }\end{array}$ & $\begin{array}{c}\text { 20 g, Start-up } \\
\text { Time (hr:min:s) }\end{array}$ & $\begin{array}{c}\text { 23 g, Start-up } \\
\text { Time (hr:min:s) }\end{array}$ & $\begin{array}{c}\text { 28 g, Start-up } \\
\text { Time (hr:min:s) }\end{array}$ \\
\hline \hline 5 & $0: 17: 36$ & $0: 24: 36$ & $0: 25: 17$ & $2: 20: 27$ \\
10 & $0: 15: 17$ & $0: 19: 11$ & $0: 24: 24$ & $0: 52: 00$ \\
15 & $0: 07: 48$ & $0: 10: 06$ & $0: 02: 12$ & $0: 22: 49$ \\
20 & $0: 06: 02$ & $0: 04: 54$ & $0: 09: 00$ & $0: 10: 28$ \\
\hline
\end{tabular}

In general, the effect of fluid inventory does not appear to be a dominant factor for start-up. The state of the working fluid within the system and wick just prior to start-up appears to have a much greater impact. However, it is noted that the amount of working fluid can impact the amount of superheating or time required before start-up, since less fluid will typically result in less liquid collection within the vapour grooves at any given time. As will be discussed in the following section, fluid inventory has a much greater impact on the steady-state operating temperature and maximum heat transfer of the LHP.

\subsubsection{Steady-State Operating Temperatures}

After LHP startup was observed, power cycling tests were employed to study the effect of fluid inventory on LHP operational stability, by handling changes in heat loads. Tests involved successive application of increasing heat loads while maintaining a constant sink temperature of $5^{\circ} \mathrm{C}$. As discussed in the operating procedures, temperatures were 
allowed to reach steady state before each increase in power. Steady-state was defined as a temperature change of no more than $0.5^{\circ} \mathrm{C}$ over a period of at least 20 minutes. Figure 5-20 and Figure 5-21 illustrate the temperature profiles obtained during power cycling tests for fluid charges of $20 \mathrm{~g}$ and $23 \mathrm{~g}$ respectively. For each fluid charge, stable operation was obtained between $10 \mathrm{~W}$ and $50 \mathrm{~W}$ without de-priming or significant temperature overshoot. Both curves indicate that the operating temperature increases with input power in an approximate linear relationship, suggesting that the LHP was operating in constant conductance mode for both cases. As will be shown, the other two fluid charges presented similar results, but in a much narrower power range.

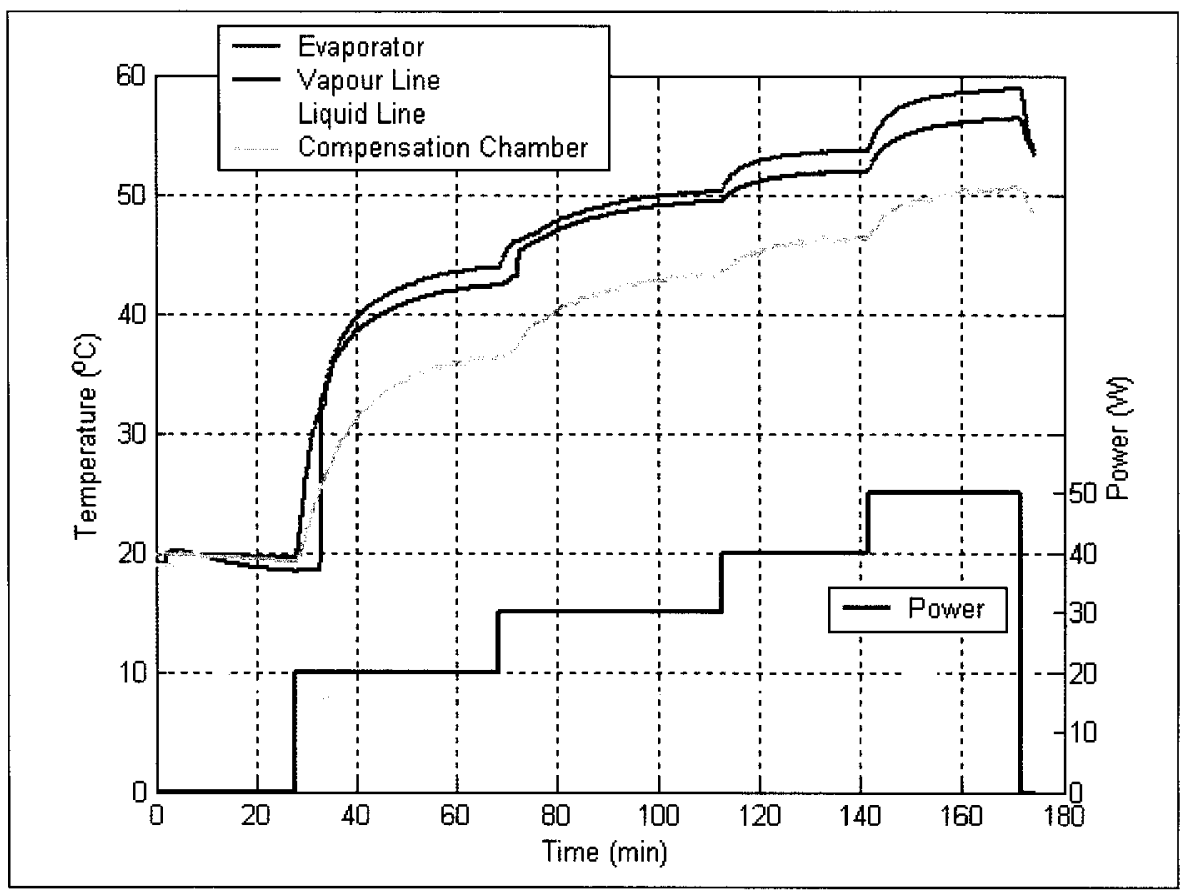

Figure 5-20: Temperature Profile during Power Cycling Tests for 20 g Fluid Inventory 


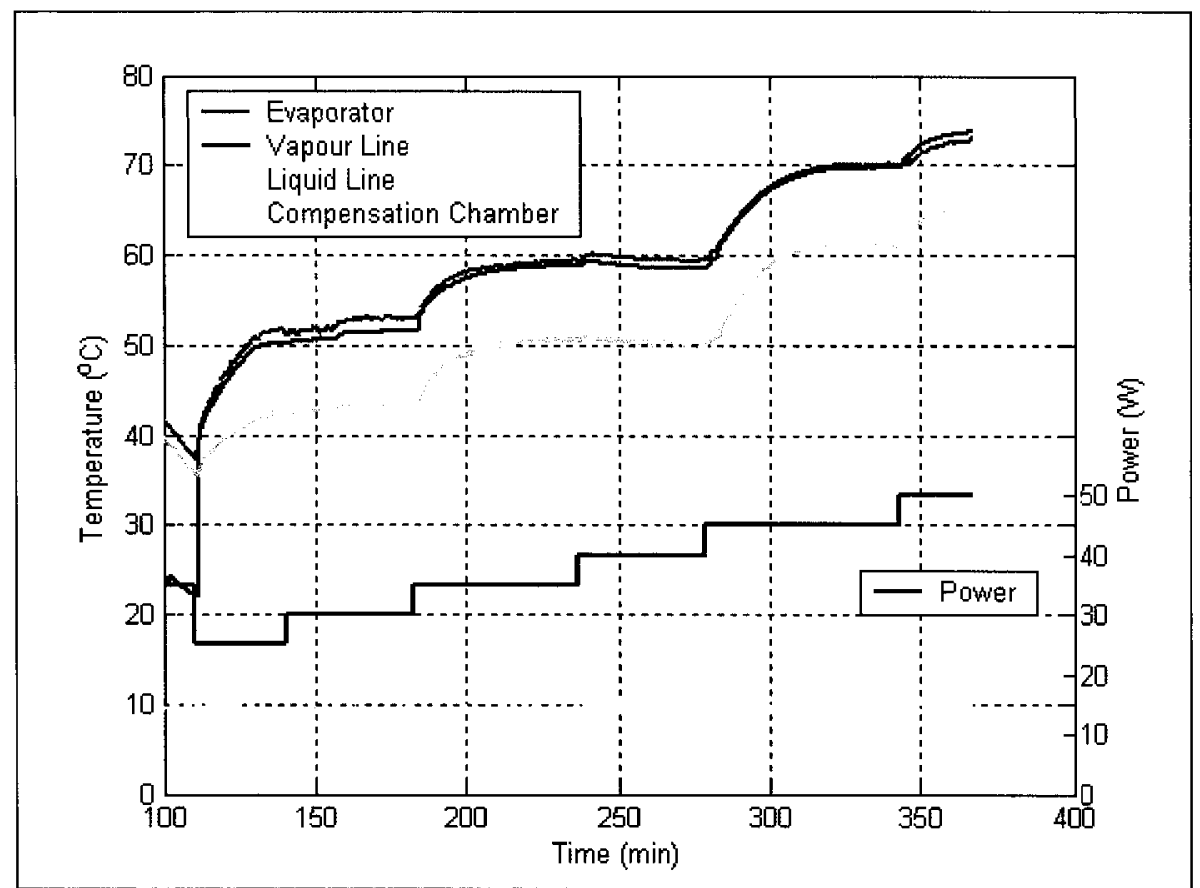

Figure 5-21: Temperature Profile during Power Cycling Tests for 23 g Fluid Inventory

Additional power cycling tests were used to generate performance curves for each fluid charge. The resulting performance curve for each fluid charge is shown in Figure 5-22. The results represent the average steady-state temperature of the evaporator at each power load. Figure 5-22 illustrates that LHP operation is very sensitive to fluid charge. It was observed that steady-state operating temperature and maximum/minimum heat transfer capacity of the LHP varied significantly between the highest and lowest charges $(15 \mathrm{~g}, 28 \mathrm{~g})$ and the nominal charges $(20 \mathrm{~g}, 23 \mathrm{~g})$. The LHP demonstrated successful operation between an applied power of $10 \mathrm{~W}$ and $50 \mathrm{~W}$ for fluid charges of $20 \mathrm{~g}$ and 23 g. In comparison, the LHP demonstrated successful operation between a much narrower power range of $5 \mathrm{~W}$ and $20 \mathrm{~W}$ for fluid charges of $15 \mathrm{~g}$ and $28 \mathrm{~g}$. 


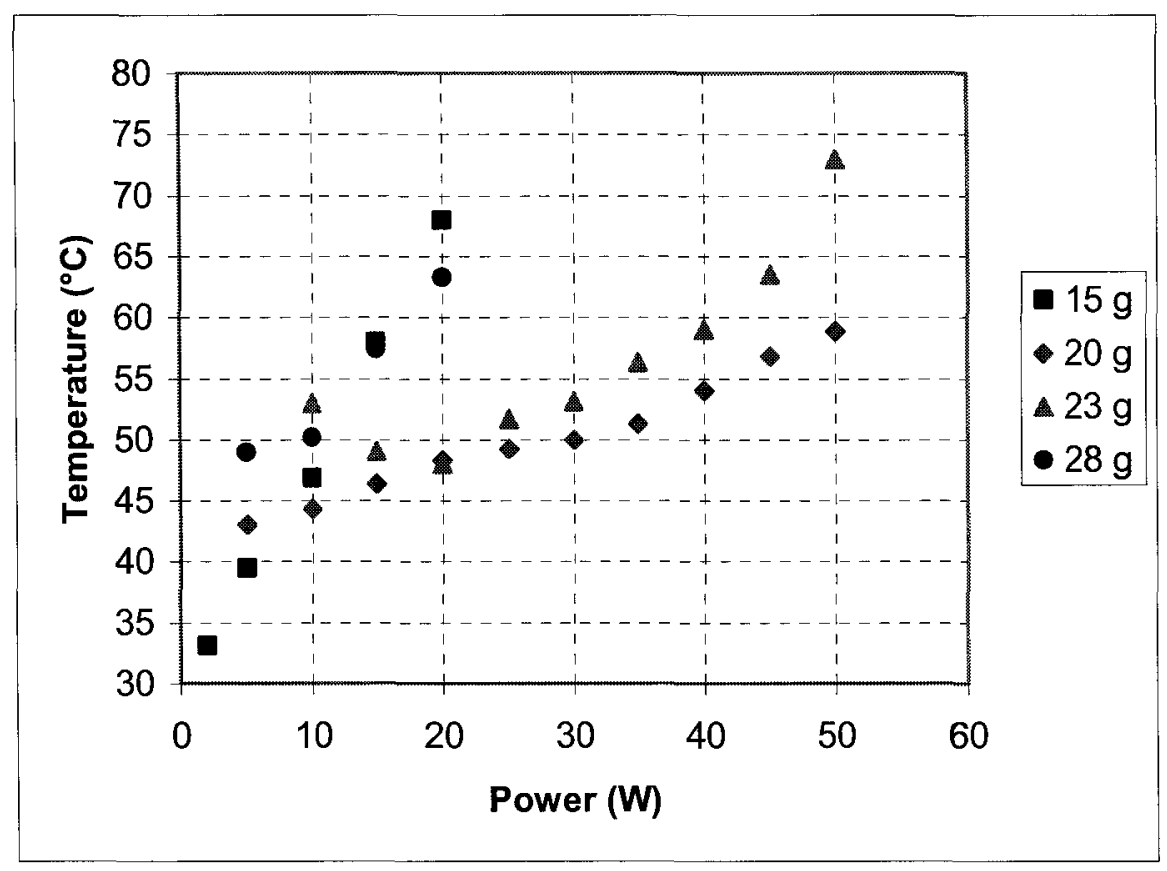

Figure 5-22: Performance Curve for each Fluid Inventory

The specified power range indicates the maximum and minimum heat transfer capacity of the LHP for each fluid charge. The heat transfer capacity was considered to reach a maximum if the temperature at the evaporator surface began to exceed the maximum allowable temperature of the wick $\left(>75^{\circ} \mathrm{C}\right)$. The minimum power required to sustain stable operation yielded the minimum heat transfer capacity of the LHP. An interesting feature of Figure 5-22 is that the smallest fluid charge of $15 \mathrm{~g}$ results in the lowest steadystate operating temperature at low heat loads. Specifically, the LHP operated almost 10 ${ }^{\circ} \mathrm{C}$ cooler compared to a fluid charge of $28 \mathrm{~g}$ for a power input of $5 \mathrm{~W}$. Furthermore, it was the only fluid charge to successfully start-up and sustain loop operation at $2 \mathrm{~W}$. However, tests also revealed that the maximum heat transfer for this particular charge was limited to $20 \mathrm{~W}$. Overall, a lower fluid charge of $15 \mathrm{~g}$ results in a very steep 
performance curve for this particular design, where start-up is easily initiated at low powers because of less liquid to displace, and is also susceptible to early dry-out at high powers due to insufficient subcooling. Similar results were obtained for a fluid charge of $28 \mathrm{~g}$. In this case, however, a relatively low maximum heat transfer is not the result of wick dry-out. Instead, a large fluid inventory may result in hard-filling the reservoir. In general, the vapour-liquid interface moves towards the end of the condenser to provide the required subcooling at high heat loads. For this particular design, a subcooler was added to the liquid line since the available area for heat transfer in the condenser was relatively small. Therefore, at high heat loads, the vapour-liquid interface may move into the liquid line to provide sufficient cooling. When this happens, the liquid from the condenser and part of the liquid line is displaced into the compensation chamber. If the vapour-liquid interface moves too far into the liquid line, the compensation chamber will become hard-filled and block the flow of cool liquid. Consequently, the liquid inside the compensation chamber will stagnate and increase in temperature due to parasitic heating. Heat leak from the evaporator to the compensation chamber will then dominate, causing the operating temperature of the LHP to increase. The most effective fluid charge for this particular design was found to be $20 \mathrm{~g}$. With a fluid inventory of $20 \mathrm{~g}$, the LHP demonstrated successful operation between a power range of 5 and $50 \mathrm{~W}$. Even at a power load of $50 \mathrm{~W}$, the resulting operating temperature of $58{ }^{\circ} \mathrm{C}$ was well below the critical cut-off temperature, indicating that the LHP was capable of handling higher heat loads. Similar results were obtained for a fluid charge of $23 \mathrm{~g}$, however, the performance 
curve increased at a much faster rate for applied heat loads higher than $20 \mathrm{~W}$. At an applied load of $50 \mathrm{~W}$, the temperature difference between the two curves was almost 15 ${ }^{\circ} \mathrm{C}$. The difference in temperatures may lie in the difference between start-up characteristics for each charge. If vapour bubbles are still present in the wick after startup, then the operating temperature of the LHP may increase for the same applied power. For a fluid charge of $23 \mathrm{~g}$, it is also possible that similar conditions to those found for a fluid charge of $28 \mathrm{~g}$ may be present in the compensation chamber at high heat loads.

\subsubsection{Effective Thermal Resistance}

LHP efficiency can also be examined in terms of effective thermal resistance. The effective thermal resistance of an LHP is a function of the steady-state temperature of the evaporator and condenser and is defined as:

$$
R_{e f f}=\frac{\Delta T}{Q}=\frac{T_{e}-T_{c o n d}}{Q_{e}}
$$

Figure 5-23 demonstrates the effective thermal resistance of the LHP for each fluid inventory, based on the results obtained from power cycling. It should be noted that the average temperature of the evaporator and condenser was used for calculating the thermal resistance. The evaporator thermocouple was situated at the centre of the evaporator while the condenser thermocouple was situated near the condenser exit. In general, this assumption is more accurate when the condenser is completely utilized and the average temperature approaches the liquid temperature at the condenser exit (Maidanik et al., 2005). 


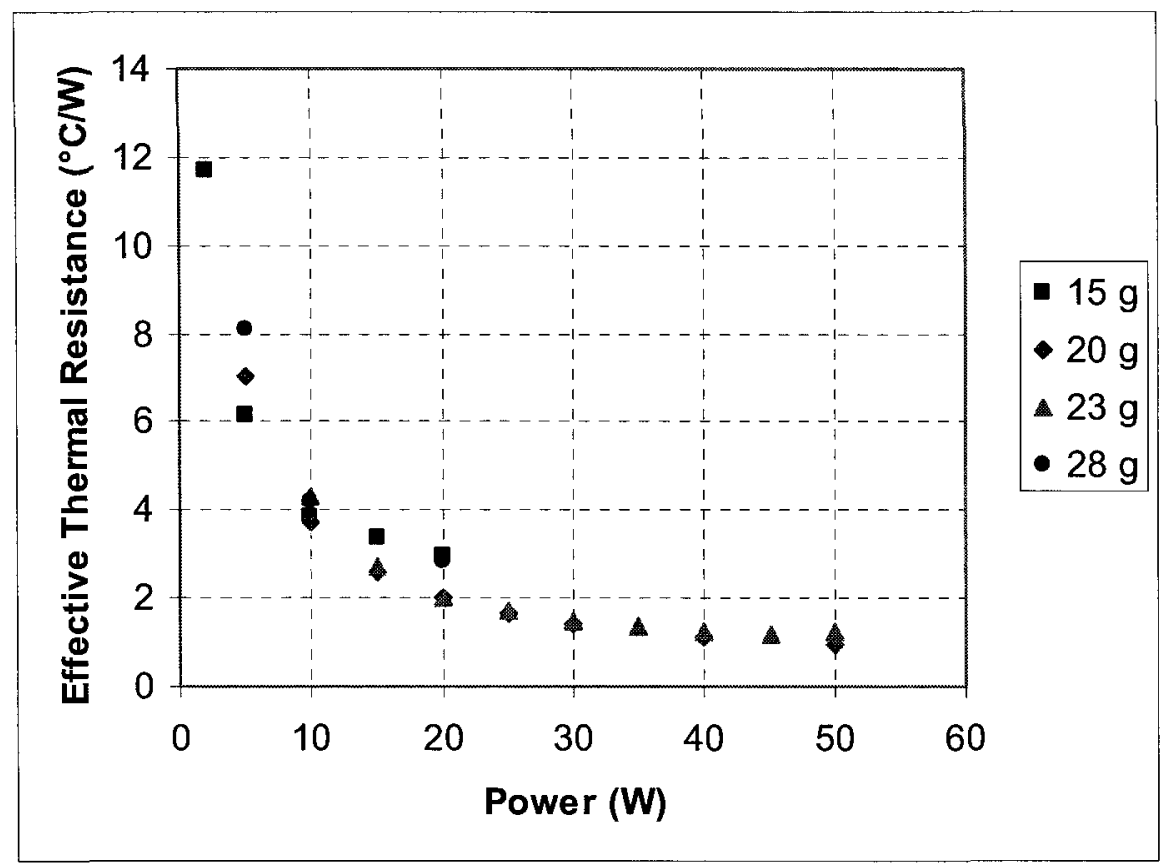

Figure 5-23: Effective Thermal Resistance for each Fluid Inventory

The data indicates that the effective thermal resistance decreases as the heat load to the evaporator increases. As expected, the minimum thermal resistance observed during testing occurred for a fluid charge of $20 \mathrm{~g}$ and was approximately $0.951{ }^{\circ} \mathrm{C} / \mathrm{W}$. Variations in LHP thermal resistance between each fluid charge were a result of differences in the evaporator thermal resistance. The thermal resistance of a LHP can also be defined in terms of the heat transfer coefficient and the active surface area as follows:

$$
\mathrm{R}_{e f f}=\frac{1}{\alpha_{e} S_{e}}+\frac{1}{\alpha_{c} S_{\text {cond }}}
$$

where:

$\alpha_{e} \quad$ is the heat transfer coefficient of the evaporator 
$\alpha_{\text {cond }} \quad$ is the heat transfer coefficient of the condenser

$\mathrm{S}_{\mathrm{e}} \quad$ is the active area of the evaporator

$\mathrm{S}_{\mathrm{cond}} \quad$ is the active surface of the condenser

The first component determines the thermal resistance of the evaporator while the second component determines the thermal resistance of the condenser. In general, the active surface area of the condenser and heat transfer during condensation is quite large in comparison to the evaporator. As such, the condenser term in Eq. (5.2) has minimal impact on the effective thermal resistance of a LHP. It therefore becomes clear that in order to decrease the effective thermal resistance, the heat exchange in the evaporator must be maximized. That means that in cases where there is wick dry-out or the compensation chamber is hard-filled, the total thermal resistance of the system will increase. This is evident at high heat loads for fluid charges of 15 and $28 \mathrm{~g}$.

\subsubsection{Heat Transfer Coefficient}

The heat transfer coefficient in the evaporator is another useful characteristic to help quantify efficiency of a LHP. The heat transfer coefficient is calculated as follows:

$$
\alpha_{e}=\frac{Q_{e}}{S_{e} \Delta T_{e}}
$$

where $\Delta T_{e}=T_{e}-T_{v_{\text {intet }}}$ is the temperature difference between the evaporator and the vapour line inlet, and $S_{e}$ is the active evaporator area. Ideally, the temperature of the evaporator should be measured at the inner wall surface of the casing. However, since it is difficult to position thermocouples on the inner surface of the evaporator, the external 
wall temperature was used instead. Figure 5-24 illustrates the heat transfer coefficient for each fluid charge. As expected, the heat transfer coefficient increases with increasing power, based on Eq. (5.3). An interesting feature is that the heat transfer coefficient experiences an abrupt change as the LHP approaches its critical operating temperature. For example, the heat transfer coefficient is reduced from 261 to $248 \mathrm{~W} / \mathrm{m}^{2} \mathrm{~K}$ as the applied power is increased from 45 to $50 \mathrm{~W}$ for a fluid charge of $23 \mathrm{~g}$. Similar results were observed for fluid charges of 15 and $28 \mathrm{~g}$. These results suggest that the evaporator experienced a sudden increase in thermal resistance for three of the four charges as each approached the maximum cut-off temperature. This also suggests that the LHP was not tested to its full potential with a fluid charge of $20 \mathrm{~g}$.

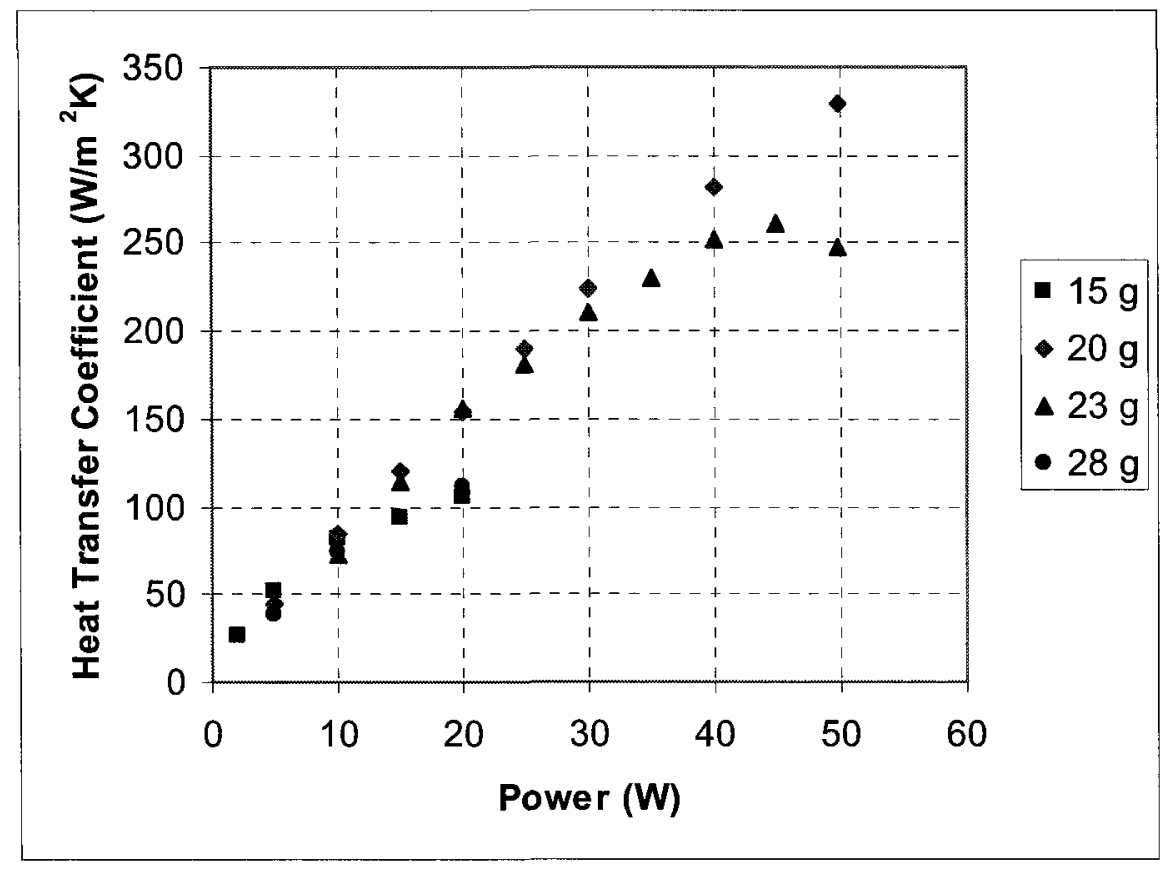

Figure 5-24: Heat Transfer Coefficient for each Fluid Inventory 


\subsection{Test Phase 3: Experimental Study of LHP Operating Characteristics}

For the current LHP design, a fluid charge of $20 \mathrm{~g}$ produced the best all around and consistent results during the second phase of testing. As a result, a fluid charge of $20 \mathrm{~g}$ was selected for the final phase of testing. The primary objective of the final phase of testing was to study the effect of elevation and periodic heating on LHP performance. Additionally, tests were conducted to investigate the possibility of temperature hysteresis.

\subsubsection{Effect of Elevation}

The effect of elevation on LHP performance was studied for four configurations: $5^{\circ}$ positive elevation, no elevation, $5^{\circ}$ degree adverse elevation, $10^{\circ}$ adverse elevation. Elevation refers to the position of the evaporator with respect to the condenser. An adverse elevation means the evaporator is positioned above the condenser while a positive elevation means the evaporator is positioned below the condenser. The steadystate operating temperature profiles for all four elevations are shown in Figure 5-25. 


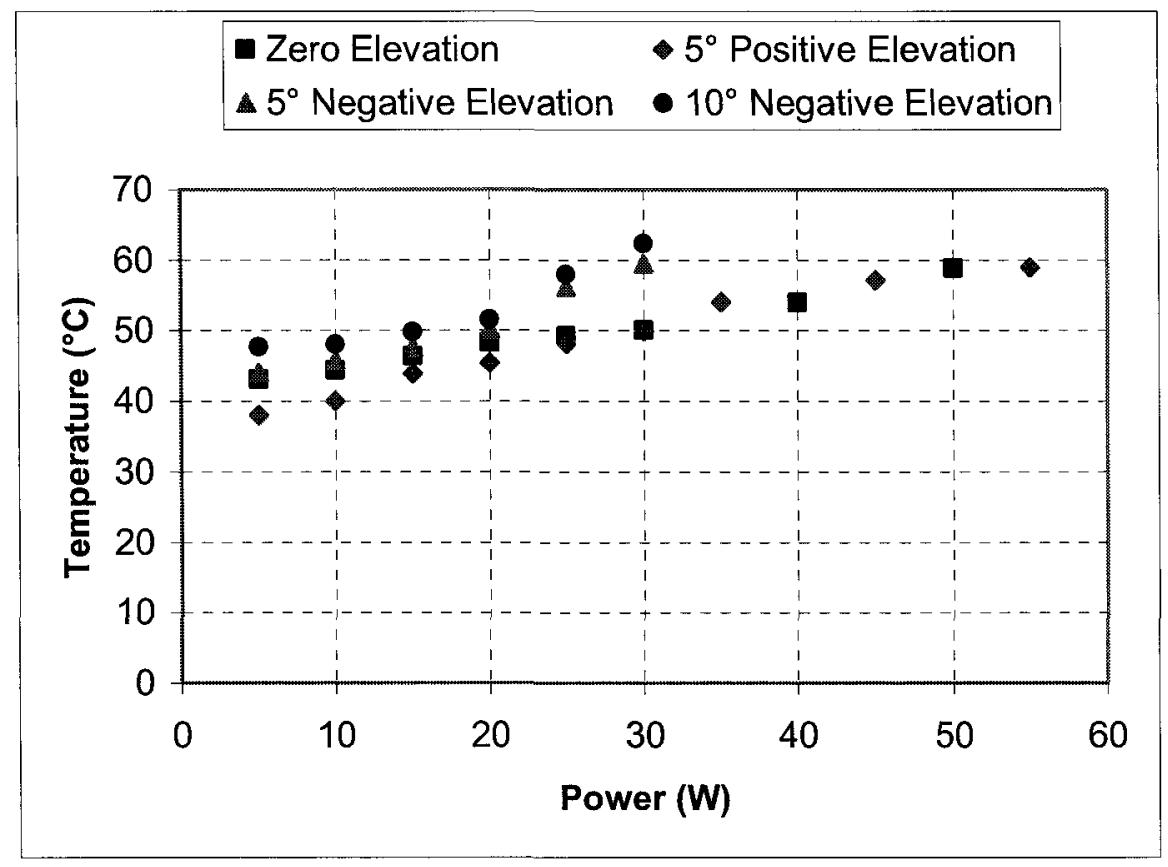

Figure 5-25: Effect of Elevation on Steady-State Operating Temperatures

The overall trend of the data suggests that elevation has a significant influence on performance at low powers. Figure 5-25 shows that steady-state temperatures increased with increasing adverse elevation, up to an applied power of $20 \mathrm{~W}$. The increase in temperature can be explained as follows. As the pressure difference across the wick increases due to gravity head, the difference in saturation temperatures must also increase, as required by Eq. (2.7). Since the liquid enthalpy entering the compensation chamber does not change, an increase in evaporator vapour temperature must occur to satisfy the increasing pressure drop. An increase in evaporator temperature leads to a higher heat leak which in turn increases the operating temperature of the LHP. Therefore, higher adverse elevations result in an increase in heat leak which must be compensated for by an increase in steady-state operating temperature for low heat loads. 
At higher heat loads, heat leak is compensated for by an increase in liquid subcooling, $m C_{p} \Delta T$, through an increase in mass flow rate. Thus, at higher heat loads, gravitational pressure losses have an almost negligible effect on steady-state operating temperatures. This was demonstrated for zero elevation and $5^{\circ}$ positive elevation. Both curves begin to converge immediately and follow approximately the same trend for heat loads above 30 W. It is noted that the temperature profiles for $5^{\circ}$ and $10^{\circ}$ adverse elevation also converge immediately. However at approximately $20 \mathrm{~W}$, they begin to diverge from the other two curves and rise much faster in temperature. The rise in temperature may be due to partial dry-out of the wick since the current design does not include a secondary wick or bayonet tube to directly supply fluid to the primary wick.

\subsubsection{Periodic Heating}

The main purpose of periodic heating was to investigate the effect of rapidly varying heat loads, thus simulating conditions which may be encountered during operation such as a spacecraft entering into eclipse or variable power dissipations from a payload or electronic devices. For these tests, power was increased from $0 \mathrm{~W}$ to $15 \mathrm{~W}$ in constant intervals of 10 minutes after startup. As demonstrated in Figure 5-26, rapid power changes did not have any negative effect on the performance of the LHP. In fact, the LHP experienced a temperature overshoot of almost $10^{\circ} \mathrm{C}$ at start-up compared to the average temperature observed during periodic heating. This suggests that the working 
fluid may have been in an unfavourable state within the loop prior to startup, as described in Section 5.5.2.

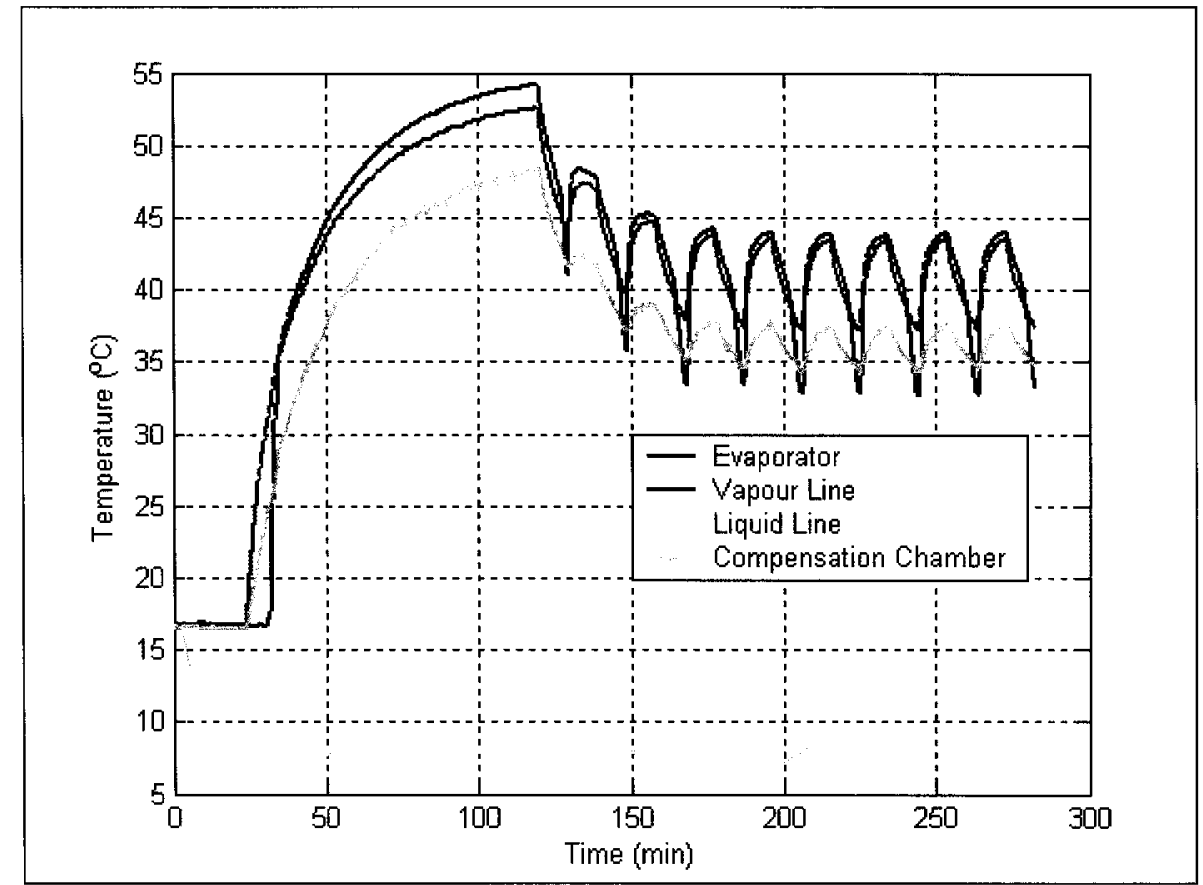

Figure 5-26: LHP Operation During Periodic Heating. $15 \mathrm{~W}, 10 \mathrm{~min}$ cycle

\subsubsection{Temperature Hysteresis}

Power cycling tests were also used to investigate whether or not the current design displays characteristics typical of temperature hysteresis. Temperature hysteresis is identified when the loop operating temperature depends on the recent history of the applied power even when all other test conditions, including ambient and sink temperature, remain constant. As discussed in Section 2.2.3, there is strong evidence that temperature hysteresis is directly related to the void fraction of the evaporator core (Kaya et al., 1999). An accumulation of vapour bubbles in the evaporator core increases heat 
leak between the evaporator and compensation chamber thus resulting in a higher operating temperature. It has also been reported in literature that in designs without a secondary wick, temperature hysteresis may be caused by tiny vapour bubbles entrapped in the wick that cannot completely collapse or vent to the compensation chamber $(\mathrm{Ku}$, 1999). Experimental data obtained during power cycling supports this hypothesis. As shown in Figure 5-27, temperature hysteresis in the current design was evident. In this example, the input power to the evaporator was cycled in steps of $10 \mathrm{~W}$.

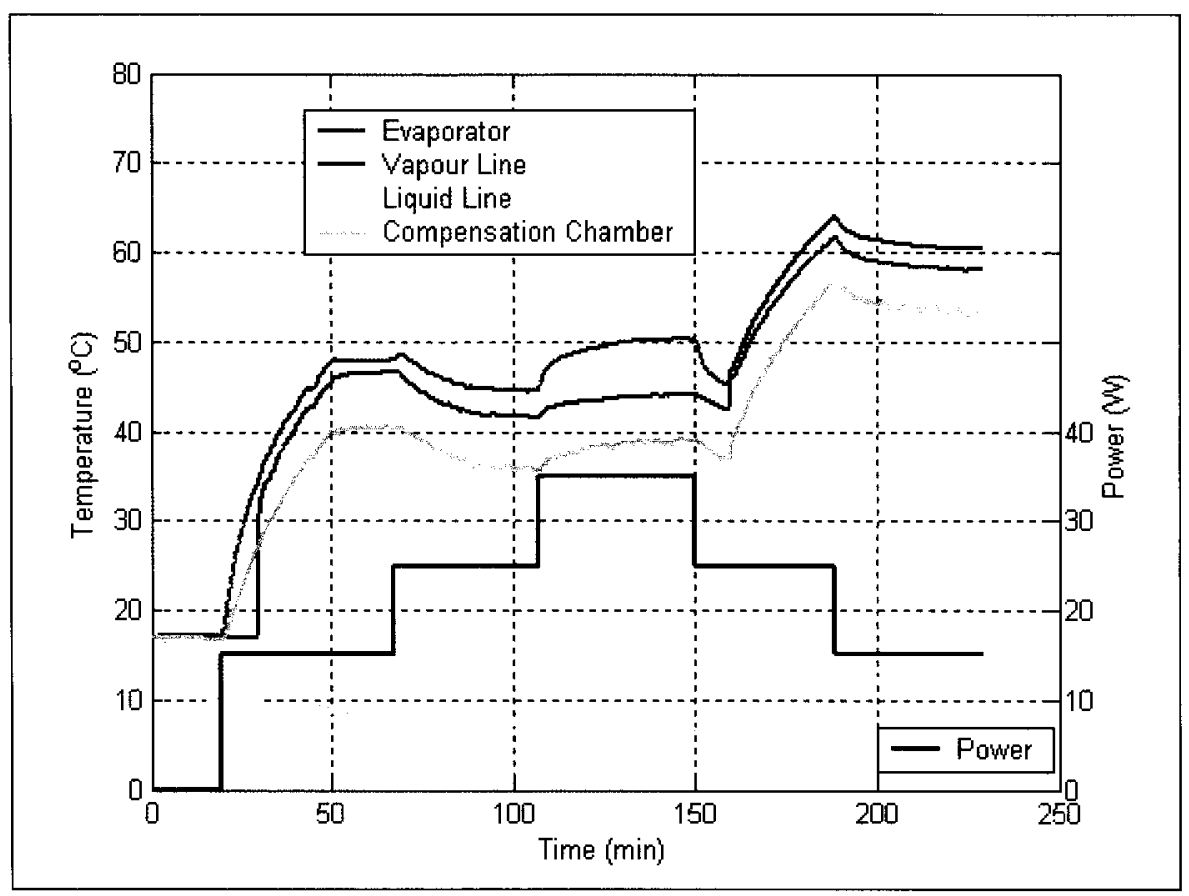

Figure 5-27: Temperature Hysteresis

Additional tests for hysteresis produced similar results, especially after large steps in power $(>10 \mathrm{~W})$. These results suggest that for the current design, a significant amount of vapour bubbles collect in the polyethylene wick after large steps in applied power. Such 
observations have also been made when testing CPLs with polyethylene wicks (Nikitkin and Cullimore, 1998). Vapour bubbles in the wick can block liquid return paths, resulting in partial dry-out of the wick thus reducing the effective area of vaporization and increasing the thermal resistance of the evaporator. This leads to sharp increases in loop operating temperature and in some cases loop de-priming. These results were similar to those obtained during start-up tests, described in Section 5.5.2. In many cases, it was found that the LHP required some 'pre-conditioning' to remove any vapour bubbles from the wick. Specifically, an excessive heat load was applied to the evaporator to collapse the vapour bubbles in the wick. Once the loop reached its maximum cut-off temperature, the heat load was removed until the temperatures dropped below a certain value. This method proved to be successful since steady-state temperatures were obtained. 


\section{Chapter 6: Mathematical Modeling}

\subsection{Software Development}

As discussed in Chapter 3, the software package EASY 2000, developed by TAIS Ltd., was used to help optimize initial LHP designs. However, due to its limitations, in-house software was required and was subsequently developed in parallel with the final LHP. Developing in-house software avoids the use of some black-box solutions introduced with EASY 2000 and provides greater flexibility during design and reduces long term costs. Due to time constraints, efforts were focused on developing the software necessary for completing the LHP design and testing portions of this study. Numerical models were developed in Matlab and provide functions such as estimating properties of various working fluids, calculating fluid inventory, and sizing the compensation chamber. These models provide the foundation for future work on 1-D steady-state performance solvers (see Appendix A for details). Details of each model are provided below.

\subsubsection{Graphical User Interface (GUI) \& Input/Output Parameters}

The Matlab Graphical User Interface Development Environment (GUIDE) was used to develop a GUI to simplify the process of entering input data, calculating LHP characteristics, and extracting the output results. The software is organized into a series 
of modules, with each module providing a specific function such as calculating properties of a specific fluid or calculating and displaying the figure of merit. As shown in Figure 6-1, the main toolbar provides an interface for the user to access each individual module.

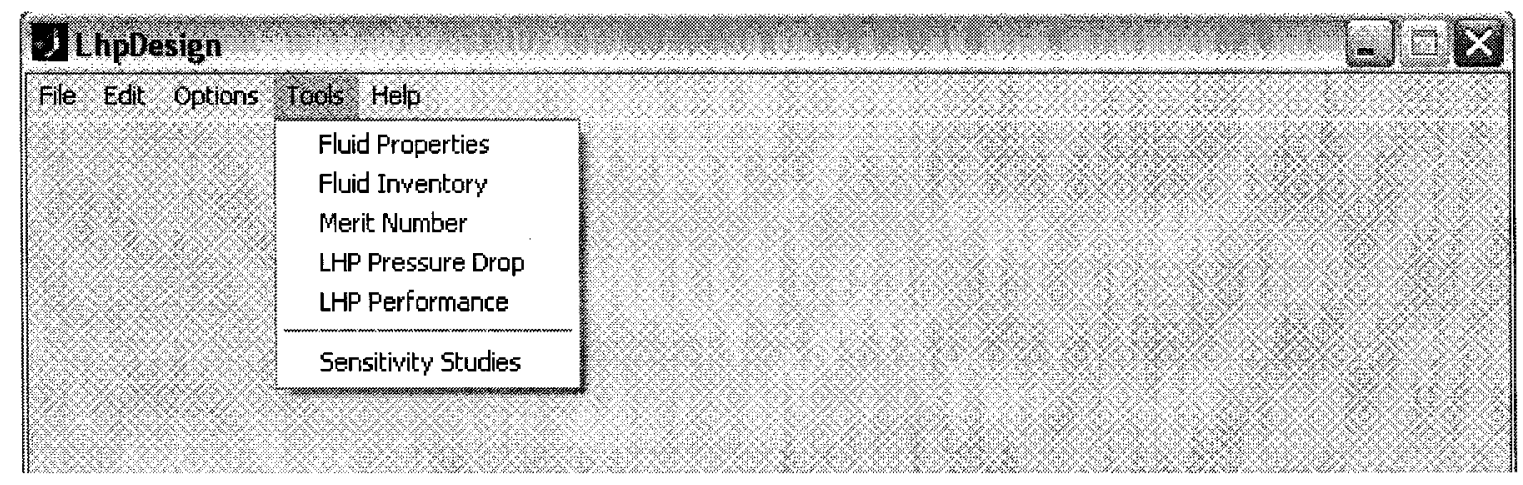

Figure 6-1: LHP Design Software Toolbar

Typically, the first task is to enter the physical properties and conditions of the LHP. This is accomplished by accessing the edit properties form from the 'Edit' menu on the main toolbar. As illustrated in Figure 6-2, input parameters include the detailed dimensions of each component, wick porosity, wick permeability and wick effective pore radius. It also includes external conditions such as the sink temperature, cooling water volume flow rate, ambient temperature, and external thermal conductance of the condenser. It is noted that the external thermal conductance of the condenser refers to the thermal conductance per unit length from the inner surface of the condenser tube to the outer surface of the condenser plate and can typically vary between 1 and $20 \mathrm{~W} / \mathrm{m}-\mathrm{K}$, depending on the flow arrangement and thermal contact resistance between the condenser tube and the condenser plate. All input data is saved as a .txt file under a specified directory (Matlab working directory by default) and is editable. 


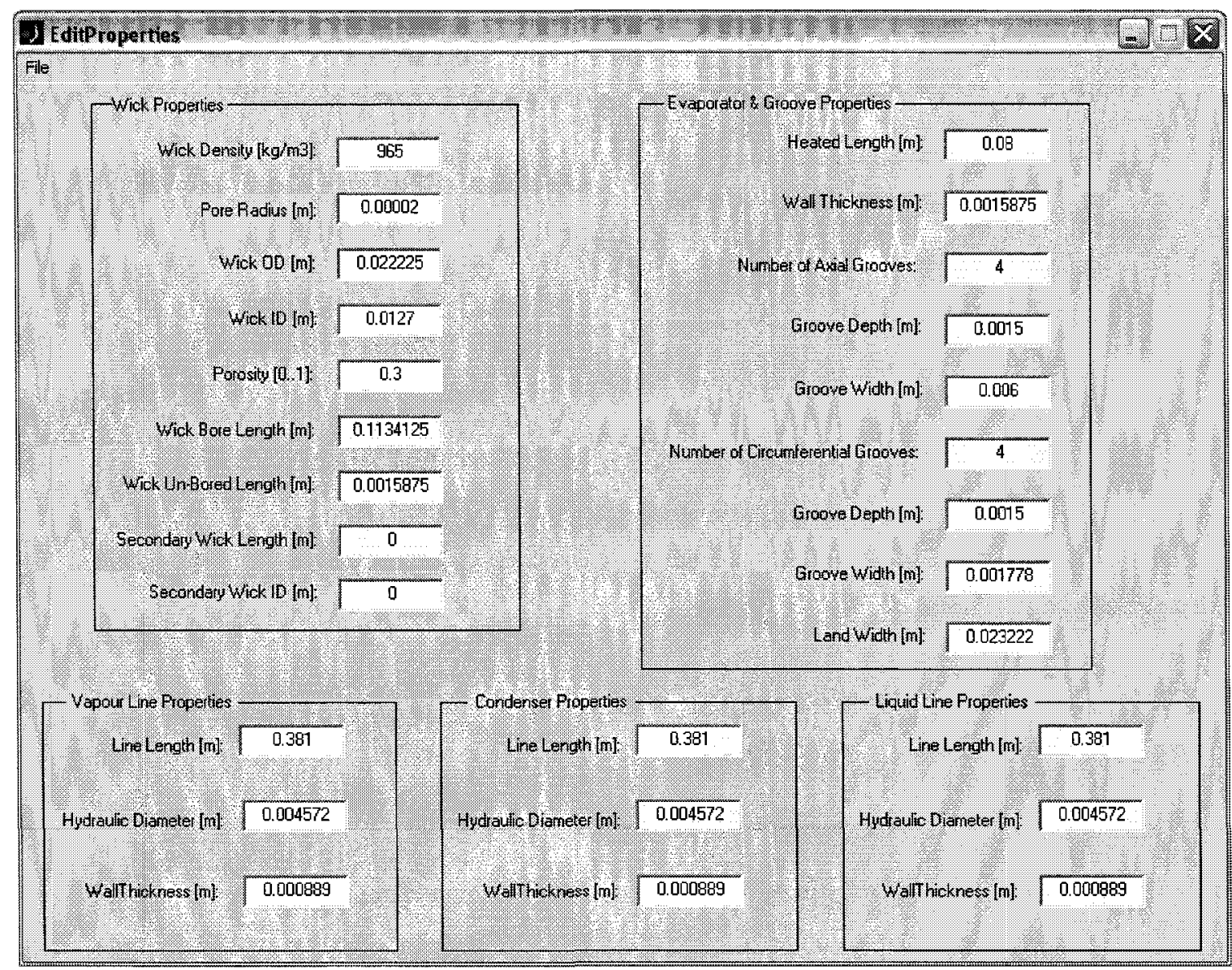

Figure 6-2: Edit Properties

As shown in Figure 6-1, each calculation module is available under the 'Tools' menu and currently includes algorithms to calculate fluid properties, fluid inventory, and merit number. Additionally, the user can study the effects of varying the input parameters. The program is also designed for easy integration of future modules. 


\subsubsection{Fluid Properties}

The fluid properties module allows the user to review relevant working fluid properties for a specified saturation temperature. As shown in Figure 6-3, the trend of each property over a range of saturation temperatures is also displayed.

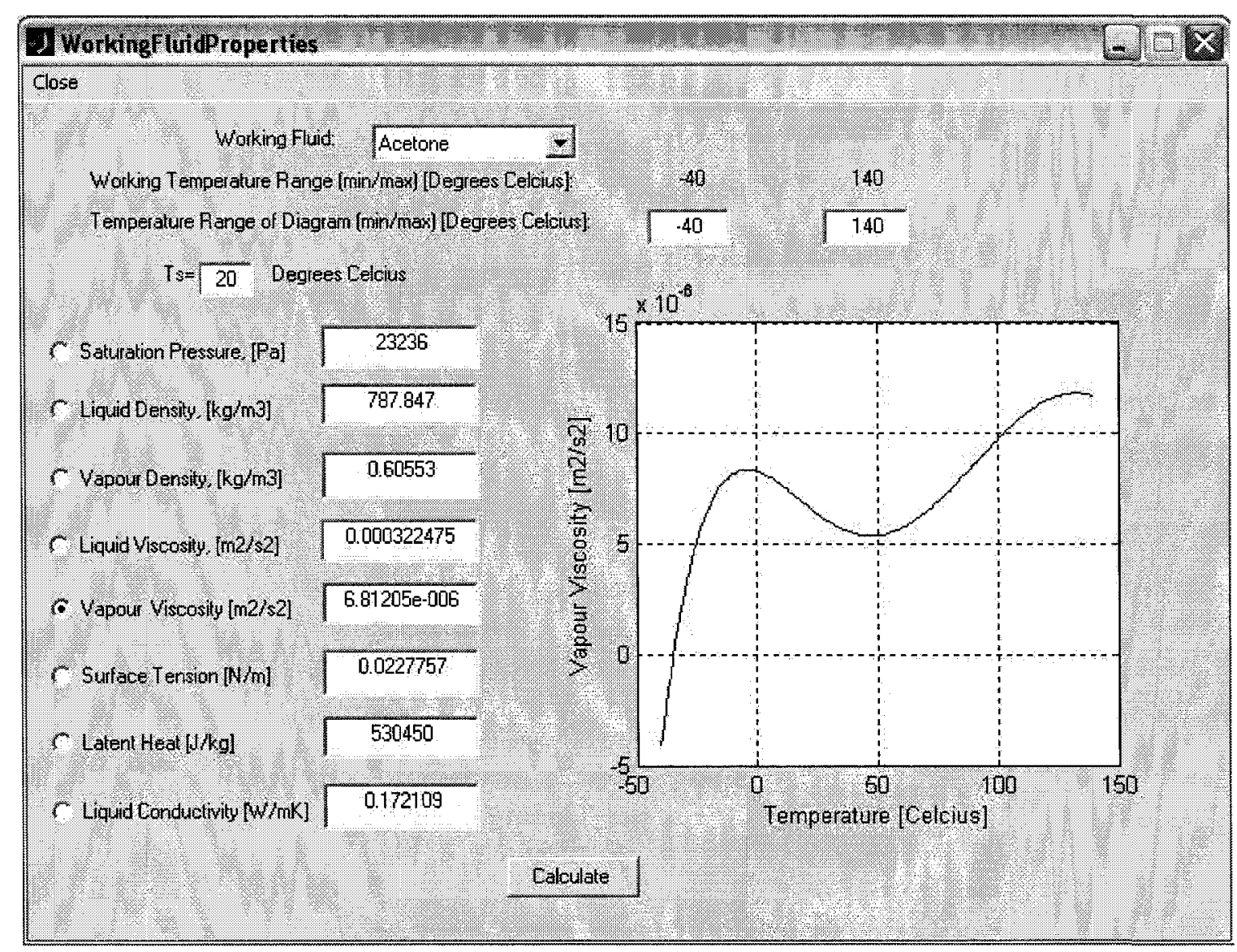

Figure 6-3: Working Fluid Properties Calculator

The relevant properties of the working fluid are saturation pressure, liquid density, vapour density, liquid viscosity, vapour viscosity, surface tension, latent heat, and liquid thermal conductivity. The algorithms used in this module to calculate each working fluid property are also accessed by other modules to accurately calculate fluid inventory and 
compensation chamber volume. Each fluid property was expressed as a function of the LHP operating temperature (saturation temperature, $\mathrm{T}_{\mathrm{sat}}$ ) and was curve fitted into a fifthorder polynomial with errors of approximately $1-5 \%$.

$$
Z=\sum_{n=1}^{5} A_{n} T_{s a t}^{n}
$$

where:

$\mathrm{Z} \quad$ is the fluid property

$A_{n} \quad$ is the corresponding coefficient

The coefficients of the polynomials were obtained from (Faghri, 1995). The model currently includes coefficients for four working fluids: acetone, ammonia, methanol, and water. Coefficients for other fluids can easily be added to the module.

\subsubsection{Figure of Merit}

As discussed in Section 2.3.1, the liquid density, surface tension, liquid thermal conductivity, and liquid viscosity of a working fluid are combined to form a dimensionless parameter known as the merit number or liquid transport factor. The merit number can be used evaluate and compare the effectiveness of various working fluids at specific operating temperatures. It is helpful in selecting the appropriate working fluid when designing a LHP for a specific temperature range and task. The merit number was defined as:

$$
N_{l}=\frac{\rho_{l} \sigma \lambda}{\mu_{l}}
$$


The merit number module produces a figure of merit as shown in Figure 6-4. The user can select which working fluids to plot and the temperature range.

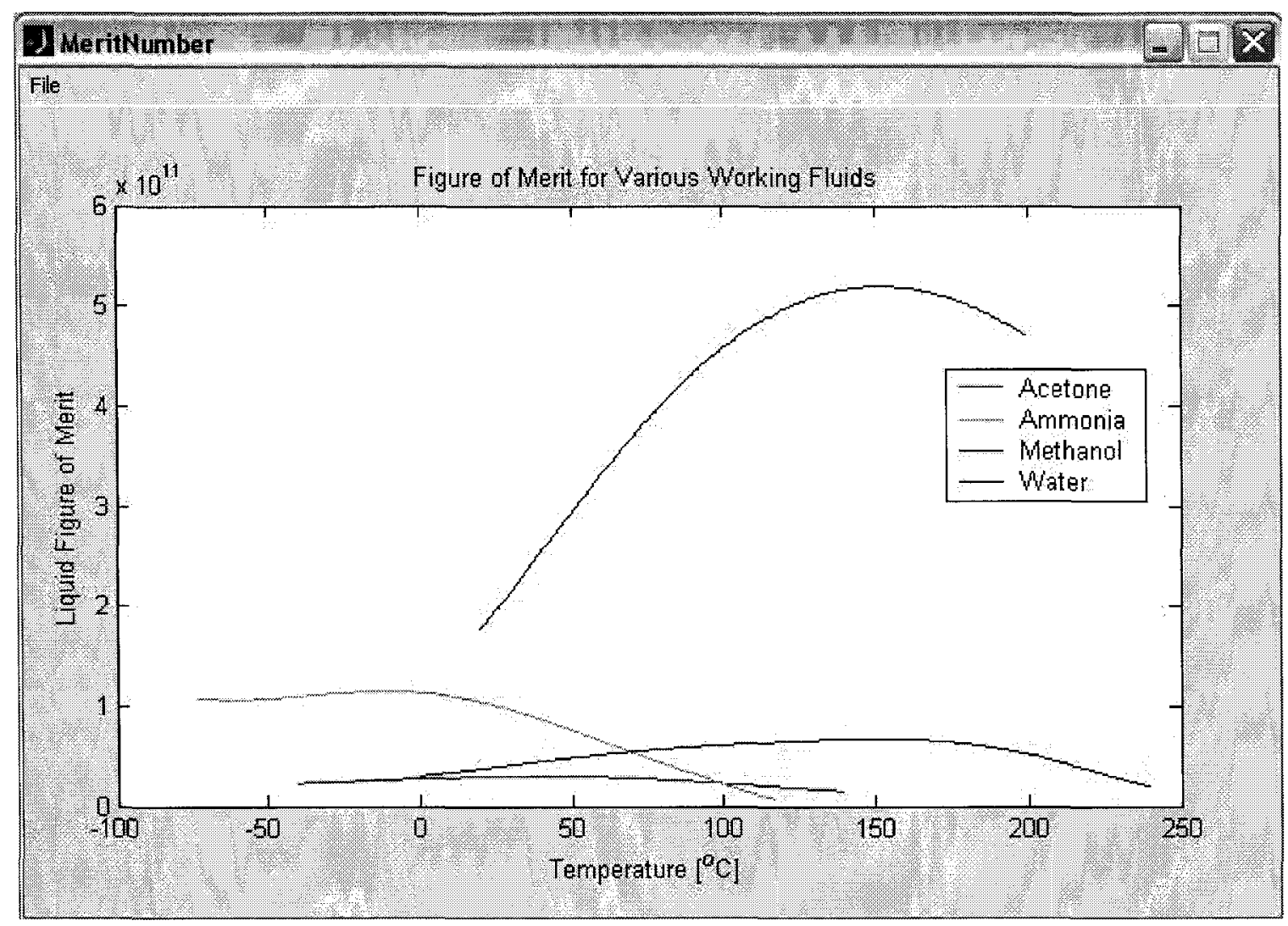

Figure 6-4: Figure of Merit

\subsubsection{Fluid Inventory}

The fluid inventory module was designed to estimate the fluid charge and compensation chamber volume. The module includes code for both calculation methods described in Section 2.3.4 and allows the user to select between the two. The user can specify the working fluid, operating temperature range, and compensation chamber void volume for each method. By default, the code is setup to concurrently estimate the fluid charge and 
compensation chamber volume. However, it is possible to calculate the fluid charge separately by specifying the dimensions or volume of the compensation chamber. Figure 6-5 demonstrates an example of the output produced by the fluid inventory module.

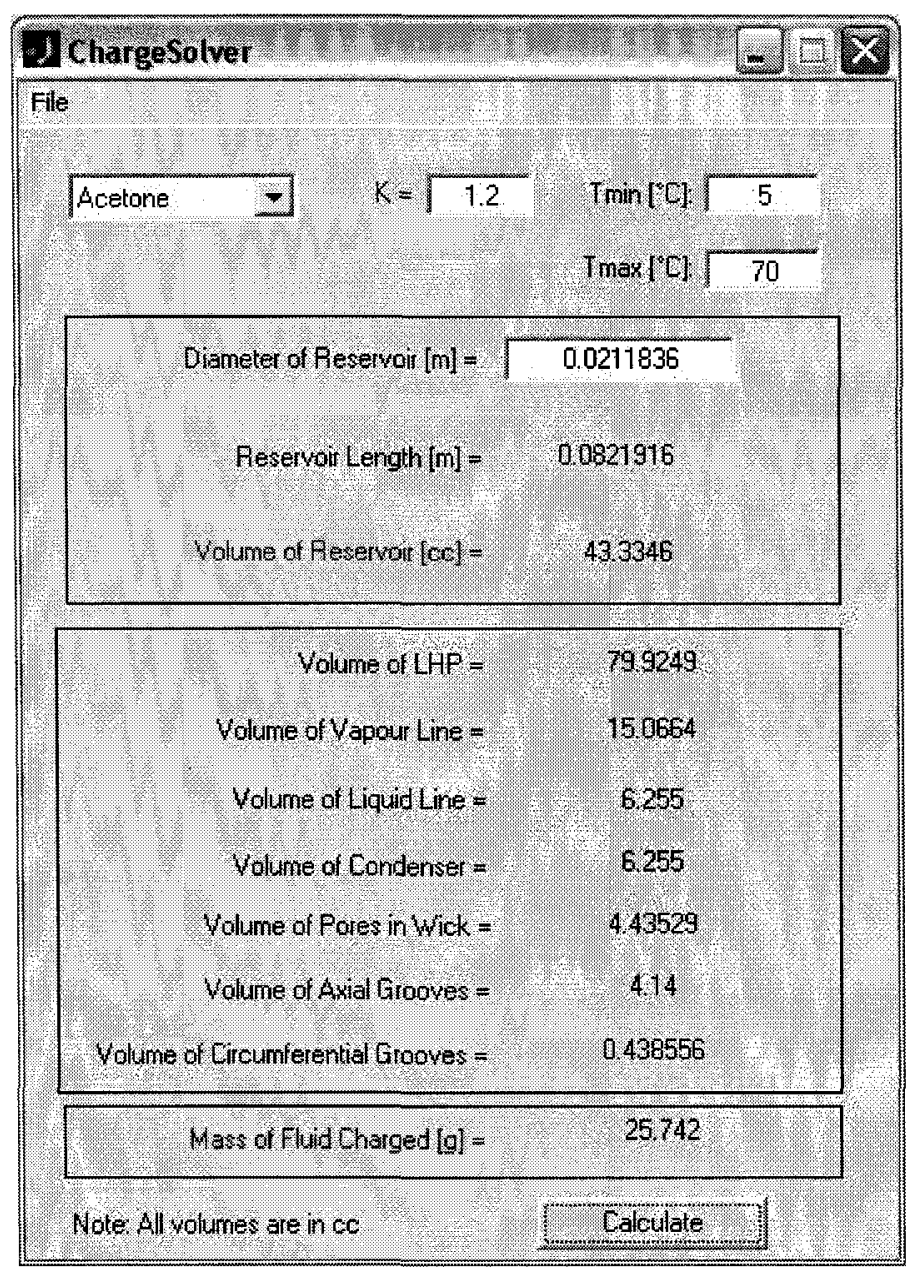

Figure 6-5: Fluid Inventory and Compensation Chamber Sizing 


\section{Chapter 7: Conclusions and Recommendations}

\subsection{Summary and Conclusions}

This thesis presented a theoretical and experimental analysis of LHPs. In particular, it discussed the procedures of designing and developing LHPs for testing. Additionally, an experimental investigation of LHP performance was also discussed. The purpose was to establish a solid understanding of LHP technology and to demonstrate its flexibility, reliability, and robustness for a wide range of thermal control applications.

In this study, three LHPs were designed, manufactured and tested in sequence, and with each new design incorporated design changes based on test results obtained from the previous unit. Initially, components were selected based on a set of criteria which included flight heritage, cost, availability, compatibility, and performance characteristics. Each component was then optimized to minimize pressure losses and therefore maximize the potential heat load limit. Each unit was subsequently constructed following a strict procedure which included machining, cleaning, assembly, evacuation, charging, and sealing.

An experimental investigation of LHP performance characteristics was performed in three phases: investigate LHP functionality; investigate sensitivity of LHP performance with respect to fluid charge; and study the effect of elevation and periodic heating on the 
maximum transport capacity and stability of the LHP. In the first phase of testing, the first test unit demonstrated clear start-up characteristics and stable operation. However, over time the performance of the unit degraded until it was no longer functional. Inspection of the wick revealed minor damage to the outer layer of the material, possibly due to operation beyond its maximum operating temperature. After reviewing the results, the second LHP was designed with minor modifications to increase performance. Unfortunately, test results of the second unit revealed no significant fluid flow in the loop. Upon examination, it was found that the LHP failed due to small leaks at the Swagelok interfaces. With consideration of these findings, the final LHP was constructed using seamless stainless steel tubing with much greater tolerances. Furthermore, a subcooler was added to the liquid line to increase liquid subcooling in the compensation chamber to enable testing in a wider range of powers. Preliminary tests demonstrated clear start-up and excellent performance. Continuous and stable operation was also demonstrated. The third test unit was therefore selected for the second phase of testing.

In the second phase of testing, sensitivity studies were performed to evaluate the effect of fluid inventory on LHP performance. In particular, an effort was made to demonstrate the effect of fluid inventory on start-up transients, steady-state operating temperature, maximum transport capacity, effective thermal resistance, and heat transfer coefficient. A total of four fluid charges were selected for analysis. These fluid charges each corresponded to a specific void fraction in the compensation chamber during worst case hot conditions and a specific liquid-filled fraction in the compensation chamber 
during worst case cold conditions. Power cycling tests revealed that fluid inventory is not a dominant factor in start-up but may impact the time required for initiation of fluid circulation within the loop. Specifically, smaller fluid charges were found to require less time for initiation of fluid flow since less liquid was available to collect in the vapour grooves. Alternatively, higher fluid charges took significantly more time for initiation of fluid flow, possibly due to excess liquid collection in the vapour grooves which increase the amount of superheat required. Additionally, fluid inventory was found to have a significant impact on steady-state temperatures and maximum/minimum heat transfer capacities. Specifically, the lowest fluid charge of $15 \mathrm{~g}$ resulted in the lowest steady-state operating temperatures, but only for small power loads. As the input power was increased, the steady-state temperature of the loop rose sharply due insufficient liquid supply for subcooling. Consequently, wick dry-out and loop deprime was evident at power loads greater than $20 \mathrm{~W}$. Similar results were demonstrated for the highest fluid charge of $28 \mathrm{~g}$. In this case, LHP performance was also weak at higher powers and was most likely the result of hard-filling the compensation chamber wherein the liquid-vapour interface moves towards the condenser exit and liquid is pushed into the compensation chamber. If the fluid charge is too high, there may not be sufficient room in the compensation chamber to compensate for the excess liquid. In such a case, the liquid stagnates and increases in temperature due to parasitic heating. This in turn increases the loop operating temperature. It was determined that for this specific design, a fluid inventory of 20 to $23 \mathrm{~g}$ produces optimum results. In particular, a fluid charge of $20 \mathrm{~g}$ 
produces excellent performance characteristics and was therefore selected for the final phase of testing.

The final phase of testing was performed to study the effect of elevation and periodic heating on LHP performance, as well as test for the presence of temperature hysteresis. Initial tests revealed that elevation can have a significant impact on loop performance at low powers. Specifically, the steady-state temperature of the loop was found to increase with increasing adverse elevation for the same power load, up to $20 \mathrm{~W}$. This effect decreased with increasing power, as each performance curve converged. It is noted, however, that at higher elevations the LHP had an increased tendency to deprime for power loads greater than $20 \mathrm{~W}$. This was attributed to the fact that there was no secondary wick or bayonet tube to help supply the primary wick with fluid. Periodic heating tests were used to investigate the effect of rapidly varying heat loads, thus simulating conditions which may be encountered during typical operation. It was found that rapid changes in power did not have any negative effect on LHP performance. In fact, in many cases it helped free trapped vapour bubbles in the wick thus decreasing the average temperature of the evaporator. Finally, power cycling tests were performed to investigate temperature hysteresis. Temperature hysteresis was identified when the loop operating temperature varied for the same applied power, even when all test conditions including ambient and sink temperature remained constant. Several instances of temperature hysteresis were observed during testing. It was concluded that such characteristics may be a result of the void fraction in the evaporator core or excess vapour 
bubbles trapped in the wick structure. Vapour bubbles in the wick may block liquid return paths, resulting in partial dry-out of the wick and an increase in temperature.

Overall, the results of the study suggest that the techniques and procedures used for designing and manufacturing a LHP were successful. After optimizing the fluid inventory, the LHP demonstrated reliable start-up and stable operation between a power load range of 5 to $55 \mathrm{~W}$. Additionally, the LHP showed no adverse effects due to periodic heating. There were, however, some inconsistencies during operation. Specificlaly, temperature hysteresis was sometimes visible during power cycling tests. This issue may be resolved by using a more efficient primary wick or by including a secondary wick. These results provide a solid base for future work towards developing smaller, more efficient LHPs for spacecraft thermal control and electronics cooling.

\subsection{Recommendations}

Based on the results of this study, the following recommendations were made for future work.

\section{LHP Laboratory at Carleton University}

The LHP laboratory at Carleton University is adequately equipped for manufacturing and testing LHPs. However, there are several options which may be explored to improve the facility and increase the efficiency of testing. They are as follows:

- Design and build a new test frame that can accommodate a wider range of LHP designs and can more accurately determine LHP orientation; 
- Improve data acquisition by automating test processes such as varying heater power and automatic shut-down; and

- Design and construct an environmental chamber with the capability to control ambient conditions. It is suggested that the chamber be designed to control the ambient temperature and simulate both forced and natural convection conditions.

\section{LHP Design}

The following highlights some key areas of interest regarding loop performance or data extraction and are based on the results obtained from this study:

- Design and construct a more efficient condenser and heat exchanger, and increase the active cooling area of the condenser;

- Construct a new evaporator saddle that can accommodate a second heater strip and more effectively distribute the applied power, which is currently limited to $60 \mathrm{~W}$;

- Develop an LHP with instruments to measure pressure and mass flow rate within the loop. As well as, increase the number of temperature measurements along the loop; and

- Begin development of smaller designs based on the results of this study, starting with a $1 / 2 "$ evaporator. In addition, evaluate the feasibility of employing current manufacturing and assembly techniques. 


\section{Performance Testing}

Detailed testing may be performed in a number of new areas, including:

- Active temperature control of the compensation chamber using a thermal electric cooler (TEC);

- Study the effect of varying ambient and sink temperatures;

- Study the effect of positive elevation and tilt;

- Study the effect of wick structures with varying effective thermal conductivities; and

- Conduct a more in depth examination of start-up transients.

\section{Mathematical Modeling}

The models developed for estimating properties of various working fluids, calculating fluid inventory, and sizing the compensation chamber were adequate for this study. However, future development of an algorithm to model the steady-state performance of a LHP in variations conditions and orientations is necessary. The following is a list of recommendations to achieve this goal:

- Develop and incorporate a LHP steady-state performance model in the current Matlab models, and make accessible through the GUI;

- Perform experimental validation of the model (ie., compare results of the model to those obtained through experimental testing); and 
- Perform parametric study of LHP performance characteristics using the steadystate model. Areas of interest may include effect of sink temperature, ambient temperature, elevation, heat leak, and condenser conductance. 


\section{References}

Chi, S. W. (1976). Heat pipe theory and practice : a sourcebook. Washington, Hemisphere Pub. Corp.

Chuang, P. Y. (2003). An Improved Steady-State Model of Loop Heat Pipes Based on Experimental and Theoretical Analyses. Department of Mechanical and Nuclear Engineering, Pennsylvania State University. Doctor of Philosophy: 271.

Dunn, P. D. and D. A. Reay (1982). Heat pipes. Oxford; New York, Pergamon Press.

Faghri, A. (1995). Heat pipe science and technology. Washington, DC, Taylor \& Francis.

Holman, J. P. (1990). Heat transfer. New York, McGraw-Hill.

Kaya, T. and T. Hoang (1999). Mathematical Modeling of Loop Heat Pipes and Experimental Validation. Journal of Thermophysics and Heat Transfer 13(3): 314-320.

Kaya, T. and J. Ku (2003). Thermal Operational Characteristics of a Small-Loop Heat Pipe. Journal of Thermophysics and Heat Transfer 17(4): 464-470.

Kaya, T., J. Ku, T. Hoang, K. Cheung (1999). Investigation of Low Power Start-Up Characteristics of a Loop Heat Pipe. Space Technology and Applications International Forum.

Khrustalev, D. (2001). Loop Heat Pipe Technology for Electronics Cooling. International Conference on High-Density Interconnect and Systems Packaging.

Kim, J. and E. Golliher (2002). Steady State Model of a Micro Loop Heat Pipe. 18th IEEE Semi-Therm Symposium, JINHA Sciences, Inc.

$\mathrm{Ku}$, J. (1993). Overview of Capillary Pumped Loop Technology. ASME 29th National Heat Transfer Conference, Atlanta, GA,.

$\mathrm{Ku}$, J. (1999). Operating Characteristics of Loop Heat Pipes. 29th International Conference On Environmental Systems, Denver, USA, Society of Automotive Engineers. 
Lashley, C., S. Krein, P. Barcomb (1998). Deployable Radiators - A Multi-Discipline Approach. Society of Automotive Engineers 981691.

MacDonald, E. (2004). Experimental and Numerical Investigation of Passive Two-Phase Heat Transfer Devices for Space Applications. Mechanical and Aerospace Engineering. Ottawa, ON, Carleton University. Master of Applied Science: 133.

Maidanik, Y. F. (2003). Loop Heat Pipes - Development and Application. 7th International Heat Pipe Symposium, Jeju, Korea.

Maidanik, Y. F. (2005). Review - Loop Heat Pipes. Applied Thermal Engineering 25: 635-657.

Maidanik, Y. F., S. Vershinin, J. Dolggirev (1985). Heat Transfer Apparatus. United States. 4515209.

Maidanik, Y. F., S. V. Vershinin, M. A. Korukov, J. M. Ochterbeck (2005). Miniature Loop Heat Pipes - A Promising Means for Cooling Electronics. IEEE Transactions on Components and Packaging Technologies 28(2): 290-296.

Nikitkin, N. and B. Cullimore (1998). CPL and LHP Technologies: What are the Differences, What are the Similarities? 28th International Conference on Environmental Systems, Denver, USA, Society of Automotive Engineers.

Pastukhov, V. G., Y. F. Maidanik, C. V. Vershinin, M. A. Korkov (2003). "Miniature Loop Heat Pipes for Electronics Cooling." Applied Thermal Engineering 23: 1125-1135.

Peterson, G. P. (1994). An introduction to heat pipes : modeling, testing, and applications. New York, Wiley.

Riehl, R. and T. Dutra (2005). Development of an Experimental Loop Heat Pipe for Application in Future Space Missions. Applied Thermal Engineering 25: 101-112.

TAIS (2000). EASY2000. Moscow: Application Program Package Manual. 


\section{Appendix A}

\section{A.1 1-D Steady-State Analytical Model}

Future work on a steady-state performance solver will be required to help improve the efficiency of current LHP designs. A short study of the mathematical models formulated by Kaya and Hoang (1999) is provided below and is intended as a starting point for future work. The model is ideal for estimating performance characteristics such as the pressure and temperature distributions along the LHP, mass flow rate, heat leak, and liquid subcooling as a function of input power for given LHP conditions such as sink temperature and ambient temperature. The algorithm has proven success ((Kaya and Hoang, 1999), (Chuang, 2003), (Riehl and Dutra, 2005)), and has high flexibility with the ability to incorporate more accurate two-phase flow approximations or account for various operating conditions such as adverse orientations, changes in sink temperature and ambient temperature, and insulation.

In general, the steady-state model is based on a control volume analysis. That is, the LHP operating temperature is calculated by solving the energy balance equation for incoming and outgoing heat flows for each LHP component. However, since the energy balance equations are dependent on fluid properties, system pressure drop, mass flow rate, and heat transfer coefficients which are in turn dependent on the saturation 
temperature, an iterative algorithm is required. Below is a list of the assumptions required to develop the 1-D steady-state solver (Kaya and Hoang, 1999):

1. Heat is uniformly applied to the evaporator with no losses to ambient.

2. The compensation chamber and the evaporator core contain both liquid and vapour phases (two-phase fluid) and are therefore always at saturated conditions.

3. Single-phase flow correlations are employed to calculate the pressure drop throughout entire LHP.

4. Heat exchange between the LHP and ambient is assumed to be due to natural convection only.

5. The LHP achieves steady-state for a given loop condition.

As discussed in Section 2.2.1, the LHP operating temperature is established in the compensation chamber and is a result of the energy balance equation:

$$
Q_{H L}=Q_{s c}+Q_{c c-a}
$$

During LHP operation, the energy balance equation for the compensation chamber is achieved only at steady-state conditions. In order to reach a steady-state condition, the LHP self-adjusts the saturation temperature in the compensation chamber. When a steady-state condition is achieved, this saturation temperature becomes the steady-state LHP operating temperature (Chuang, 2003). Thus, equation 6.3 must be solved iteratively to determine the LHP operating temperature for a given heat load. 


\section{A.1.1 Heat Leak}

Two different flow paths exist for heat leak from the evaporator to the compensation chamber: radially and axially. Axial heat leak is due to conduction from the evaporator material adjacent to the compensation chamber material, and is written as:

$$
Q_{H L-A}=k A_{\text {evap }} \frac{\left(T_{e}-T_{c c}\right)}{L}
$$

Radial heat leak is due to conduction across the primary wick (from the high pressure side to the low pressure side) and into the evaporator core and is written as:

$$
Q_{H L-R}=\frac{2 \pi k_{e f f} L_{\text {wick }}}{\ln \left(D_{\text {wick }}^{\text {out }} / D_{\text {wick }}^{\text {in }}\right)} \Delta T_{\text {wick }}
$$

Since the outer and inner surfaces of the wick are at saturation conditions, the temperature difference across the primary wick is obtained from the pressure difference across the wick:

$$
\Delta T_{\text {wick }}=\left(\frac{d T}{d P}\right)_{s a t}\left(\Delta P_{\text {tot }}-\Delta P_{\text {wick }}\right)
$$

The slope of the vapour-pressure curve $(\partial T / \partial P)_{\text {sat }}$ can be calculated by the ClausiusClapeyron relation. By combining radial and axial heat leak, the total heat leak is written as:

$$
Q_{H L}=\frac{2 \pi k_{e f f} L_{\text {wick }}}{\ln \left(D_{\text {wick }}^{\text {out }} / D_{\text {wick }}^{\text {in }}\right)} \Delta T_{\text {wick }}+k A_{\text {evap }} \frac{\left(T_{e}-T_{c c}\right)}{L}
$$




\section{A.1.2 Effective Thermal Conductivity of the Wick}

The effective thermal conductivity of the wick saturated with the working fluid is required to calculate the radial heat leak from Eq.(A.3). Assuming a homogeneous and isotropic wick structure, the effective thermal conductivity of the wick was obtained by representing the volumetric average of the two phases in parallel (Kim and Golliher, 2002), yielding:

$$
k_{e f f}=k_{w i c k}(1-\varepsilon)+\varepsilon k_{L}
$$

where $k_{L}$ is the thermal conductivity of the working fluid and $\varepsilon$ is the porosity of the wick.

\section{A.1.3 Single Phase Pressure Drop}

The total system pressure drop is the sum of the pressure drops of each LHP component along the flow path. It also includes pressure drops in the wick structure, and vapour grooves. Additionally, if the LHP is elevated against gravity, the pressure difference due to gravity must also be taken into account. The total pressure drop across the LHP is calculated by Eq. (2.1). The pressure drop in each section of the LHP is largely dominated by frictional losses. For single phase duct flow of any cross-section, the frictional pressure drop is represented by the Darcy-Weisbach equation (Holman, 1990):

$$
\Delta P=f\left(\frac{L}{D_{h}}\right)\left(\frac{\rho V^{2}}{2}\right)
$$

where: 
$f$ is the Darcy friction factor, $f=\left\{\begin{array}{c}64 \mathrm{Re}^{-1}, \text { for laminar flow } \\ 0.316 \mathrm{Re}^{-1 / 4}, \text { for turbulent flow } \mathrm{Re} \geq 4000\end{array}\right.$

Furthermore, the pressure drop across the wick is calculated using Eq. (2.3). It is again noted that the maximum pressure created by the wick must be greater than the sum of the pressure drops in the LHP.

\section{A.1.4 Single Phase Heat Transfer}

The overall heat transfer coefficient from the working fluid to ambient or the sink is expressed as follows:

$$
\left(\frac{U A}{L}\right)_{\text {F-a o r F-sink }}=\frac{1}{\frac{1}{\left(\pi N u_{D} k_{L}\right)}+\frac{1}{\left(h_{o} A_{o} / L\right)_{\text {a o s sink }}}}
$$

Eq. (A.8) assumes a constant thin wall and single phase throughout the area of heat transfer. For fully-developed laminar flow through a circular cross-section, the Nusselt number is a constant of either:

$$
N u_{D}=\left\{\begin{array}{c}
4.36 \text { for constant surface heat flux } \\
3.66 \text { for constant surface temperature }
\end{array}\right.
$$

For fully-developed turbulent flow, the Nusselt number must be determined through empirical correlations such as (Holman, 1990):

$$
N u=0.023 \operatorname{Re}^{4 / 5} \operatorname{Pr}^{n}
$$

Where $\operatorname{Pr}$ is the Prandtl number is either 0.4 (for heating) or 0.3 (for cooling). Heat exchange between the outer surface of the LHP and ambient is assumed to be through 
natural convection. A simplified natural convection correlation for a horizontal cylinder in air is (Holman, 1990):

$$
h_{o}=1.32\left(\frac{T_{\text {wall }}-T_{a m b}}{D_{o}}\right)^{1 / 4}
$$

Heat exchange between the outer surface of the LHP and the sink may vary depending on the cooling configuration at the condenser. Consequently, the heat transfer coefficient between the LHP and the sink must be determined experimentally (Chuang, 2003).

\section{A.1.5 Liquid Subcooling}

The liquid temperature of single-phase fluid flow along the pipe can be calculated by integrating the energy balance equation in the liquid-filled portions of the pipe and is expressed as:

$$
-\dot{m} C_{p} d T_{f}=\left[\left(\frac{U A}{L}\right)_{\mathrm{F}-\mathrm{a}}\left(T_{\mathrm{f}}-T_{\mathrm{a}}\right)+\left(\frac{U A}{L}\right)_{\mathrm{f}-\text { sink }}\left(T_{\mathrm{f}}-T_{\text {sink }}\right)\right] d z
$$

where, $T_{f}$ is the local fluid temperature. It is noted that $(U A / L)_{\mathrm{f}-\mathrm{sink}}$ is zero along the transportation lines since no heat is rejected to the sink. The amount of subcooling supplied by the liquid in the liquid line is calculated using the following:

$$
Q_{s c}=\dot{m} C_{p}\left(T_{s a t}-T_{l l_{\text {out }}}\right)
$$

where, $T_{l_{\text {out }}}$ is the liquid line exit temperature and can be derived from Eq.(A.12). 


\section{A.1.6 Loop Operating Temperature}

The heat loss or gain between the compensation chamber and ambient is usually through natural convection and is expressed as,

$$
Q_{c c-a}=(U A / L)_{c c-a} L_{C C}\left(T_{s a t}-T_{a m b}\right)
$$

Finally, by substituting Eqs. (A.5), (A.13), and (A.14) into (A.1), the LHP operating temperature, $\mathrm{T}_{\text {sat, }}$ can be solved iteratively given $\mathrm{T}_{\text {sink}}, \mathrm{T}_{\mathrm{amb}}$, and $Q_{a p p}$. 